\title{
Estudo do efeito de três exercícios de ioga na capacidade respiratória em pacientes com distrofia muscular progressiva tipo Duchenne (DMD)
}

Dissertação apresentada à Faculdade de Medicina da Universidade de São Paulo para obtenção do título de Mestre em Ciências

Área de Concentração: Neurologia

Orientador: Profa. Dra. Suely Kazue Nagahashi Marie 
Dados Internacionais de Catalogação na Publicação (CIP)

Preparada pela Biblioteca da

Faculdade de Medicina da Universidade de São Paulo

Creprodução autorizada pelo autor

Rodrigues, Marcos Rojo

Estudo do efeito de três exercícios de ioga na capacidade respiratória em pacientes com distrofia muscular progressiva tipo Duchenne (DMD) / Marcos Rojo Rodrigues. -- São Paulo, 2007.

Dissertação(mestrado)--Faculdade de Medicina da Universidade de São Paulo. Departamento de Neurologia.

Área de concentração: Neurologia.

Orientadora: Suely Kazue Nagahashi Marie.

Descritores: 1.Distrofia muscular de Duchenne 2.Volume expiratório forçado 3.Capacidade vital 4.Yoga 5.Espirometria/utilização

USP/FM/SBD-210/07 


\section{AGRADECIMENTOS}

Ao Prof. Dr. Celso R. F. de Carvalho por todas as avaliações e aulas magnas das terças feiras.

À Profa. Dra Suely Kazue Nagahashi Marie por acreditar no projeto, pela confiança, pela firmeza e pela paciência a mim dedicados.

À incansável Alzira Nakayama, por toda organização e constante estímulo nos momentos difíceis.

Às maravilhosas professoras de ioga Alzira Nakayama, Cecília Michiko, Daniela Barbosa, Márcia Plesman, Maria Beatriz Simões, Maria Cristina Watanabe, Luiza Nogueira, Terezinha, Mario, Susan, Rosely Baldassin, Paula Bragalia, Sandrine Giordanengo e Susan Bierrenbach, pela dedicação, carinho e competência no atendimento às crianças.

Ao amigo Danilo Forghieri Santaella, que não consegui descobrir o limite de sua dedicação e presteza.

Às voluntárias Alice Taeco Yamada e Célia Kazuko Miyagi por organizarem com carinho e competência nossos atendimentos semanais.

À Adriana Claudia Lunardi pelas avaliações respiratórias.

Aos Senhores Júlio Bierrenbach, Fabio Mazzoneto e Susan Bierrembach, por tornarem o projeto possível pela doação de equipamentos.

Às contagiantemente alegres voluntárias do ambulatório da neurologia, Ivete e Maria Aparecida.

À equipe do laboratório de Biologia Molecular e Celular do Departamento de Neurologia da Faculdade de Medicina da Universidade de São Paulo, pelos exames de laboratório.

À Sandra Celidonia, a Vera Maria e suas equipes da secretaria e da enfermagem da neurologia.

À minha mulher por toda ajuda e aos meus filhos por suportarem meu mau humor. Obrigado Carol.

Dedico este trabalho aos pacientes com Distrofia Muscular de Duchenne e seus cuidadores que autorizaram este estudo e que pelo exemplo nos ensinaram muito mais do que nos foi possível retribuir. 


\section{SUMÁRIO}

Lista de abreviaturas

Lista de figuras

Lista de tabelas

Lista de anexos

Resumo

Summary

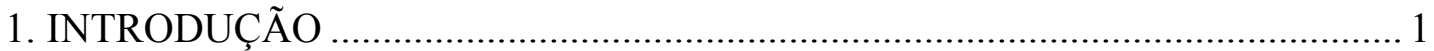

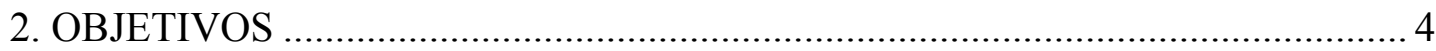

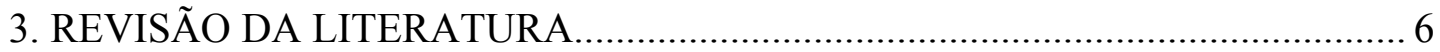

3.1 Ioga 7

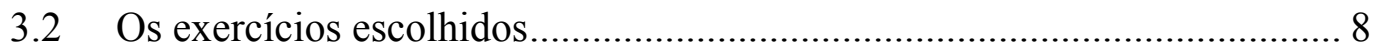

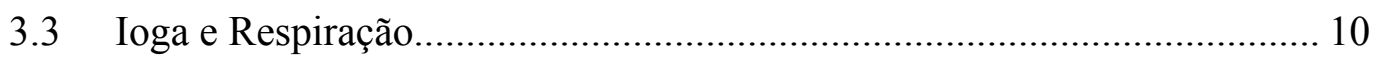

3.4 Distrofia Muscular de Duchene (DMD) ................................................ 11

3.5 Complicações Respiratórias no Paciente com Distrofia Muscular de

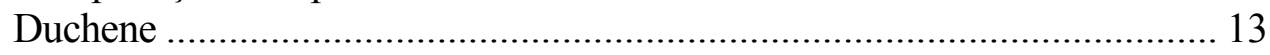

3.6 Função Pulmonar e Pressões Respiratórias ................................................ 15

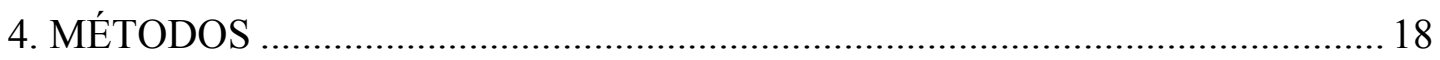

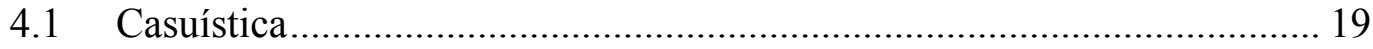

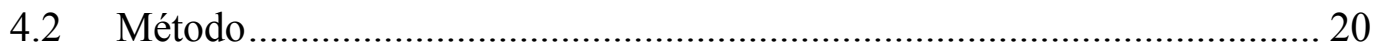

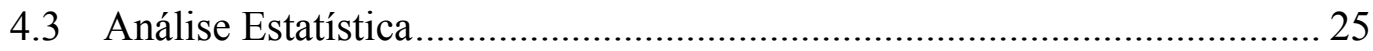

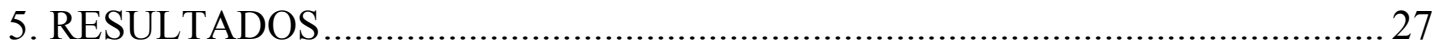

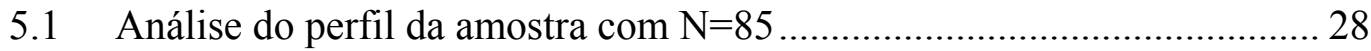

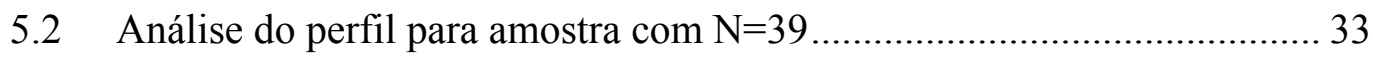

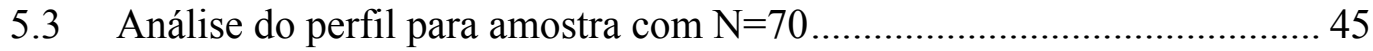

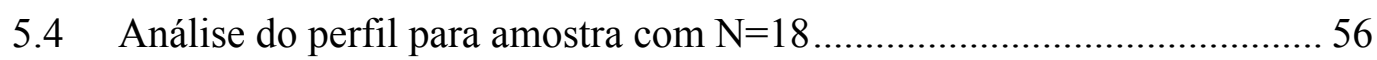

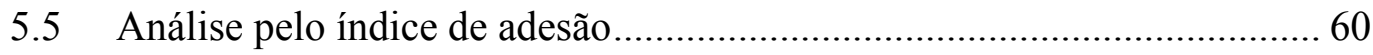

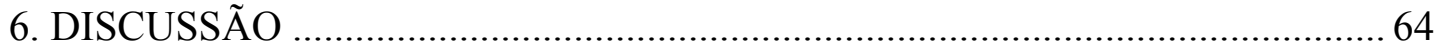

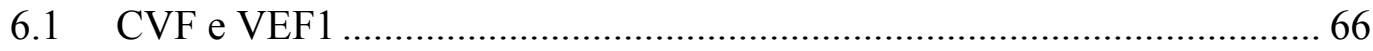

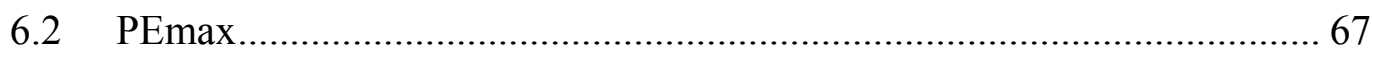

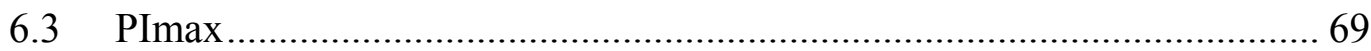

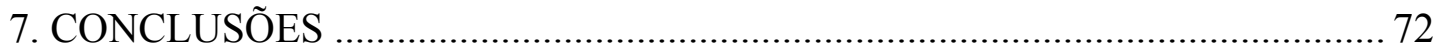




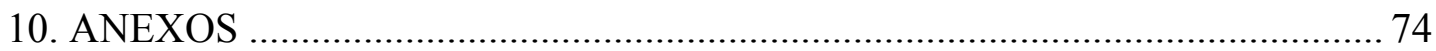

Anexo I - Ficha de acompanhamento da prática individual ........................... 75

Anexo II - Relação dos pacientes com o número dos registros no Hospital das Clínicas, dados antropométricos, idade e índice de adesão ao projeto

Anexo III - Relação das datas de introdução dos exercícios............................... 79

Anexo IV - Resultados das avaliações da capacidade vital forçada.................... 81

Anexo V - Resultados das avaliações da capacidade vital forçada em porcentagem do predito

Anexo VI - Resultados das avaliações do volume expiratório forçado no $1^{\circ}$ minuto

Anexo VII- Resultados das avaliações do volume expiratório forçado no $1^{\circ}$ minuto em porcentagem do predito.

Anexo VIII - Resultados das avaliações da força expiratória máxima

Anexo IX - Resultados das avaliações da força expiratória máxima em porcentagem do predito

Anexo X - Carta de aprovação pela Comissão de Ética da Faculdade de Medicina da Universidade de São Paulo

Anexo XI - Folha de Rosto do Ministério da Saúde para Pesquisa

Envolvendo Seres Humanos

Anexo XII - Termo de Consentimento Livre Esclarecido. 95

11. REFERÊNCIAS 98 


\section{LISTA DE ABREVIATURAS}

$\begin{array}{ll}\text { DMD } & \text { Distrofia Muscular de Duchenne } \\ \text { VEF1 } & \text { Volume expiratório forçado no } 1^{\circ} \text { segundo } \\ \text { PEmax } & \text { Capacidade vital forçada } \\ \text { PImax } & \text { Pressão expiratória máxima } \\ \text { CO2 } & \text { Dióxido de carbono } \\ \text { L } & \text { Litros } \\ \text { cmH2O } & \text { Centímetros de água } \\ \% \text { predito } & \text { Percentual em relação ao valor predito para o indivíduo } \\ \bar{X} & \text { Média } \\ \text { DP } & \text { Desvio Padrão } \\ \text { EP } & \text { Erro padrão } \\ \mathrm{N} & \text { Número de casos }\end{array}$




\section{LISTA DE FIGURAS}

FIGURA 1 - Esquema Cronológico das avaliações (Aval.) e da ordem de introdução dos exercícios de ioga $(\mathrm{K}=$ kapalabhati; $\mathrm{U}=$ =uddiyana; $\mathrm{A}=$ =agnisara).

FIGURA 2 - Porcentagem do tempo de prática de cada exercício no momento da avaliação 2. As datas estão demonstradas no Anexo III.

FIGURA 3 -Avaliação da CFV em litros para o grupo total de crianças no tempo 0. Foram avaliadas 85 pacientes com DMD com idades entre 6 e 14 anos. Cada ponto do gráfico representa o melhor valor deste índice de cada paciente.

FIGURA 4 - Avaliação da CFV em valores percentuais do predito para o grupo total de crianças no tempo 0. Foram avaliadas 85 pacientes com DMD com idades entre 6 e 14 anos. Cada ponto do gráfico representa o melhor valor deste índice de cada paciente.

FIGURA 5 - Avaliação da VEF1 em litros para o grupo total no tempo 0. Foram avaliadas 85 pacientes com DMD com idades entre 6 e 14 anos. Cada ponto do gráfico representa o melhor valor de cada um para este índice.

FIGURA 6 - Avaliação da VEF1 em valores percentuais do predito, para o grupo total no tempo 0. Foram avaliadas 85 pacientes com DMD com idades entre 6 e 14 anos. Cada ponto do gráfico representa o melhor valor de cada um para este índice.

FIGURA 7 - Avaliação da PEmax em cmH2O para o grupo total no tempo 0. Foram avaliadas 85 pacientes com DMD com idades entre 6 e 14 anos. Cada ponto do gráfico representa o melhor valor de cada um para este índice.

FIGURA 8 - Avaliação da PEmax em valores percentuais do predito, para o grupo total no tempo 0. Foram avaliadas 85 pacientes com DMD com idades entre 6 e 14 anos. Cada ponto do gráfico representa o melhor valor de cada um para este índice.

FIGURA 9 - Gráfico dos valores absolutos da CVF, considerando as avaliações 0 e 2. Para o grupo total $(\mathrm{N}=39)$, os de 6 a 9 anos $(\mathrm{N}=25)$ e para os de 10 a 14 $(\mathrm{N}=14)$. Valores calculados pela mediana. $* \neq 0 \quad \mathrm{p} \leq 0,05$

FIGURA 10 - Gráfico dos valores percentuais aos do predito da CVF, considerando as avaliações 0 e 2. Para o grupo total $(\mathrm{N}=39)$, os de 6 a 9 anos $(\mathrm{N}=25)$ e para os de 10 a $14(\mathrm{~N}=14)$. Valores calculados pela mediana. $* \neq 0$ $\mathrm{p} \leq 0,05$. 
FIGURA 11 - Gráfico dos valores absolutos da VEF1, considerando as avaliações 0 e 2 . Para o grupo total $(\mathrm{N}=39)$, os de 6 a 9 anos $(\mathrm{N}=25)$ e para os de 10 a $14(\mathrm{~N}=14)$. Valores calculados pela mediana. $* \neq 0 \mathrm{p} \leq 0,05$.

FIGURA 12 - Gráfico dos valores percentuais aos do predito do VEF1, considerando as avaliações 0 e 2. Para o grupo total $(\mathrm{N}=39)$, os de 6 a 9 anos $(\mathrm{N}=25)$ e para os de 10 a $14(\mathrm{~N}=14)$. Valores calculados pela mediana.

FIGURA 13 - Gráfico dos valores absolutos da PEmax, considerando as avaliações 0 e 2. Para o grupo total $(\mathrm{N}=39)$, os de 6 a 9 anos $(\mathrm{N}=25)$ e para os de 10 a $14(\mathrm{~N}=14)$. Valores calculados pela mediana. $* \neq 0 \mathrm{p} \leq 0,05$.

FIGURA 14 - Gráfico da PEmax em valores percentuais ao predito, considerando as avaliações 0 e 2. Para o grupo total $(\mathrm{N}=39)$, os de 6 a 9 anos $(\mathrm{N}=25)$ e para os de 10 a $14(\mathrm{~N}=14)$. Valores calculados pela mediana.

FIGURA 15 - Avaliação da CVF em litros para o grupo de pacientes antes e após 10 meses de treinamento. Foram avaliadas 39 pacientes com DMD com idades entre 6 e 14 anos.

FIGURA 16 - Avaliação da CVF em valores percentuais aos do predito para o grupo de pacientes antes e após 10 meses de treinamento Foram avaliadas 39 pacientes com DMD com idades entre 6 e 14 anos.

FIGURA 17 - Avaliação da VEF1 em litros para o grupo de pacientes antes e após 10 meses de treinamento. Foram avaliadas 39 pacientes com DMD com idades entre 6 e 14 anos.

FIGURA 18 - Avaliação da VEF1 em porcentagem do predito para o grupo de pacientes antes e após 10 meses de treinamento Foram avaliadas 39 pacientes com DMD com idades entre 6 e 14 anos.

FIGURA 19 - Avaliação da PEmax em valores absolutos para o grupo de pacientes antes e após 10 meses de treinamento Foram avaliadas 39 pacientes com DMD com idades entre 6 e 14 anos.

FIGURA 20 - Avaliação da PEmax em valores percentuais aos do predito para o grupo de pacientes antes e após 10 meses de treinamento. Foram avaliadas 39 pacientes com DMD com idades entre 6 e 14 anos.

FIGURA 21 - Avaliação da CVF em litros para o grupo de pacientes com pelo menos mais uma das avaliações (1 e/ou 2), além da avaliação inicial (0), com um $\mathrm{N}=70$, divididos em dois grupos, um de 6 a 9 anos $(\mathrm{N}=41)$ e outro de 10 a 14 anos $(\mathrm{N}=29)$. Os dados foram expressos pela média. $* \neq 0, \mathrm{p} \leq 0,05$

FIGURA 22 - Avaliação da CVF em valores percentuais do predito, para o grupo de pacientes com pelo menos mais uma das avaliações (1 e/ou 2), além da avaliação inicial (0), com um $\mathrm{N}=70$, divididos em dois, um de 6 a 9 anos $(\mathrm{N}=41)$ e outro de 10 a 14 anos $(\mathrm{N}=29) . * \neq 0, \mathrm{p} \leq 0,05$. 
FIGURA 23 - Avaliação da VEF1 em litros, para o grupo de pacientes com pelo menos mais uma das avaliações (1 e/ou 2), além da avaliação inicial (0), com um $\mathrm{N}=70$, divididos em dois, um de 6 a $9 \operatorname{anos}(\mathrm{N}=41)$ e outro de 10 a 14 anos $(\mathrm{N}=29) .{ }^{*} \neq 0, \mathrm{p} \leq 0,05$

FIGURA 24 - Avaliação da VEF1 em valores percentuais do predito, para o grupo de pacientes com pelo menos mais uma das avaliações ( 1 e/ou 2), além da avaliação inicial (0), com um $\mathrm{N}=70$, dividido em dois grupos, um de 6 a 9 $\operatorname{anos}(\mathrm{N}=41)$ e outro de 10 a $14 \operatorname{anos}(\mathrm{N}=29) . * \neq 0, \mathrm{p} \leq 0,05$

FIGURA 25 - Avaliação da PEmax em valores absolutos, para o grupo de pacientes com pelo menos mais uma das avaliações (1 e/ou 2), além da avaliação inicial (0), com um $\mathrm{N}=70$, dividido em dois grupos, um de 6 a 9 anos $(\mathrm{N}=41)$ e outro de 10 a 14 anos $(\mathrm{N}=29) .{ }^{*} \mathrm{p} \leq 0,05$.

FIGURA 26 - Avaliação da PEmax em valores proporcionais ao predito, para o grupo de pacientes com pelo menos mais uma das avaliações ( 1 e/ou 2), além da avaliação inicial (0), com um $\mathrm{N}=70$, dividido em dois grupos, um de 6 a 9 $\operatorname{anos}(\mathrm{N}=41)$ e outro de 10 a $14 \operatorname{anos}(\mathrm{N}=29)$.

FIGURA 27 - Avaliação da CVF em litros antes e após 1 ano de treinamento. Foram avaliados 70 pacientes com DMD com idades entre 6 e 14 anos. Cada ponto do gráfico representa o melhor valor de cada paciente para este índice.

FIGURA 28 - Avaliação da CVF em valores percentuais ao predito antes e após 1 ano de treinamento. Foram avaliados 70 pacientes com DMD com idades entre 6 e 14 anos. Cada ponto do gráfico representa o melhor valor de cada paciente para este índice.

FIGURA 29 - Avaliação da VEF1 em litros antes e após 1 ano de treinamento. Foram avaliados 70 pacientes com DMD com idades entre 6 e 14 anos. Cada ponto do gráfico representa o melhor valor de cada paciente para este índice.

FIGURA 30 - Avaliação da VEF1 em valores percentuais do predito antes e após 1 ano de treinamento. Foram avaliadas 70 pacientes com DMD com idades entre 6 e 14 anos. Cada ponto do gráfico representa o melhor valor de cada paciente para este índice.

FIGURA 31 - Avaliação da PEmax em valores absolutos antes e após 1 ano de treinamento. Foram avaliados 70 pacientes com DMD com idades entre 6 e 14 anos. Cada ponto do gráfico representa o melhor valor de cada paciente para este índice.

FIGURA 32 - Avaliação da PEmax em valores percentuais aos do predito antes e após 1 ano de treinamento. Foram avaliadas 70 pacientes com DMD com idades entre 6 e 14 anos. Cada ponto do gráfico representa o melhor valor de cada paciente para este índice. 
FIGURA 33 - Avaliação da CVF absoluta (L) e relativa (\%) dos pacientes com todas as avaliações $(0,1,2,3$, e 4$)$ no período de dois anos de treinamento, $\mathrm{N}=18$. Valores calculados pela mediana.

FIGURA 34 - Resultado do VEF1 absoluto (L) e RELATIVO (\%) dos pacientes com todas as avaliações $(0,1,2,3$, e 4$)$ no período de dois anos de treinamento, $\mathrm{N}=18$. Valores calculados pela mediana.

FIGURA 35 - Resultado da PEmax em valores absolutos e percentuais do predito, dos pacientes com todas as avaliações $(0,1,2,3$, e 4$)$ no período de dois anos de treinamento, $\mathrm{N}=18$. Valores calculados pela mediana.

FIGURA 36 - Resultados da CVF em valores percentuais ao predito no momento inicial (0) e após 10 meses de treinamento (2). Foram avaliados 10 pacientes com DMD com idades entre 6 e 14 anos com índice de adesão 1 (baixo) ao projeto.

FIGURA 37 - Resultados da CVF em valores percentuais ao predito no momento inicial (0) e após 10 meses de treinamento (2). Foram avaliados 13 pacientes com DMD com idades entre 6 e 14 anos com índice de adesão 3 (total) ao projeto.

FIGURA 38 - Resultados do VEF1 em valores percentuais ao predito no momento inicial (0) e após 10 meses de treinamento (2). Foram avaliados 10 pacientes com DMD com idades entre 6 e 14 anos com índice de adesão 1 (baixo) ao projeto.

FIGURA 39 - Resultados do VEF1 em valores percentuais ao no momento inicial (0) e após 10 meses de treinamento (2). Foram avaliados 13 pacientes com DMD com idades entre 6 e 14 anos com índice de adesão 3 (total) ao projeto.

FIGURA 40 - Resultados da PEmax em valores percentuais ao predito no momento inicial (0) e após 10 meses de treinamento (2). Foram avaliados 10 pacientes com DMD com idades entre 6 e 14 anos com índice de adesão 1 (baixo) ao projeto.

FIGURA 41 - Resultados da PEmax em valores percentuais ao predito no momento inicial (0) e após 10 meses de treinamento (2). Foram avaliados 13 pacientes com DMD com idades entre 6 e 14 anos com índice de adesão 3 (total) ao projeto. 


\section{LISTA DE TABELAS}

TABELA 1 - Capacidade vital forçada (CVF) em valores absolutos obtidos no início (0), após 5 meses de treinamento (1) e após 10 meses de treinamento (2). Pacientes que fizeram as três primeiras avaliações $(\mathrm{N}=39)$

TABELA 2 - Capacidade vital forçada (CVF) em valores percentuais ao predito, obtidos no início (0), após 5 meses de treinamento (1) e após 10 meses de treinamento (2). Para os pacientes que fizeram as três primeiras avaliações. Todos, $\mathrm{N}=39.6$ a $9, \mathrm{~N}=25.10$ a $14, \mathrm{~N}=14$.

TABELA 3 - VEF1 em valores absolutos, obtidos no início (0), após 5 meses de treinamento (1) e após 10 meses de treinamento (2). Para os pacientes que fizeram as três primeiras avaliações. Todos, $\mathrm{N}=39.6$ a 9, $\mathrm{N}=25.10$ a 14, $\mathrm{N}=14$

TABELA 4 - VEF1 em valores percentuais ao predito, obtidos no início (0), após 5 meses de treinamento (1) e após 10 meses de treinamento (2). Para os pacientes que fizeram as três primeiras avaliações. Todos, $\mathrm{N}=39.6$ a 9 , $\mathrm{N}=25.10$ a $14, \mathrm{~N}=14$.

TABELA 5 - PEmax em valores absolutos, obtidos no início (0), após 5 meses de treinamento (1) e após 10 meses de treinamento (2). Para os pacientes que fizeram as três primeiras avaliações. Todos, $\mathrm{N}=39.6$ a 9, $\mathrm{N}=25.10$ a 14 , $\mathrm{N}=14$

TABELA 6 - PEmax Relativo dos pacientes que fizeram as três primeiras avaliações: início (0), 5 meses de treinamento (1) e 10 meses de treinamento (2). Todos, $\mathrm{N}=39 ; 6$ a $9, \mathrm{~N}=25$ e 10 a $14, \mathrm{~N}=14$

TABELA 7 - Avaliação da CVF em litros para o grupo de pacientes com pelo menos mais uma das avaliações (1 e/ou 2), além da avaliação inicial (0), com um $\mathrm{N}=70$, divididos em dois grupos, um de 6 a 9 anos $(\mathrm{N}=41)$ e outro de 10 a 14 anos $(\mathrm{N}=29)$. Os dados foram expressos pela média

TABELA 8 - Avaliação da CVF em valores percentuais do predito, para o grupo de pacientes com pelo menos mais uma das avaliações (1 e/ou 2), além da avaliação inicial (0), com um $\mathrm{N}=70$, divididos em dois, um de 6 a 9 anos $(\mathrm{N}=41)$ e outro de 10 a $14 \operatorname{anos}(\mathrm{N}=29)$.

TABELA 9 - Avaliação da VEF1 em litros, para o grupo de pacientes com pelo menos mais uma das avaliações (1 e/ou 2), além da avaliação inicial (0), com um $\mathrm{N}=70$, divididos em dois, um de 6 a 9 anos $(\mathrm{N}=41)$ e outro de 10 a 14 $\operatorname{anos}(\mathrm{N}=29)$ 
TABELA 10 - Avaliação da VEF1 em valores percentuais do predito, para o grupo de pacientes com pelo menos mais uma das avaliações (1 e/ou 2), além da avaliação inicial (0), com um $\mathrm{N}=70$, dividido em dois grupos, um de 6 a 9 $\operatorname{anos}(\mathrm{N}=41)$ e outro de 10 a 14 anos $(\mathrm{N}=29)$.

TABELA 11 - Avaliação da PEmax em valores absolutos, para o grupo de pacientes com pelo menos mais uma das avaliações (1 e/ou 2), além da avaliação inicial (0), com um $\mathrm{N}=70$, dividido em dois grupos, um de 6 a 9 anos $(\mathrm{N}=41)$ e outro de 10 a 14 anos $(\mathrm{N}=29)$

TABELA 12 - Avaliação da PEmax em valores proporcionais ao predito, para o grupo de pacientes com pelo menos mais uma das avaliações (1 e/ou 2), além da avaliação inicial (0), com um $\mathrm{N}=70$, dividido em dois grupos, um de 6 a 9 $\operatorname{anos}(\mathrm{N}=41)$ e outro de 10 a $14 \operatorname{anos}(\mathrm{N}=29)$.

TABELA 13 - Avaliação da CVF absoluta (L) e relativa (\%) dos pacientes com todas as avaliações $(0,1,2,3$, e 4) no período de dois anos de treinamento, $\mathrm{N}=18$. Valores calculados pela mediana

TABELA 14 - Resultado do VEF1 em valores absolutos e percentuais do predito, dos pacientes com todas as avaliações $(0,1,2,3$, e 4$)$ no período de dois anos de treinamento, $\mathrm{N}=18$. Dados expressos pela mediana

TABELA 15 - Resultado da PEmax em valores absolutos e percentuais do predito, dos pacientes com todas as avaliações $(0,1,2,3$, e 4$)$ no período de dois anos de treinamento, $\mathrm{N}=18$. Dados expressos pela mediana 


\section{RESUMO}

Rodrigues MR. Estudo do efeito de três exercícios respiratórios de ioga na função respiratória em pacientes com distrofia muscular progressiva tipo Duchenne [dissertação]. São Paulo: Faculdade de Medicina, Universidade São Paulo; 2007. 103p.

A evolução da Distrofia Muscular de Duchenne (DMD) culmina na morte dos pacientes por problemas respiratórios, que aparentemente estão relacionados com a fraqueza de sua musculatura. O propósito deste estudo foi avaliar o efeito de três exercícios respiratórios de ioga na função respiratória em pacientes com DMD. A escolha dos exercícios foi motivada pelo fato de não se encontrar similares nos procedimentos fisioterápicos atuais no ocidente e por poderem ser praticados sem a necessidade de aparatos ou ajuda externa, facilitando sua execução diária. Os exercícios foram ensinados individualmente no ambulatório do Hospital das Clínicas da Universidade de São Paulo em dias regulares de consultas dos pacientes. As séries, bem como a sua progressão, levaram em consideração as limitações individuais. Foi realizada uma avaliação inicial das condições respiratórias (função pulmonar e pressões respiratórias) em 85 pacientes com idade entre 6 e 14 anos. Estas avaliações foram repetidas a cada 5 meses (em média) ao longo do treinamento. Os dados foram analisados de diferentes maneiras: pacientes que fizeram todas as avaliações ao longo de 10 meses $(\mathrm{N}=39)$; ao longo de 20 meses $(\mathrm{N}=18)$ e com os resultados dos pacientes que fizeram pelo menos uma avaliação além da inicial ao longo de 10 meses $(\mathrm{N}=70)$. Os grupos foram divididos por faixa etária em dois subgrupos (6 a 9 anos e 10 a 14 anos de idade). Constatou-se na análise com $\mathrm{N}=39$ e $\mathrm{N}=70$ que os pacientes mais novos que executaram os exercícios aplicados, apresentaram depois de 10 meses de treinamento, elevação nos valores absolutos e relativos da capacidade vital forçada (CVF), volume expiratório forçado em 1 segundo (VEF1) e pressão expiratória máxima (PEmax) e que os pacientes mais velhos, depois de 10 meses de treinamento, apresentaram melhora nos índices de pressão expiratória máxima (PEmax) em valores absolutos e relativos. $\mathrm{Na}$ análise com $\mathrm{N}=18$ observou-se que os pacientes obtiveram melhora nos valores absolutos da função pulmonar (CVF e VEF1) até os 20 meses de treinamento quando comparamos com os valores do início e para a PEmax em valores absolutos, os resultados aumentam até 10 meses de treinamento e depois se mantém estáveis. Observou-se diminuição no declínio dos índices de função pulmonar dos pacientes quando comparados com crianças normais (porcentagem do predito). Constatou-se na análise determinada pela curva dos resultados da PEmax por faixa etária em valores relativos, que após 10 meses de prática dos exercícios de ioga, o declínio de seus valores foi retardado. O grande fator de melhora destes pacientes foi o aumento da força muscular expiratória forçada conseguido especialmente com a prática da técnica denominada kapalabhati. Recomendamos que estes exercícios sejam incorporados à prática clínica dos pacientes com DMD com a intenção de minimizar os danos causados pela perda da capacidade respiratória.

Descritores: 1.Distrofia muscular de Duchenne 2.Volume expiratório forçado 3.Capacidade vital 4.Yoga 5.Espirometria/utilização 


\section{SUMMARY}

Rodrigues MR. Effects of three respiratory techniques of yoga in the respiratory function of patients with Duchenne's progressive muscular dystrophy [dissertation]. São Paulo: "Faculdade de Medicina, Universidade São Paulo"; 2007. 103p.

Duchenne Muscular Dystrophy (DMD) has a progression that culminates in the death of the patients for respiratory problems, which are apparently related to the weakness of the respiratory muscles. The objective of this study was to investigate the effects of three respiratory techniques of yoga in the respiratory function of patients with DMD. The selection of the exercises was conducted taking into account that there are no similar ones in the actual western physiotherapeutic procedures, and due to the fact that all of them may be practiced without the need of any apparatus or external help, making their daily practice easy. The exercises were taught individually in the Ambulatory of the General Hospital of the University of São Paulo during the regular appointments of the patients. The series of exercises, as well as their progressions, took into consideration the individual limitations. In order to establish the respiratory conditions (FVC, FEV1, PImax, and PEmax) of the group, an initial evaluation was conducted with 85 patients between 6 and 14 years old. The follow-up evaluations were carried out on an average 5-month interval, during the training period. Data were analyzed in different ways: subjects which had all the evaluations during 10 months of training $(\mathrm{N}=39)$; during 20 months of training $(\mathrm{N}=18)$ and with the results of patients that had at lest one evaluation besides the initial in the first 10 months $(\mathrm{N}=70)$. Furthermore, the total group was divided by age into 2 subgroups: (from 6 to 9 years old, and from 10 to 14 years old). The analysis of the groups with $\mathrm{N}=39$, and $\mathrm{N}=70$ revealed that, after 10 months of training, the younger subjects had increased their absolute and relative values of forced vital capacity (FVC), expiratory forced volume in $1 \mathrm{sec}$ (FEV1), and maximal expiratory pressure (PEmax), and that the older subjects, after the same period, had their absolute and relative PEmax also increased. In the analysis of the subgroup with $\mathrm{N}=18$, there was an increase in the absolute values for pulmonary function (FVC and FEV1) until 20 months of training, while for PEmax this increase was seen only until 10 months, and afterwards there was a maintenance of its values. There was a reduction in the decline of the pulmonary function indexes of the patients when compared with healthy subjects (percentage of the predicted). The curve results of relative PEmax according to age revealed that after 10 months of practicing the prescribed exercises, the decline of its values was postponed. The greatest improvement in these children was found in the expiratory muscle power, attained through the practice of the technique called kapalabhati. We recommend the inclusion of these exercises to the clinical treatment of the DMD patients with the intention of minimizing the damage caused by the loss of respiratory capacity.

Descriptor: 1.Muscular dystrophy, Duchenne 2.Forced expiratory volume 3.Vital capacity 4.Yoga 5.Spirometry/utilization 
A Distrofia Muscular de Duchene (DMD) é a distrofia mais freqüente nas crianças, com incidência de 1 para cada 3500 nascimentos masculinos (Simonds, 2002). Apesar dos avanços da terapia gênica, não se tem até o momento tratamento eficaz para esta doença.

Os pacientes evoluem com a perda progressiva das fibras musculares pela deficiência da distrofina. Esta perda muscular tem seu início na cintura pélvica, progride para a cintura escapular e termina acometendo a musculatura respiratória. A insuficiência respiratória decorrente é agravada por pneumopatias de repetição, que é a causa do óbito da maioria destes pacientes (Simonds, 2002).

Recente trabalho realizado no Hospital das Clinicas da Universidade de São Paulo (Carvalho, 2004), mostrou que crianças com DMD atingiram os valores máximos de força muscular respiratória, volume expiratório forçado no $1^{\circ}$ segundo (VEF1) e capacidade vital forçada (CVF) entre 9 e 12 anos de idade. Os valores máximos de VEF1 e CVF foram atingidos entre 11 e 12 anos de idade e de pressão expiratória máxima (PEmax) aos 9 anos de idade. Concluiu-se que a força muscular expiratória era a mais comprometida com o passar dos anos nas crianças com esta doença.

Os estudos sobre a aplicação de exercícios respiratórios para este tipo de pacientes, ainda não são conclusivos (Simonds, 2002; Koessler et al., 2001; Abe et al., 1998).

Ioga é uma filosofia indiana que reconhece a importância de se trabalhar com o corpo para a aquisição de saúde física e mental (Eliade, 1996). Ficou mais 
conhecida no ocidente pelas técnicas corporais, os asanas, que se caracterizam pela permanência em posturas específicas em condições de conforto e estabilidade e técnicas de controle de movimentos e ritmos respiratórios, conhecidas como pranayamas (Kuvalayananda, 1993). O sistema respiratório recebeu atenção especial dos antigos praticantes de ioga, como é observado nos seus textos mais importantes, que datam do século XV d.C., o Hatha Yoga Pradipika e o Gheranda Samhita (Digambarji e Kokage, 1970; Digambargi e Gharote, 1978).

Na Índia, os estudos científicos em ioga começaram em 1920, com subsídios do governo, sob a coordenação do Swami Kuvalayananda, com publicação intitulada "X-Ray experiments on Uddiyana and Nauli” (Karambelkar, 1983). Em 1960, Anand, Chhina e Singh, publicaram um artigo pelo Departamento de Fisiologia do Instituto de Ciências Médicas da Índia em Nova Delhi, considerando alterações eletroencefalográficas em iogues (Anand et al.,1961). As pesquisas sobre esse assunto começam a surgir nas publicações ocidentais somente em 1970, (Patel, 1973 e 1975). Daniel Goleman, um dos mais recentes investigadores sobre o assunto, acredita que a ciência ocidental e a filosofia oriental não são antagônicas, mas de certa forma complementares (Goleman, 1999).

Com a finalidade de analisar as técnicas de ioga com a leitura da metodologia ocidental, selecionamos três exercícios respiratórios para aplicarmos em crianças com DMD, pelo período de dois anos com avaliações trimestrais da função respiratória. Os exercícios propostos foram orientados no ambulatório do Hospital das Clínicas da Universidade de São Paulo e foi solicitado aos pacientes que os repetissem diariamente em suas casas. A escolha dos exercícios foi motivada pelo fato de atuarem na musculatura respiratória, por não se encontrarem similares na educação física ou fisioterapia e por poderem ser feitos pelas crianças sem a necessidade de um agente externo, mesmo com as limitações impostas pela doença. 
- Avaliar a possibilidade da aplicação de três técnicas respiratórias de ioga em pacientes com DMD:

Kapalabhati.

Uddiyana.

Agnisara.

- Avaliar durante a aplicação das técnicas de ioga propostas os parâmetros de função respiratória e pressão respiratória máxima:

Capacidade Vital Forçada (CVF).

Volume Expiratório Forçado no $1^{\circ}$ segundo (VEF1)

Pressão Inspiratória Máxima (PImax).

Pressão Expiratória Máxima (PEmax).

- Comparar os resultados obtidos com os dados descritos na literatura. 


\subsection{Ioga}

Etimologicamente a palavra ioga deriva da raiz sânscrita yuj, que entre outros significados quer dizer "união" ou "integração". Originou o termo latino jungere, jugum e o inglês yoke (Eliade, 1996).

Não existe uma referência cronológica que determine quando a ioga surgiu, mas a maioria dos estudiosos afirma que foi sistematizada ou compilada no século IV a.C. por "Patanjali", no texto apresentado em forma de aforismos, conhecido como os "Yoga Sutras de Patanjali” (Taimni, 1996).

Patanajali apresenta a ioga como um sistema de oito partes, sendo que duas delas se referem às técnicas corporais, asanas e pranaymas, que são posturas físicas que se caracterizam pela permanência em condições de conforto e estabilidade e técnicas respiratórias, respectivamente (Taimni, 1996). Trata inicialmente do cultivo de atitudes psicológicas corretas, sugerindo um esforço consciente, para que o praticante evite situações emocionais negativas que podem ser controladas. É portanto, um sistema que inclui o cultivo de atitudes saudáveis, práticas físicas corporais e respiratórias como ponto de partida para se considerar as questões filosóficas da vida (Kuvalayananda, 1971).

Com o passar do tempo, a ioga foi originando diferentes linhas e sistemas, que se diferenciam pelas estratégias utilizadas. Os exercícios escolhidos para este 
trabalho são originários do sistema conhecido como Hatha Yoga, a linha de ioga que enfatiza o trabalho do corpo. Nos baseamos em dois dos principais textos desta linha que são o Hahta Yoga Pradipika e o Gharanda Samhita e que fazem a seguinte classificação das técnicas (Souto, 2004):

- Asanas- posturas físicas que se caracterizam pela permanência em condições de conforto e estabilidade.

- Pranayamas- exercícios de controle dos movimentos e ritmo respiratório.

- Bandhas e Mudras - manipulação das pressões internas, de forma aumentada ou diminuída, através do controle de certos músculos de ação voluntária e automática, como os esfínteres, diafragma pélvico e músculos respiratórios (Gharote, 2000).

- Kriyas- exercícios de purificação e limpeza. São consideradas técnicas preparatórias em ioga.

Cada grupo de técnicas possui subdivisões e são compostos por vários exercícios que em conjunto compõe um sistema de trabalho. Selecionamos dois exercícios do grupo dos kriyas (kapalabhati e agnisara) e uma do grupo dos bandhas (uddiyana) que em conjunto trabalham com toda musculatura respiratória.

\subsection{Os exercícios escolhidos}

- Kapalabhati - significa literalmente "crânio fulgoroso" ou "crânio brilhante". Embora seja um exercício respiratório, não pertence à classificação dos pranayamas, mas sim aos kriyas, por seu efeito de limpeza das vias respiratórias 
superiores, pela ação da saída vigorosa do ar pelo nariz (Kuvalayananda e Vinekar, 1971). São movimentos rápidos de contração da musculatura abdominal, com vigorosa expiração, seguida do relaxamento da mesma musculatura e consequente inspiração. Pela intensidade e velocidade da contração da musculatura expiratória determinada pelo ritmo rápido do exercício, toda região pélvica é automaticamente contraída, resultando também na contração dos esfíncteres anais (Kuvalayananda, 1983). Desta forma entram em ação os músculos da expiração forçada na região abdominal (reto abdominal, oblíquos do abdome, quadrado lombar, transverso do abdome e serrátil posterior inferior), os glúteos, esfíncteres interno e externo, diafragma pélvico e musculatura perineal (Coutler, 1939; Lippert, 1996).

Neste exercício a expiração é ativa e a inspiração é passiva. O ritmo da respiração na fase inicial é de uma expiração por segundo e pode chegar até dois por segundo, de acordo com a capacidade individual (Kuvalayananda, 1983).

- Uddiyana - faz parte do grupo dos bandhas, literalmente significa "elevar, subir ou o que vai para cima" é a expansão da caixa torácica, após profunda expiração, sem permitir a entrada do ar, ou seja, o movimento de inspiração da região torácica em apnéia (Kuvalayananda e Vinekar, 1971). Tal expansão, sem a conseqüente entrada do ar, cria na região toráxica uma pressão subatmosférica (vácuo) que suga o diafragma para dentro da sua cavidade, promovendo o alongamento desta musculatura (Coutler, 1939). Toda musculatura da inspiração forçada (intercostais externos, esternocleidomastóideo, escalenos, elevador das costelas, serrátil, elevador da escápula, trapézio, rombóides e peitoral maior), é mantida em contração durante a permanência no exercício (Lippert, 1996).

- Agnisara - pertence ao grupo dos kriyas, e literalmente significa "avivar o fogo". Mantendo-se a apnéia após profunda expiração, repetir movimentos de projeção e recolhimento da parede abdominal, especialmente da parte mediana e baixa, na maior amplitude possível, com a constante contração de sua musculatura (Kuvalayananda e Vinekar, 1971). A musculatura expiratória acessória mantém-se em ação o tempo todo neste exercício, mais intensamente no momento em que a 
parede abdominal se movimenta na direção da coluna e como musculatura de "resistência" ao diafragma no momento de projeção da parede abdominal (Puilip, 1989). A musculatura abdominal e diafragmática trabalham como agonista e antagonista, a primeira em resistência à outra, exigindo a contração intensa do diafragma no momento de projeção e dos músculos da expiração forçada (descritos no kapalabhati) no momento de recolhimento (Lippert, 1996).

Nos três exercícios, o paciente trabalha com a musculatura inspiratória e expiratória em ritmo e intensidade diferentes dos que propõem as técnicas conhecidas no ocidente.

\subsection{Ioga e Respiração}

O sistema respiratório recebeu atenção especial dos antigos praticantes de ioga uma vez que a respiração é uma função que apresenta os controles voluntário e involuntário.

O controle voluntário sobre a atividade respiratória foi inicialmente investigado em praticantes de ioga por Anand e colaboradores em 1961. Estes autores observaram as respostas respiratórias e metabólicas à alta concentração de $\mathrm{CO} 2$ num iogue que permaneceu durante dez horas deitado no interior de uma câmara com volume de ar conhecido, medindo-se o consumo de $\mathrm{O} 2$ e a concentração de $\mathrm{CO} 2$ no gás expirado. Neste experimento observou-se que o iogue não apresentava hiperpnéia ou taquicardia mesmo quando havia diminuição de oxigênio e aumento na concentração de dióxido de carbono, havendo diminuição do consumo de $\mathrm{O} 2$ e eliminação de $\mathrm{CO} 2$ muito abaixo dos valores basais. Posteriormente, Stanescu e equipe (1981), estudaram a 
resposta ventilatória ao $\mathrm{CO} 2$ em praticantes e não praticantes de ioga durante respiração com fases controladas e observaram que devido à respiração lenta, ambos os grupos apresentavam respostas menores àquela condição. Quando foram realizados os testes respiratórios com maior concentração de $\mathrm{CO} 2$, verificou-se que os dois grupos de indivíduos aumentavam a ventilação, mas que os praticantes de ioga apresentavam nos dois últimos minutos do teste, freqüência respiratória menor daquelas encontradas no grupo controle e atribuíram essas características à prática repetida de exercícios respiratórios da ioga. Os autores verificaram que os praticantes de ioga apresentavam maior volume corrente e respiração mais lenta quando comparados aos não praticantes durante respirações livres. A diminuição da atividade simpática nos iogues é uma das explicações sugeridas.

Spicuzza et al. (2000) investigaram a sensibilidade reflexa dos quimiorreceptores em praticantes de ioga e concluíram que a respiração lenta reduzia a sensibilidade quimiorreflexa, mas que a prática prolongada de ioga resultava na redução generalizada da atividade reflexa dos quimiorreceptores.

\subsection{Distrofia Muscular de Duchene (DMD)}

O termo distrofia muscular tem sido classicamente utilizado para definir um grupo de miopatias caracterizadas por perda muscular e fraqueza progressiva devido à degeneração da musculatura esquelética, mas, sem alteração do sistema nervoso central ou periférico (Patel, 1975). As distrofias podem ser subdivididas pelo modo 
de hereditariedade, idade de início, distribuição dos músculos envolvidos, velocidade de progressão e a evolução da doença a longo prazo (Ervasti e Campbell, 1991).

A Distrofia Muscular de Duchene (DMD) é a mais comum das distrofias musculares da infância, com incidência de um em cada 3500 nascimentos masculinos e é decorrente de uma deficiência na expressão da distrofina, uma proteína subsarcolemal, cujo gene está localizado no braço curto do cromossomo X (Petrof, 1998).

A distrofina é uma grande molécula localizada na membrana sarcolemal e parte integrante do complexo glicoproteína associada à distrofina (GAD). O complexo GAD é essencial para manter a integridade da membrana sarcolemal durante a contração e o relaxamento da fibra muscular. Sua ausência leva a mionecrose, fibrose muscular progressiva com reposição de gordura (Cohn e Campbell, 2000). No músculo esquelético, a distrofina é encontrada em todos os tipos de fibras musculares e ocupa, aproximadamente, 5\% da superfície da membrana associada ao citoesqueleto (Lido et al.,1995). Apesar dos enormes progressos na compreensão das bases moleculares da DMD, a função precisa da distrofina e os mecanismos pelos quais a sua ausência causa uma patologia muscular progressiva permanecem especulativos. O diagnóstico de DMD baseia-se na determinação da mutação no gene e da expressão da distrofina, no músculo esquelético (Love et al., 1993).

Os sintomas decorrentes da ausência de distrofina se iniciam, em média, aos três anos de idade, os pacientes ficam gravemente afetados na adolescência e a morte ocorre invariavelmente na $3^{\mathrm{a}}$ década de vida, decorrente de problemas respiratórios e cardíacos (Smith et al., 1987). Os músculos das cinturas escapular e pélvica ficam 
enfraquecidos e reduzem de massa determinando certas peculiaridades clínicas. A fraqueza da musculatura abdominal e paravertebrais, determina a postura lordótica e o abdome protuberante quando em pé e as costas cifóticas quando sentado. A fraqueza bilateral dos músculos extensores dos joelhos e quadril interfere no equilíbrio e em atividades como subir escadas, levantar da cadeira ou ficar em posição ortostática. $\mathrm{O}$ andar digitígrado, a marcha anserina e a incapacidade de correr são as manifestações características da doença e o paciente perde a capacidade de deambulação com a idade média de 10 anos (Rideau et al., 1983). O envolvimento tardio do coração e o retardo mental são freqüentemente observados.

Apesar de não haver um tratamento definitivo disponível para os pacientes com DMD, a corticoterapia pode prolongar o tempo de deambulação por um período de até três anos (Biggar et al., 2006), porém observando-se efeitos colaterais, entre eles o ganho de peso. Apesar da rápida evolução da doença e dos escassos tratamentos disponíveis, é importante encorajar o paciente a levar a sua vida o mais próximo possível da normalidade.

\subsection{Complicações Respiratórias no Paciente com Distrofia Muscular de Duchene}

$\mathrm{Na} \mathrm{DMD}$, os problemas respiratórios são a causa da mortalidade em mais de $70 \%$ dos pacientes (Gomes e Bach, 2002) e estima-se que entre 55\% (Mukoyama et al., 1987; Brooke et al., 1989) e 90\% dos pacientes (Inkley et al., 1974; Rideau et al., 1983) morrem de insuficiência respiratória entre 16 e 19 anos de 
idade. O comprometimento respiratório depende de diversos fatores, mas o grau de envolvimento dos músculos inspiratórios, a rigidez da caixa torácica e alterações na regulação dos centros respiratórios têm sido considerados os fatores mais importantes.

A perda da função respiratória induz a maioria dos pacientes a um círculo vicioso que se inicia pelo declínio da capacidade respiratória e termina com a incidência de pneumonia, infecções respiratórias recorrentes, hipoxemia durante o sono e restrição das atividades do paciente com o aumento da incidência de hospitalização (Bach, 1996). A inatividade ou internação mesmo que por curtos períodos de tempo enfraquecem ainda mais a musculatura do paciente e reduzem sua capacidade ventilatória, levando à insuficiência respiratória (De Troyer et al., 1980; Mier et al., 1988). É provável que esta seja a explicação para mais de $90 \%$ das pneumonias e infecções das vias aéreas superiores como causa de hospitalizações em indivíduos com doenças neuromusculares (Bach et al.,1998).

Com a evolução da doença, o paciente com DMD apresentará um padrão pulmonar restritivo com taquipnéia ao repouso com conseqüente redução do trabalho elástico da respiração, no entanto com a desvantagem do aumento da ventilação do espaço morto. Sabe-se que um desequilíbrio entre a força e a carga imposta aos músculos inspiratórios desencadeia uma resposta de respiração curta e rápida (Rochester, 1991; Lanini et al., 2001). A fraqueza dos músculos respiratórios pode clinicamente ser avaliada pela palpação dos músculos abdominais, visto que os músculos expiratórios podem estar recrutados durante a fase expiratória para compensar a fraqueza muscular (Rimmer e Whitelaw, 1993). 
Deste modo, a expiração ativa nestes indivíduos permite que eles expirem abaixo da capacidade residual funcional (CRF) e quando os músculos abdominais relaxam ao fim da expiração, as forças passivas do sistema respiratório irão assistir à inspiração.

\subsection{Função Pulmonar e Pressões Respiratórias}

A fraqueza muscular respiratória pode reduzir o funcionamento da bomba ventilatória limitando a habilidade em diminuir a pressão intra-torácica para inflar o pulmão. Deste modo, as provas de função pulmonar em pacientes com doenças neuromusculares são caracterizadas por um padrão restritivo com a capacidade pulmonar total e a capacidade vital reduzidas (Braun et al., 1983; Vincken et al., 1987; Dolmage et al., 1992) enquanto a CRF pode estar normal ou reduzida (Fallat et al., 1979; De Troyer et al., 1980). O fluxo expiratório forçado está reduzido nestes pacientes e o VEF1 está geralmente reduzido na proporção da redução da CVF de modo que a relação entre estes parâmetros (índice de Tiffenau) está preservada. Um estudo longitudinal mostrou que a CVF é um parâmetro importante para o acompanhamento da queda da função respiratória dos pacientes com DMD (Rideau et al.,1983). Baydur et al., em 1991, mostrou ainda que há um declínio anual de 5\% na CVF.

A fraqueza muscular respiratória progressiva continua sendo um dos maiores problemas no controle de pacientes com DMD. A redução da complacência pulmonar e da caixa torácica observada nos pacientes com doença 
neuromuscular (Smith et al., 1987) aumenta a carga mecânica sustentada a cada respiração pela musculatura já enfraquecida. Com o aumento da fraqueza muscular, o paciente tende a hipoventilar e a pressão arterial de dióxido de carbono $(\mathrm{PaCO} 2)$ aumenta, atingindo muitas vezes uma hipercapnia (Braun et al., 1983; Baydur, 1991). É possível que este aumento excessivo da hipercapnia seja decorrente de outros fatores, tais como a modificação do controle respiratório, que podem contribuir para a retenção de $\mathrm{CO} 2$, a atelectasia e a anormalidade da caixa torácica, que reduzem a complacência e aumentam a carga elástica imposta aos músculos respiratórios (De Troyer, 1980).

Os testes mais utilizados para avaliar as forças musculares inspiratória e expiratória são as pressões inspiratória (PImax) e expiratória (PEmax) máximas. Estes parâmetros têm sido também os mais utilizados na avaliação dos pacientes com doença neuromuscular ou como parâmetros para o treinamento da musculatura respiratória (Rodillo et al., 1989; Vilovzni et al., 1994; Wanke et al., 1984). As medidas de PImax e PEmax devem ser realizadas de modo padronizado (American Thoracic Society/Europian Respiratory Society, 2002) e sabe-se que as variações de PImax e PEmax são dependentes do grau de fraqueza neuromuscular. Além da fraqueza muscular, as alterações da coluna vertebral e da caixa torácica podem estar implicadas na perda da função pulmonar sendo que 50\% dos pacientes com DMD apresentam uma escoliose torácica importante durante o estirão de crescimento puberal (Rideau et al., 1983).

A fraqueza muscular inspiratória tem sido considerada a maior determinante na deterioração da função respiratória. Muitos pesquisadores têm sugerido que o treinamento desta musculatura é importante para melhorar a função respiratória em 
pacientes com DMD (Di Marco et al., 1985; Martin et al., 1986; Wanke et al., 1984). Entretanto, os resultados sobre este treinamento são contraditórios visto que parece haver uma melhora da resistência da musculatura inspiratória sem que isto repercuta numa melhora da função pulmonar ou na sobrevida dos pacientes. Por outro lado, a musculatura expiratória também parece estar implicada na função pulmonar dos pacientes com DMD. Neste sentido, pacientes mais velhos que permanecem em cadeira de rodas e adquirem o movimento rítmico espontâneo de "remador" (Kawamura et al., 1989), apresentam uma melhora da sua função pulmonar, fenômeno que parece ser decorrente do aumento da eficiência da musculatura abdominal e respiratória acessória (Yasuma et al., 2001).

A atividade contrátil é um dos estímulos mais eficientes para a modificação de tamanho e tipo da fibra muscular (Baldwin, 2002). Em humanos, o não uso da musculatura, causa a diminuição da sua massa em apenas algumas semanas (Narici, 1997). A interferência de exercícios na musculatura respiratória tem despertado interesse desde que se percebeu que a fadiga da musculatura respiratória pode ocorrer durante o treinamento de exercícios pesados (Johnson, 1993). Por outro lado, o uso da respiração mecânica, por necessidade, tem sido responsável por problemas posteriores em pacientes. Estudos em animais, mostraram a diminuição da força do diafragma, já após 12 horas de ventilação mecânica (Gayan-Ramires, 2002). 


\subsection{Casuística}

Avaliamos inicialmente 85 crianças entre 6 e 14 anos de idade $(9,3 \pm 2,3)$, com peso médio de $32,2 \mathrm{~kg}( \pm 15,3)$ e altura média de $130,3 \mathrm{~cm}( \pm 12,5)$ que fizeram parte dos testes de função respiratória para determinar o perfil de entrada dos pacientes. Porém, destes 85, apenas 70 pacientes continuaram com o treinamento por se encaixarem nos fatores de inclusão.

Foram incluídos todos os meninos em seguimento ambulatorial que aceitaram participar deste estudo. Foram excluídos meninos com idade inferior a cinco anos de idade e aqueles que apresentaram dificuldade ou impossibilidade de realização dos testes de função pulmonar ou de avaliação da força muscular respiratória.

Os meninos e seus cuidadores foram convidados a participar do projeto em dias regulares de consulta médica durante o período de julho de 2003 a outubro de 2005.

Fatores de inclusão:

- Diagnóstico de DMD confirmado por método molecular e/ou por expressão proteica do músculo esquelético.

- Em seguimento clínico pelo grupo de miopatias do Departamento de Neurologia do Hospital das Clínicas da Faculdade de Medicinal da Universidade de São Paulo.

- Adesão voluntária ao projeto pelo paciente e cuidador.

- Ter realizado o teste de função respiratória antes do início do treinamento. 
Os fatores de exclusão:

- Dificuldade na execução dos exercícios respiratórios por:

- estágio avançado da doença;

- retardo mental ou

- por serem muito novos.

- Não adesão voluntária do paciente ou cuidador.

\subsection{Método}

\subsubsection{Ensino}

Todas as crianças que demonstraram interesse foram atendidas individualmente, na presença dos cuidadores, pela equipe de voluntários do grupo da ioga, mesmo as que não fizeram parte do projeto pelos fatores de exclusão já apresentados. Antes da apresentação dos exercícios foi feita uma explicação sobre a importância de se trabalhar com a musculatura respiratória para este grupo.

Os exercícios foram inicialmente demonstrados, depois ensinados detalhadamente até que as crianças repetissem adequadamente. Os cuidadores também executavam as técnicas para poderem orientar as crianças que tivessem dúvidas na execução em casa. Dependendo da limitação imposta pela doença, as técnicas foram ensinadas nas macas ou em cadeiras.

A primeira técnica a ser ensinada foi o kapalabhati, a segunda foi uddiyana e a terceira agnisara. A escolha da ordem seguiu o princípio do mais simples para o mais difícil. Só foi ensinada a técnica seguinte quando o paciente apresentava boa execução da anterior (Figura 1). 
O número de repetições para cada exercício foi estabelecida a cada retorno do paciente. Desta forma, se ele conseguia executar a série proposta sem dificuldade ou cansaço, aumentávamos a quantidade, até o máximo pré-estabelecido de:

Kapalabhati - 3 séries de 120 repetições cada.

Uddiyana - 3 repetições de 10 segundos de permanência.

Agnisara - 3 séries de 5 movimentos cada.

\subsubsection{Prática}

Uma ficha de controle para a anotação da prática diária era dada ao paciente a cada encontro, com as explicações e desenhos de suas tarefas para os próximos três meses (Anexo I). As fichas foram substituídas a cada retorno. Em casa, as crianças realizaram 3 séries de cada exercício 3 vezes ao dia (manhã, tarde e noite), com o número de execuções conforme a capacidade individual. Mesmo com o número máximo de repetições para cada exercício, cada série não ultrapassava 10 minutos de prática.

Discutíamos com os cuidadores e as crianças os melhores horários e situações para o cumprimento de suas tarefas diárias.

A ficha de controle, junto com a observação da execução na repetição dos exercícios e mais o relatado pela criança e seu cuidador, nos permitiu agrupá-las em três diferentes níveis de adesão: Consideramos como nível de adesão 1 a criança que pouco se comprometeu com as repetições diárias; nível 2 àquelas que embora não reproduzissem tudo o que foi sugerido, mantiveram um índice regular de execuções e nível 3 as crianças que mantiveram a prática diária de acordo com o que foi prescrito (Anexo II). 
As avaliações foram realizadas no ambulatório do Hospital das Clínicas, a cada 3 meses, seguindo o calendário de retorno determinado pelas consultas médicas. Todas as crianças passavam pelo atendimento com os professores de ioga e depois seguiam para a avaliação respiratória, sem que o responsável pelo teste soubesse se o paciente fazia parte do grupo pertencente ao projeto. Caso apresentassem alguma modificação nas condições respiratórias, como quadro infeccioso virótico e/ou bacteriano, de vias respiratórias superiores, que pudesse prejudicar a avaliação, eram dispensados do teste com remarcação para o próximo retorno.

Os dados antropométricos, idade e as condições do paciente foram anotados junto com os resultados dos testes.

Consideramos como "Avaliação 0" a avaliação realizada antes do início da aplicação dos exercícios, ou seja, o momento de entrada dos pacientes no projeto. Logo após o início do treinamento, foram realizadas avaliações regulares em intervalos de 5 meses $( \pm 1)$ chamadas de: “avaliação 1" (5 meses); "avaliação 2" (10 meses); “avaliação 3" (15 meses) e a "avaliação 4" (20 meses) (Figura 1).

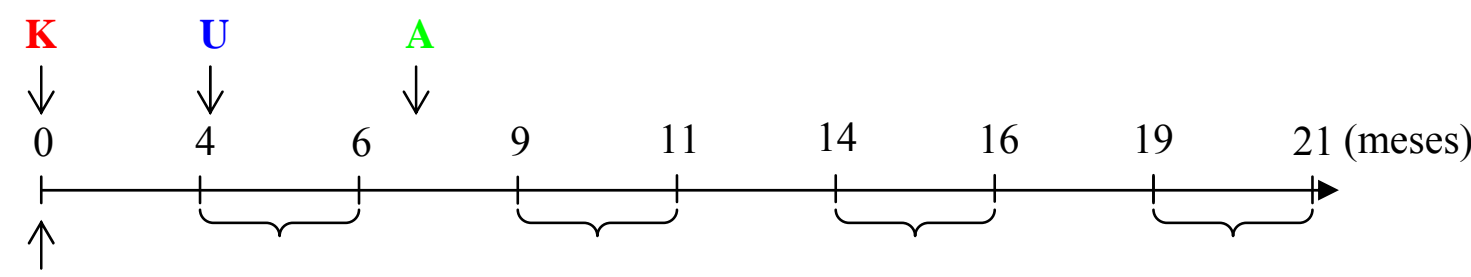
Aval. 0
Aval. 1
Aval. 2
Aval. 3
Aval. 4

FIGURA 1 - Esquema Cronológico das avaliações (Aval.) e da ordem de introdução dos exercícios de ioga $(\mathrm{K}=$ kapalabhati; $\mathrm{U}=$ uddiyana; $\mathrm{A}=$ agnisara $)$. 
O tempo de aprendizagem de cada exercício variou de paciente para paciente, de acordo com a capacidade de compreensão e possibilidade de retorno. O kapalabhati foi ensinado no dia de entrada no projeto, desta forma, todos os pacientes até a avaliação 2 (10 meses de treinamento), praticavam esse exercício $100 \%$ do tempo. Enquanto que o tempo médio de prática de uddiyana até a avaliação 2, foi de $62 \%$ e para agnisara $26 \%$ (Figura 2).

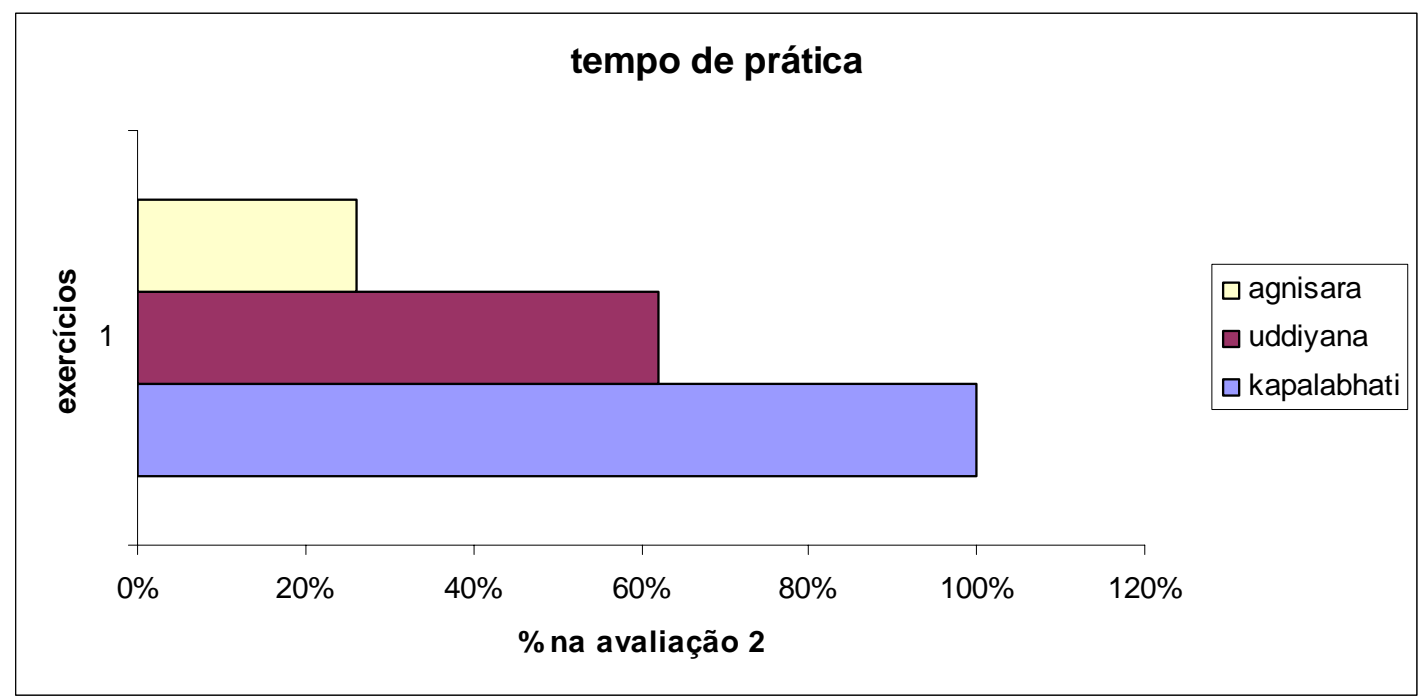

FIGURA 2 - Porcentagem do tempo de prática de cada exercício no momento da avaliação 2. As datas estão demonstradas no Anexo III.

\subsubsection{Prova de Função Pulmonar}

O procedimento técnico, os critérios de aceitabilidade, reprodutibilidade, valores de referências e interpretativos, bem como a padronização do equipamento, seguiram as recomendações da American Thoracic Society (1991, 1994). Resumidamente, cada menino realizou o teste na posição sentada numa cadeira confortável usando um nose clip e foi instruído detalhadamente de todos os 
procedimentos. O equipamento utilizado foi Microquark (Cosmed, Itália) acoplado a um microcomputador e calibrado previamente a cada utilização. Os meninos respiraram através de um bucal de papelão descartável colocado entre seus dentes e assegurado que não havia vazamentos durante a respiração. A seguir, era solicitado que ele fizesse uma inspiração máxima (próximo da capacidade pulmonar total: CPT) seguida de uma expiração máxima (próximo ao volume residual). Foram realizados no máximo oito testes em cada criança e considerados os três melhores sendo que a variabilidade entre eles foi inferior a $5 \%$ ou $200 \mathrm{ml}$. Foram considerados o volume expiratório forçado do $1^{\mathrm{o}}$ segundo (VEF1) e a capacidade vital forçada (CVF) nos seus valores absolutos e relativos, sendo este último obtido pela comparação com a curva de normalidade para todas as variáveis espirométricas seguindo as recomendações da Europian Respiratory Society (1983).

$\operatorname{CVF}(\mathrm{L})=\frac{-3376+40,9 \times \text { altura }(\mathrm{cm})}{1000}$
$\operatorname{VEF} 1(\mathrm{~L})=\frac{-2814+34,8 \times \text { altura }(\mathrm{cm})}{1000}$

\subsubsection{Avaliação das Pressões Respiratórias}

A força dos músculos respiratórios foi avaliada utilizando-se um manuvacuômetro (MHD, 500, Brasil). Os testes foram realizados com os meninos sentados e imediatamente após a realização da prova de função pulmonar, porém respeitando um período de descanso entre os testes. Antes de cada teste, os meninos foram detalhadamente orientados sobre os procedimentos. Os resultados obtidos foram avaliados nos seus valores absolutos e relativos. Para obtenção da força muscular 
inspiratória (considerada como PImax), foi solicitado ao paciente que fizesse uma inspiração máxima seguida de uma expiração máxima (próxima ao volume residual; VR). Para obtenção da força muscular expiratória (considerada como PEmax), foi solicitado ao paciente que fizesse uma expiração máxima (próxima à VR) seguida de uma inspiração máxima (Black e Hyatt, 1969). Para cada avaliação, foi considerado o valor máximo obtido em, no máximo cinco provas, desde que este valor não fosse superior a 5\% entre as três melhores provas. Os valores obtidos foram comparados com uma curva de normalidade previamente descrita $(\mathrm{PEmax}=13,68 \mathrm{x}$ idade $-32,97$; PImax $=-7,8 \times$ idade $+14,42)$, (Gaulthier e Zinman, 1983).

\subsection{Análise Estatística}

Todos os dados de variáveis respiratórias medidos foram submetidos ao teste de normalidade de Kolmogorov-Smirnov.

A amostra foi inicialmente avaliada para um $\mathrm{N}$ de 39 pacientes, por um período de um ano, em que todos (6 a 14 anos) participaram das três primeiras avaliações. Utilizou-se a análise de variâncias para medidas repetidas (on Ranks), por não serem dados distribuídos de maneira normal, tendo como variável dependente CVF, VEF1 ou PEmax e como fator de interferência o momento da amostragem $(0$ - início do protocolo; 1 - entre três e seis meses após o início e 2 - entre nove e doze meses após o início). Os parâmetros de função pulmonar, foram ainda analisados traçando-se uma curva de tendência ao longo da idade, com um modelo polinomial, utilizando-se os dados colhidos na entrada do estudo e após um ano de treinamento. Além disso, os resultados foram divididos em dois subgrupos, para verificar a influência do 
treinamento em diferentes faixas etárias, de modo que a mesma análise acima descrita foi repetida para os dois subgrupos: indivíduos entre 6 e 9 anos e entre 10 e 14 anos.

Foi realizada uma outra análise para o $\mathrm{N}$ de 70 indivíduos, em que foram incluídos todos que fizeram a avaliação de início do protocolo e pelos menos mais uma ao longo de um ano (avaliação 1- período compreendido entre três e seis meses após a avaliação inicial e/ou avaliação 2 - período compreendido entre nove e doze meses após a avaliação inicial). Os dados apresentaram distribuição normal. Os parâmetros de função pulmonar, foram analisados traçando-se uma curva de tendência ao longo da idade, com um modelo polinomial, utilizando-se os dados colhidos na entrada do estudo e após um ano de treinamento. Adicionalmente, os resultados foram divididos em dois subgrupos, para verificar a influência do treinamento em diferentes faixas etárias, de modo que a mesma análise acima descrita foi repetida para os dois subgrupos: indivíduos entre 6 e 9 anos e entre 10 e 14 anos.

Foi feita uma terceira análise para $\mathrm{N}$ de 18 , em que foram incluídos todos os indivíduos que fizeram todas as avaliações ao longo de dois anos, além da avaliação do início do protocolo. Utilizou-se a análise de variâncias para medidas repetidas (on Ranks), por não serem dados distribuídos de maneira normal, tendo como variável dependente CVF, VEF1, ou PEmax e como fator de interferência o momento da amostragem ( 0 - início do protocolo; 1 - entre três e seis meses após o início; 2 - entre nove e doze meses após o início; 3 - entre quinze e dezoito meses após o início e 4 - entre vinte e um e vinte e quatro meses após o início). Os parâmetros de função pulmonar foram também analisados traçando-se uma curva de tendência ao longo da idade, com um modelo polinomial, utilizando-se os dados colhidos na entrada do estudo e após um ano de treinamento.

Em todos os casos a significância adotada foi $\mathrm{p}<0,05$. 
Apresentamos os resultados referentes à CVF, VEF1 e PEmax, nos valores absolutos e percentuais do predito (Anexos IV a IX). Os resultados de PImax, embora tenham sido avaliados, não são mostrados por não apresentarem variação regular que permitisse uma conclusão nos índices e nas faixas etárias analisadas.

\subsection{Análise do perfil da amostra com $\mathrm{N}=85$}

Este é o perfil de todos os pacientes que fizeram as avaliações no período inicial, portanto antes do treinamento. Cada ponto do gráfico representa a melhor das três avaliações consideradas válidas para CVF e VEF1 e a melhor de cinco avaliações das consideradas válidas para PEmax.

O número de pacientes a cada idade por ocasião da prova inicial de capacidade respiratória foi distribuído da seguinte forma:

\begin{tabular}{|cccccccccc|}
\hline Idade & 6 & 7 & 8 & 9 & 10 & 11 & 12 & 13 & 14 \\
\hline $\mathbf{N}=$ & 11 & 8 & 15 & 14 & 6 & 15 & 11 & 3 & 2 \\
\hline
\end{tabular}


Para valores absolutos (litros) de CVF e VEF1 houve um aumento constante, com redução dos valores a partir dos 11 anos, sendo que os pacientes de 14 anos mantiveram a elevação da linha de perfil (Figuras 3 e 5). Os valores máximos relativos (porcentagem do predito) de CVF e VEF1, foram observados entre os 9 e 10 anos e em seguida estes valores começaram a diminuir (Figuras 4 e 6).

Para PEmax em valores absolutos (cmH2O), o pico aconteceu por volta dos 10 anos (Figura 7) seguido de queda. Foi observada grande variabilidade nos valores da PEmax entre os pacientes dentro da mesma faixa etária. Quando os valores foram expressos em relação ao predito para cada paciente, foi observada uma queda acentuada da PEmax que mostrou uma relação linear negativa à medida que os pacientes ficaram mais velhos (Figura 8). Além disso, os pacientes com idade igual ou superior a 10 anos, apresentaram um valor da PEmax abaixo dos níveis de normalidade $(<80 \%$ do predito). 


\section{CVF Absoluto}

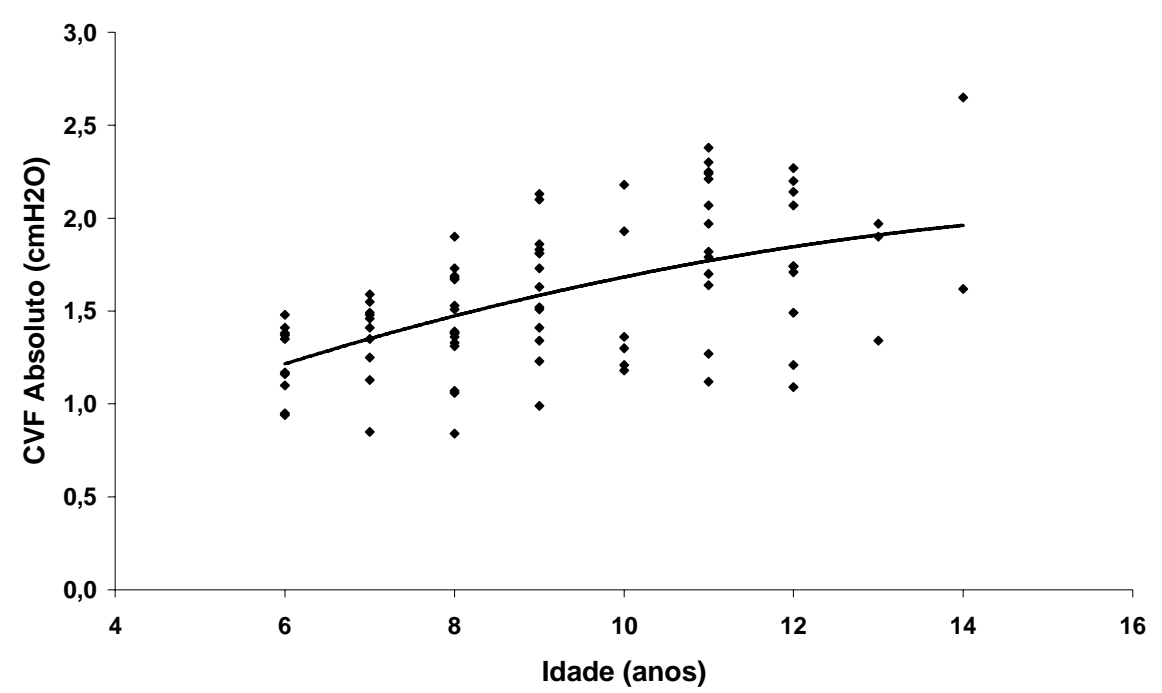

FIGURA 3 - Avaliação da CFV em litros para o grupo total de crianças no tempo 0 . Foram avaliadas 85 pacientes com DMD com idades entre 6 e 14 anos. Cada ponto do gráfico representa o melhor valor deste índice de cada paciente.

\section{CVF Relativo}

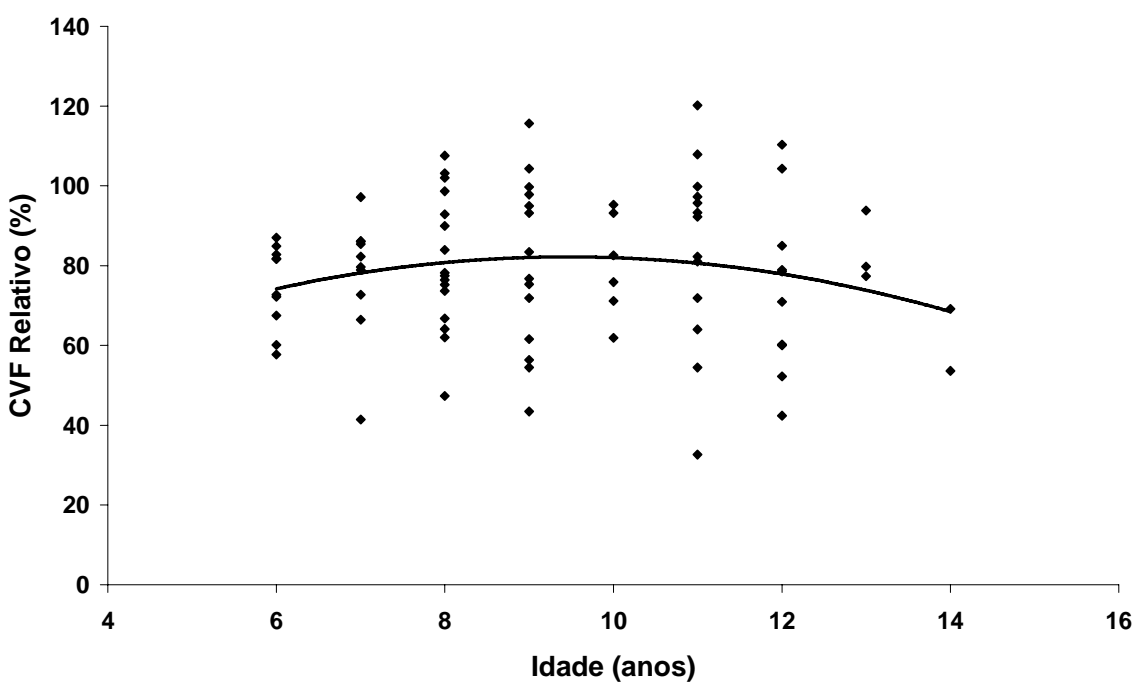

FIGURA 4 - Avaliação da CFV em valores percentuais do predito para o grupo total de crianças no tempo 0 . Foram avaliadas 85 pacientes com DMD com idades entre 6 e 14 anos. Cada ponto do gráfico representa o melhor valor deste índice de cada paciente. 
VEF1 Absoluto

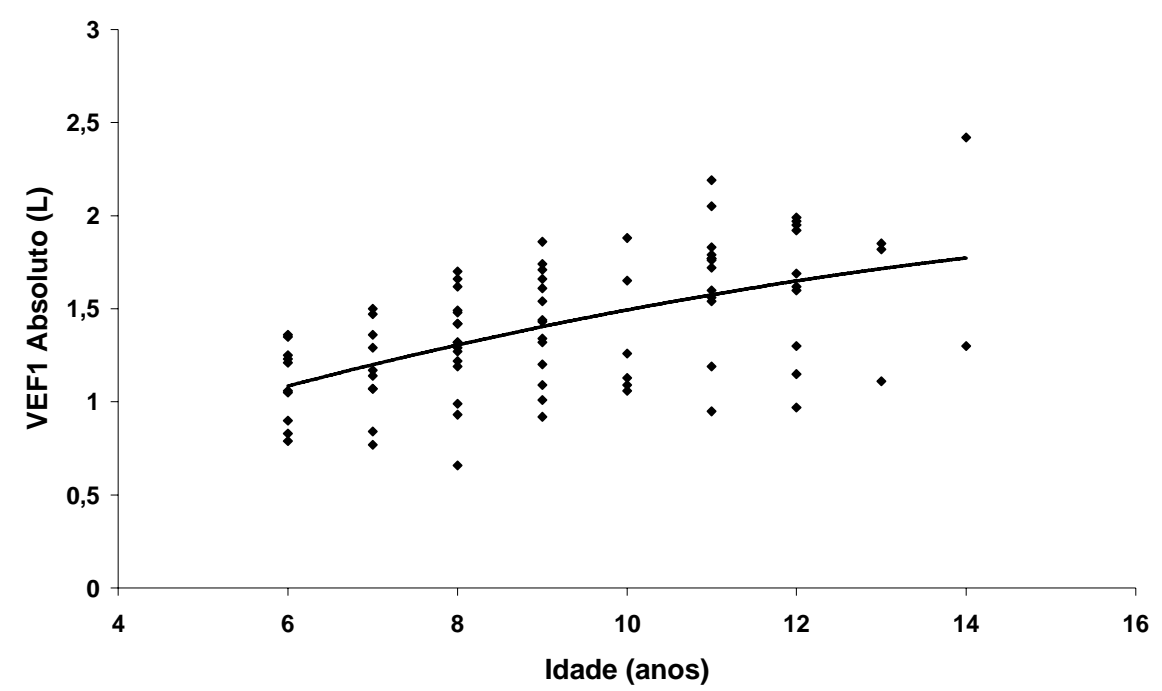

FIGURA 5 - Avaliação da VEF1 em litros para o grupo total no tempo 0. Foram avaliadas 85 pacientes com DMD com idades entre 6 e 14 anos. Cada ponto do gráfico representa o melhor valor de cada um para este índice.

VEF1 Relativo

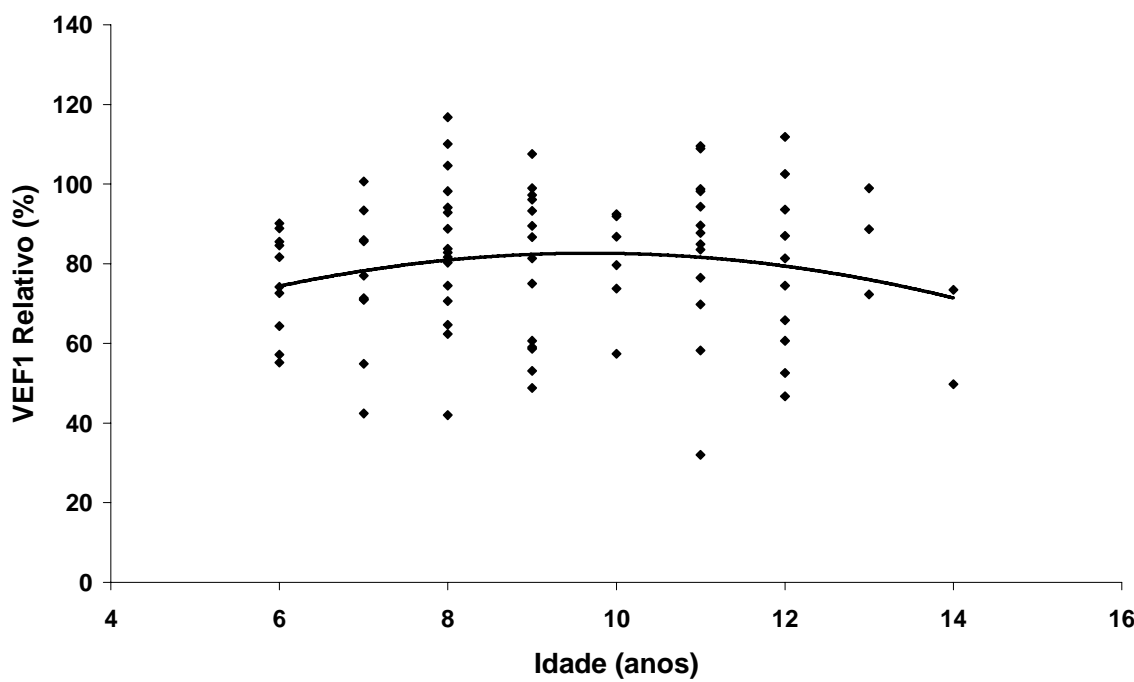

FIGURA 6 - Avaliação da VEF1 em valores percentuais do predito, para o grupo total no tempo 0. Foram avaliadas 85 pacientes com DMD com idades entre 6 e 14 anos. Cada ponto do gráfico representa o melhor valor de cada um para este índice. 
PEmax Absoluto

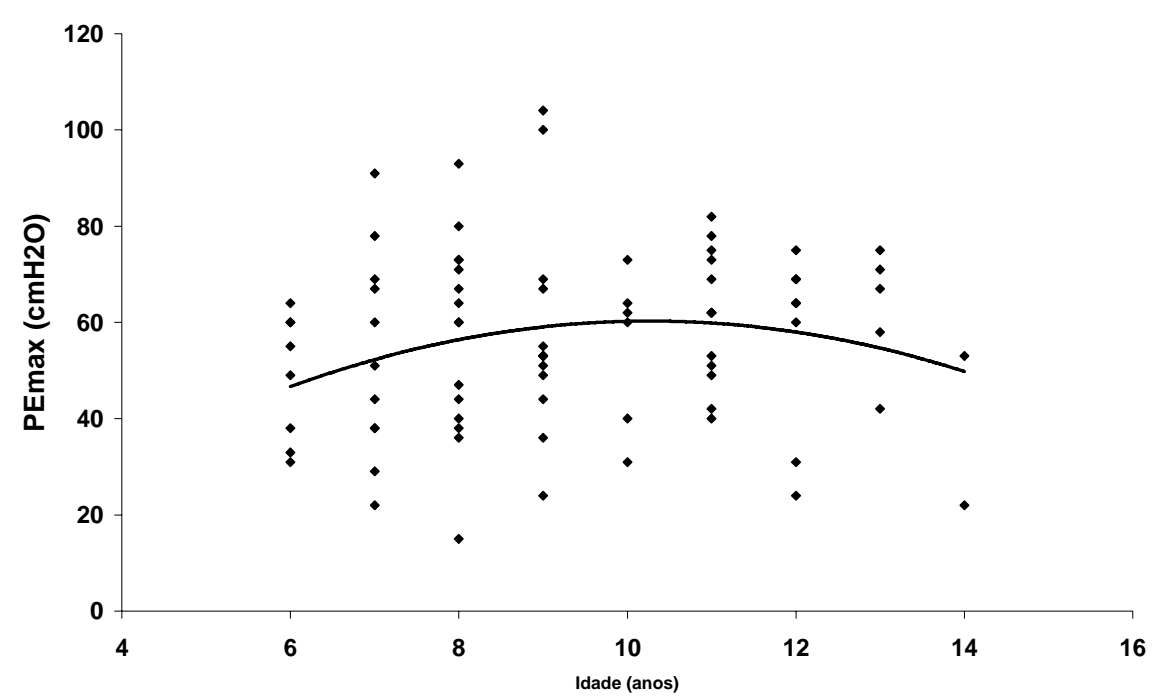

FIGURA 7 - Avaliação da PEmax em cmH2O para o grupo total no tempo 0. Foram avaliadas 85 pacientes com DMD com idades entre 6 e 14 anos. Cada ponto do gráfico representa o melhor valor de cada um para este índice.

\section{PEmax Relativo}

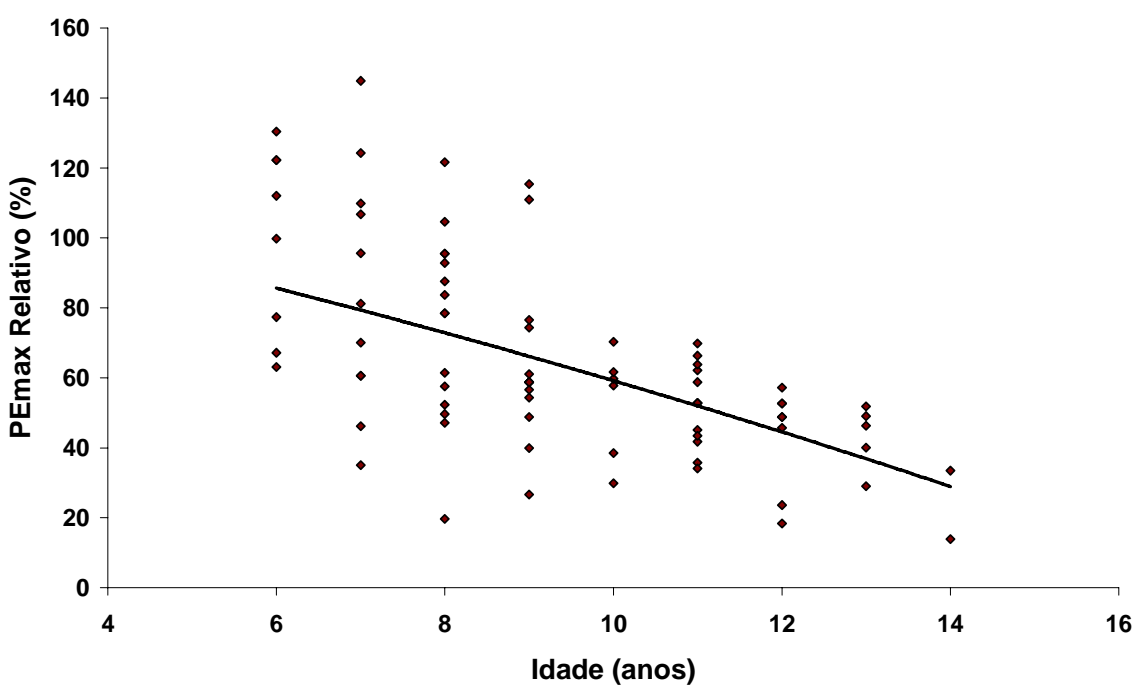

FIGURA 8 - Avaliação da PEmax em valores percentuais do predito, para o grupo total no tempo 0 . Foram avaliadas 85 pacientes com DMD com idades entre 6 e 14 anos. Cada ponto do gráfico representa o melhor valor de cada um para este índice. 
Os dados dos pacientes que participaram da aplicação dos exercícios respiratórios de ioga, foram analisados e comparados de acordo com seguintes agrupamentos:

- $\mathrm{N}=39$ pacientes que fizeram as três avaliações $(0,1$ e 2$)$ no período de 10 meses. Este grupo foi dividido em dois subgrupos ( 6 a 9 anos e 10 a 14 anos).

- $\mathrm{N}=70$ pacientes que fizeram além da avaliação inicial pelo menos mais uma das duas avaliações ( 0 e 1 ou 0 e 2 ou 0,1 e 2 ) previstas no período de 10 meses. Este grupo também foi dividido em dois subgrupos (6 a 9 anos e 10 a 14 anos).

- $\mathrm{N}=18$ pacientes que fizeram todas as avaliações $(0,1,2,3$ e 4$)$ no período de 20 meses.

\subsection{Análise do perfil para amostra com $\mathrm{N}=39$}

Trinta e nove pacientes fizeram as três primeiras avaliações $(0,1$ e 2$)$. Dividimos o grupo por faixa etária em dois subgrupos, um de 6 a 9 anos $(\mathrm{N}=25)$ e outro de 10 a 14 anos $(\mathrm{N}=14)$. O número de pacientes a cada idade por ocasião da avaliação inicial de capacidade respiratória foi distribuído da seguinte forma:

\begin{tabular}{|cccccccccc|}
\hline Idade & 6 & 7 & 8 & 9 & 10 & 11 & 12 & 13 & 14 \\
\hline $\mathbf{N}=$ & 6 & 4 & 9 & 6 & 3 & 6 & 2 & 1 & 2 \\
\hline
\end{tabular}


Para CVF em valores absolutos e relativos, houve aumento com significância, quando comparamos os resultados da avaliação inicial com os resultados depois de 10 meses de treinamento, para os grupos de 6 a 14 anos e 6 a 9 anos (Tabelas 1 e 2, Figuras 9 e 10).

Os resultados do VEF1 para valores absolutos e relativos, seguiam padrões semelhantes aos da CVF (Tabelas 3 e 4, Figuras 11 e 12), com significância no grupo de 6 a 14 anos e 6 a 9 anos.

O grupo de 10 a 14 anos se manteve praticamente estável após 10 meses de treinamento tanto para valores absolutos como para relativos de CVF e VEF1.

Os resultados da força expiratória máxima (PEmax) para valores absolutos e relativos, apresentaram aumento depois de 10 meses de treinamento, com significância nos três grupos etários (Tabelas 5 e 6, Figuras 13 e 14). 
TABELA 1 - Capacidade vital forçada (CVF) em valores absolutos obtidos no início (0), após 5 meses de treinamento (1) e após 10 meses de treinamento (2). Pacientes que fizeram as três primeiras avaliações $(\mathrm{N}=39)$

CVF ABSOLUTO (L)

\begin{tabular}{|c|c|c|c|c|c|c|c|c|c|}
\hline & \multicolumn{3}{|c|}{6 a 14 anos $(p=0,001)$} & \multicolumn{3}{|c|}{6 a 9 anos $(p=0,001)$} & \multicolumn{3}{|c|}{10 a 14 anos $(p=0,351)$} \\
\hline & $\mathbf{0}$ & 1 & 2 & 0 & 1 & 2 & $\mathbf{0}$ & 1 & 2 \\
\hline Mediana & 1,5 & $1,7^{*}$ & $1,7^{*}$ & 1,4 & $1,6^{*}$ & $1,7^{*}$ & 2,0 & 2,1 & 2,2 \\
\hline $5 \%$ & 1,0 & 1,1 & 1,2 & 0,9 & 1,1 & 1,2 & 1,2 & 1,2 & 1,2 \\
\hline $95 \%$ & 2,3 & 2,5 & 2,8 & 2,1 & 2,0 & 2,2 & 2,6 & 2,6 & 2,9 \\
\hline
\end{tabular}

\section{CVF Absoluto}

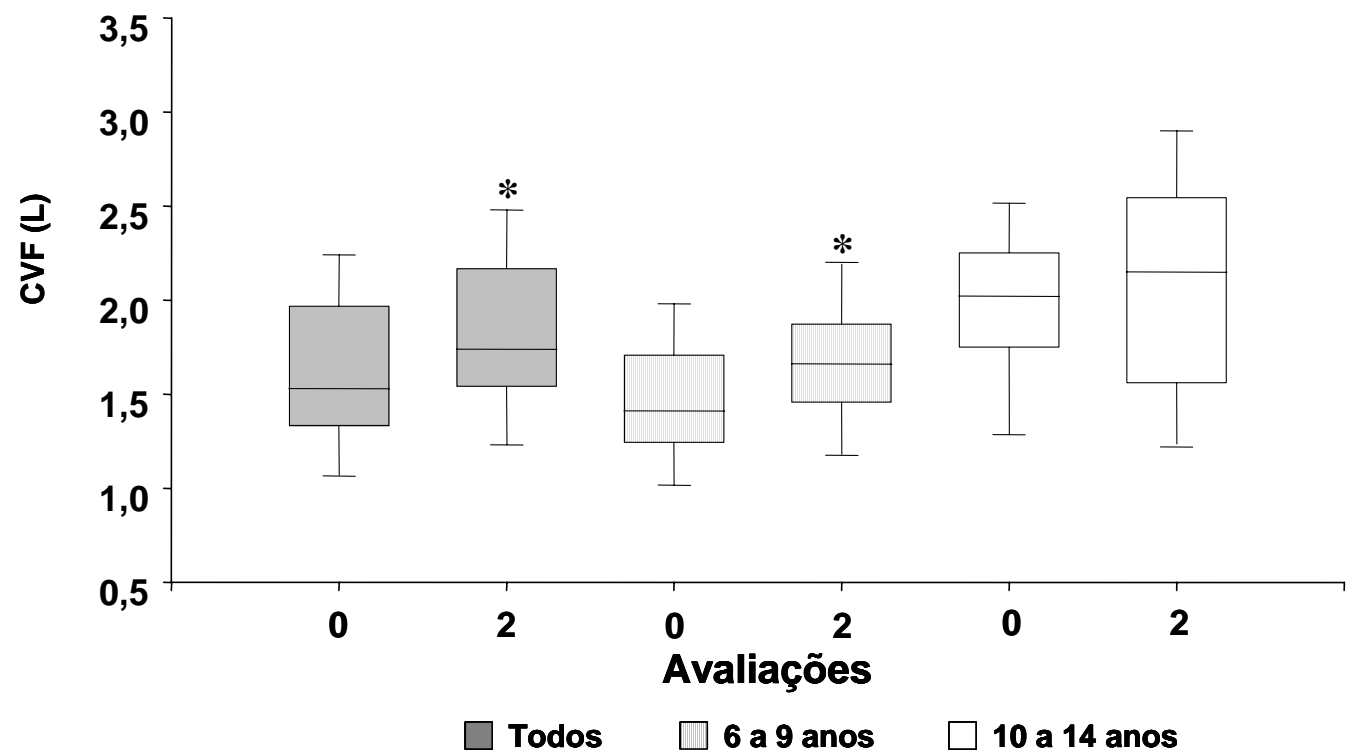

FIGURA 9 - Gráfico dos valores absolutos da CVF, considerando as avaliações 0 e 2. Para o grupo total $(\mathrm{N}=39)$, os de 6 a 9 anos $(\mathrm{N}=25)$ e para os de 10 a $14(\mathrm{~N}=14)$. Valores calculados pela mediana. $* \neq 0 \quad \mathrm{p} \leq 0,05$ 
TABELA 2 - Capacidade vital forçada (CVF) em valores percentuais ao predito, obtidos no início (0), após 5 meses de treinamento (1) e após 10 meses de treinamento (2). Para os pacientes que fizeram as três primeiras avaliações. Todos, $\mathrm{N}=39.6$ a 9, $\mathrm{N}=25.10$ a $14, \mathrm{~N}=14$

\begin{tabular}{cccccccccc}
\hline \multicolumn{7}{c}{ CVF RELATIVO (\% do predito) } \\
\hline & $\mathbf{6}$ a $\mathbf{1 4}$ anos $(\mathrm{p}=0,004)$ & $\mathbf{6}$ a $\mathbf{9}$ anos $(\mathrm{p}=0,008)$ & $\mathbf{1 0}$ a $\mathbf{1 4}$ & $\operatorname{anos}(\mathrm{p}=0,395)$ \\
\hline & $\mathbf{0}$ & $\mathbf{1}$ & $\mathbf{2}$ & $\mathbf{0}$ & $\mathbf{1}$ & $\mathbf{2}$ & $\mathbf{0}$ & $\mathbf{1}$ & $\mathbf{2}$ \\
$\mathbf{M e d i a n a}$ & $\mathbf{8 2 , 6}$ & $\mathbf{8 7 , 6}$ & $\mathbf{9 0 , 0 *}$ & $\mathbf{8 1 , 7}$ & $\mathbf{8 7 , 6}$ & $\mathbf{9 0 , 0} *$ & $\mathbf{8 8 , 6}$ & $\mathbf{8 8 , 4}$ & $\mathbf{8 8 , 8}$ \\
$\mathbf{5 \%}$ & 55,4 & 66,9 & 60,4 & 54,2 & 67,0 & 64,4 & 56,7 & 55,4 & 47,1 \\
$\mathbf{9 5 \%}$ & 109,2 & 107,0 & 120,5 & 107,1 & 105,5 & 119,1 & 109,8 & 107,6 & 144,8 \\
\hline${ }^{*} \neq 0 \mathrm{p} \leq 0,05$ & & & & & & & & &
\end{tabular}

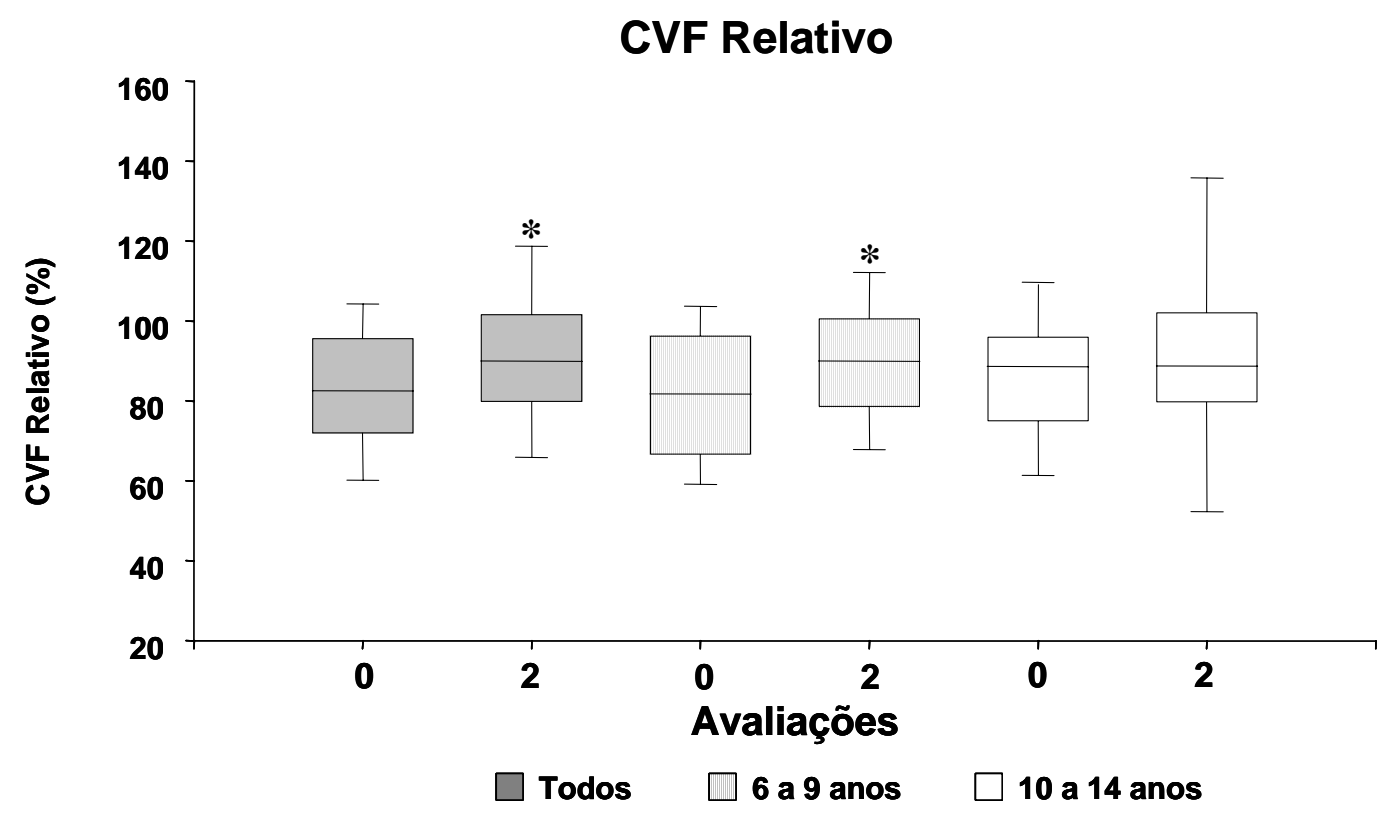

FIGURA 10 - Gráfico dos valores percentuais aos do predito da CVF, considerando as avaliações 0 e 2. Para o grupo total $(\mathrm{N}=39)$, os de 6 a 9 anos $(\mathrm{N}=25)$ e para os de 10 a $14(\mathrm{~N}=14)$. Valores calculados pela mediana. $* \neq 0 \mathrm{p} \leq 0,05$ 
TABELA 3 - VEF1 em valores absolutos, obtidos no início (0), após 5 meses de treinamento (1) e após 10 meses de treinamento (2). Para os pacientes que fizeram as três primeiras avaliações. Todos, $\mathrm{N}=39.6$ a $9, \mathrm{~N}=25$. 10 a $14, \mathrm{~N}=14$

\begin{tabular}{cccccccccc}
\hline \multicolumn{10}{c}{ VEF1 ABSOLUTO (em litros) } \\
\hline & $\mathbf{6}$ a $\mathbf{1 4}$ anos $(\mathrm{p}=0,004)$ & $\mathbf{6}$ a 9 anos $(\mathrm{p}=0,025)$ & $\mathbf{1 0}$ a $\mathbf{1 4}$ anos $(\mathrm{p}=0,395)$ \\
\hline & $\mathbf{0}$ & $\mathbf{1}$ & $\mathbf{2}$ & $\mathbf{0}$ & $\mathbf{1}$ & $\mathbf{2}$ & $\mathbf{0}$ & $\mathbf{1}$ & $\mathbf{2}$ \\
Mediana & $\mathbf{1 , 4}$ & $\mathbf{1 , 6}$ & $\mathbf{1 , 6 ^ { * }}$ & $\mathbf{1 , 3}$ & $\mathbf{1 , 4} *$ & $\mathbf{1 , 5 *}$ & $\mathbf{1 , 8}$ & $\mathbf{1 , 8}$ & $\mathbf{1 , 9}$ \\
$\mathbf{5 \%}$ & 0,9 & 1,0 & 1,0 & 0,9 & 1,0 & 1,0 & 1,2 & 1,1 & 0,9 \\
$\mathbf{9 5 \%}$ & 2,1 & 2,1 & 2,4 & 1,7 & 1,8 & 1,9 & 2,4 & 2,2 & 2,6 \\
\hline$\neq 0 \mathrm{p} \leq 0,05$ & & & & & & & & &
\end{tabular}

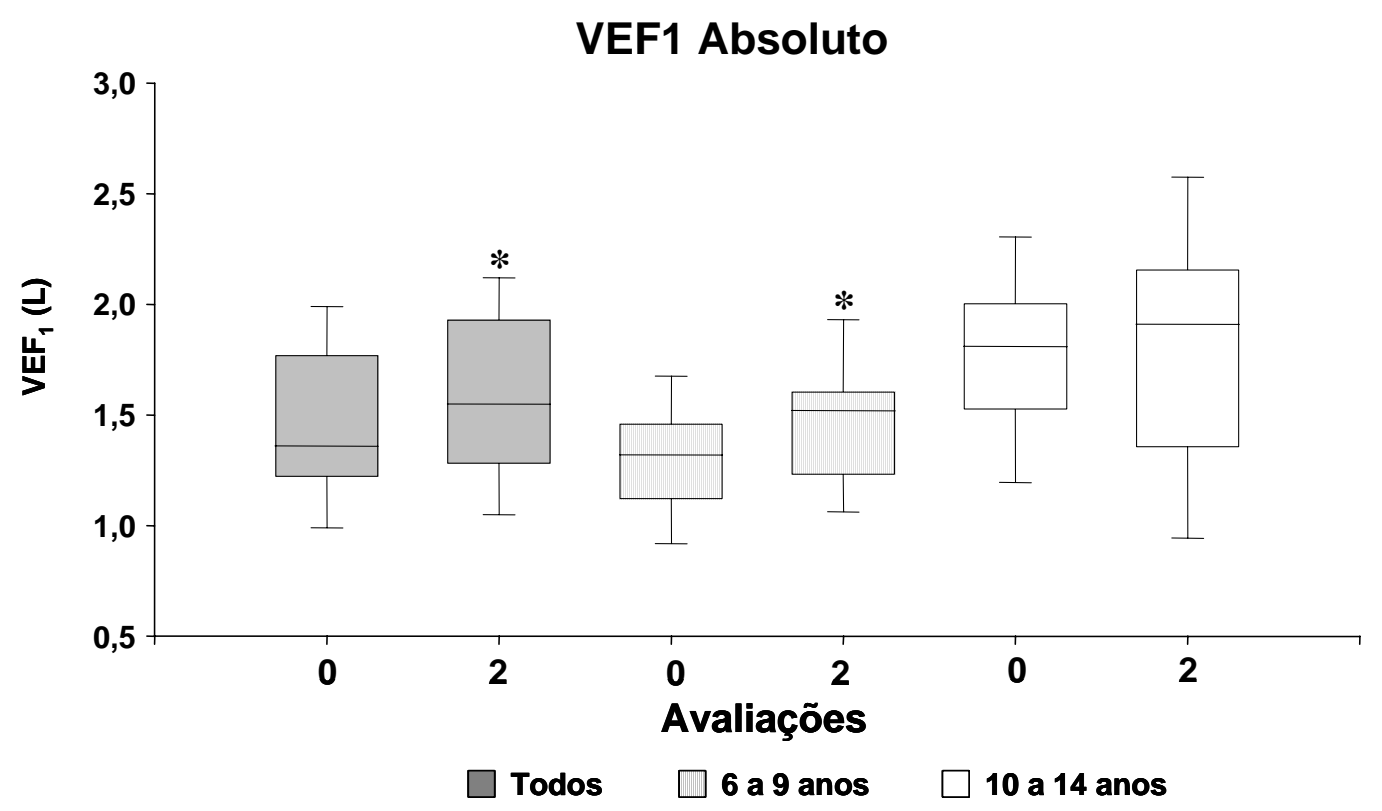

FIGURA 11 - Gráfico dos valores absolutos da VEF1, considerando as avaliações 0 e 2. Para o grupo total $(\mathrm{N}=39)$, os de 6 a 9 anos $(\mathrm{N}=25)$ e para os de 10 a $14(\mathrm{~N}=14)$. Valores calculados pela mediana. $* \neq 0 \quad \mathrm{p} \leq 0,05$ 
TABELA 4 - VEF1 em valores percentuais ao predito, obtidos no início (0), após 5 meses de treinamento (1) e após 10 meses de treinamento (2). Para os pacientes que fizeram as três primeiras avaliações. Todos, $\mathrm{N}=39$. 6 a $9, \mathrm{~N}=25.10$ a $14, \mathrm{~N}=14$

VEF1 Relativo (\% do predito)

\begin{tabular}{|c|c|c|c|c|c|c|c|c|c|}
\hline & \multicolumn{3}{|c|}{6 a 14 anos $(p=0,018)$} & \multicolumn{3}{|c|}{6 a 9 anos $(p=0,017)$} & \multicolumn{3}{|c|}{10 a 14 anos $(p=0,297)$} \\
\hline & $\mathbf{0}$ & 1 & 2 & $\mathbf{0}$ & 1 & 2 & $\mathbf{0}$ & 1 & 2 \\
\hline Mediana & 85,9 & 82,9 & $91,7^{*}$ & 82,1 & 85,9 & $90,4 *$ & 88,4 & 86,1 & $\mathbf{8 8 , 9}$ \\
\hline $5 \%$ & 53,1 & 62,7 & 62,8 & 55,1 & 63,1 & 66,0 & 55,5 & 58,6 & 44,6 \\
\hline $95 \%$ & 109,9 & 108,4 & 117,9 & 108,2 & 111,1 & 117,3 & 111,4 & 105,2 & 121,5 \\
\hline
\end{tabular}

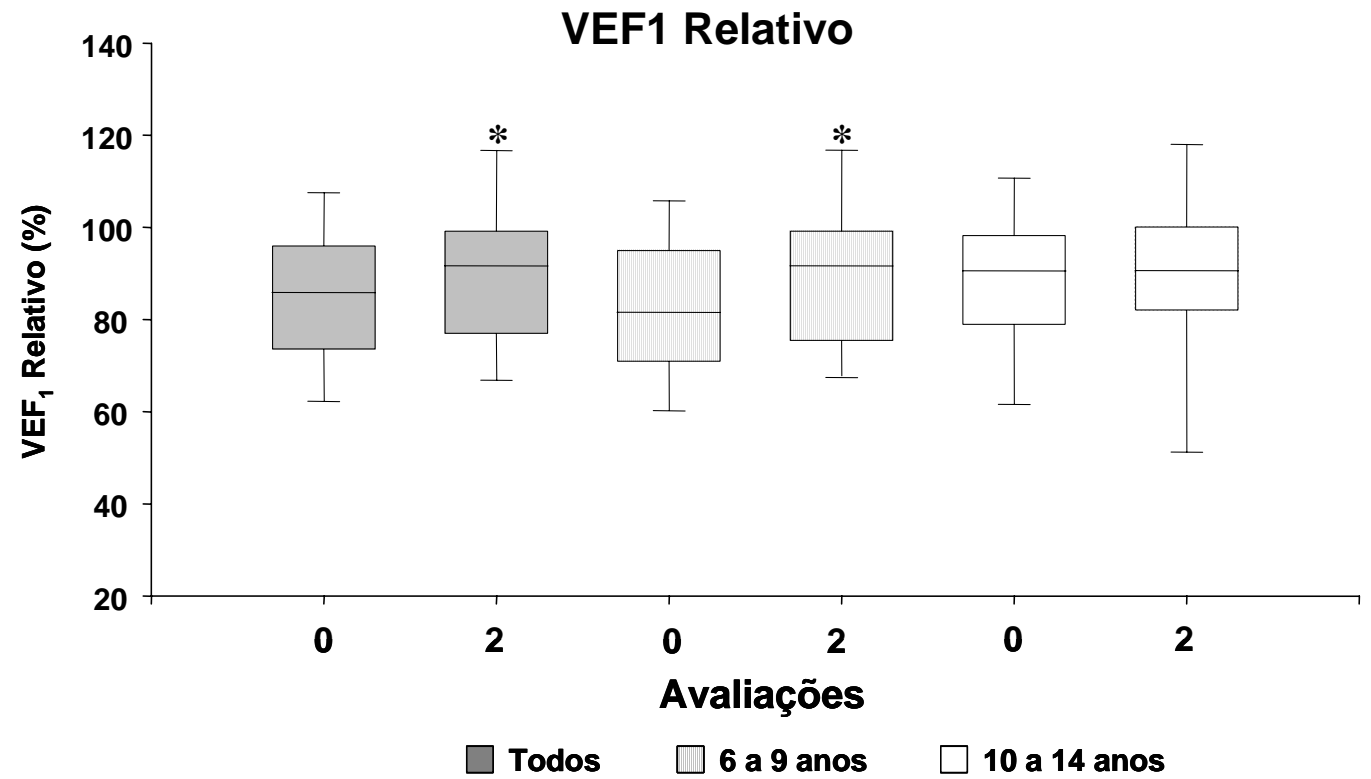

FIGURA 12 - Gráfico dos valores percentuais aos do predito do VEF1, considerando as avaliações 0 e 2. Para o grupo total $(\mathrm{N}=39)$, os de 6 a 9 anos $(\mathrm{N}=25)$ e para os de 10 a $14(\mathrm{~N}=14)$. Valores calculados pela mediana. $* \neq 0 \quad \mathrm{p} \leq 0,05$ 
TABELA 5 - PEmax em valores absolutos, obtidos no início (0), após 5 meses de treinamento (1) e após 10 meses de treinamento (2). Para os pacientes que fizeram as três primeiras avaliações. Todos, $\mathrm{N}=39.6$ a $9, \mathrm{~N}=25$. 10 a $14, \mathrm{~N}=14$

\begin{tabular}{ccccccccccc}
\hline \multicolumn{10}{c}{ PEmax ABSOLUTO $\left(\mathbf{c m H}_{\mathbf{2}} \mathbf{0}\right)$} \\
\hline & $\mathbf{6}$ a $\mathbf{1 4}$ anos $(\mathrm{p}=0,028)$ & $\mathbf{6}$ a $\mathbf{9}$ anos $(\mathrm{p}=0,012)$ & $\mathbf{1 0}$ a $\mathbf{1 4}$ & anos $(\mathrm{p}=0,028)$ \\
\hline & $\mathbf{0}$ & $\mathbf{1}$ & $\mathbf{2}$ & $\mathbf{0}$ & $\mathbf{1}$ & $\mathbf{2}$ & $\mathbf{0}$ & $\mathbf{1}$ & $\mathbf{2}$ \\
$\mathbf{M e d i a n a}$ & $\mathbf{6 0 , 0}$ & $\mathbf{6 7 , 0 *}$ & $\mathbf{7 3 , 0} *$ & $\mathbf{5 3 , 0}$ & $\mathbf{6 7 , 0}$ & $\mathbf{7 3 , 0} *$ & $\mathbf{6 4 , 0}$ & $\mathbf{6 8 , 0}$ & $\mathbf{7 2 , 0}$ \\
$\mathbf{5 \%}$ & 31,0 & 33,6 & 40,0 & 34,8 & 37,5 & 40,0 & 23,8 & 28,6 & 31,6 \\
$\mathbf{9 5 \%}$ & 96,9 & 100,9 & 110,6 & 101,0 & 95,6 & 110,3 & 80,6 & 107,8 & 146,0 \\
\hline${ }^{*} \mathrm{p} \leq 0,05 ;{ }^{+} \mathrm{p}=0,054$ & & & & & & & & &
\end{tabular}

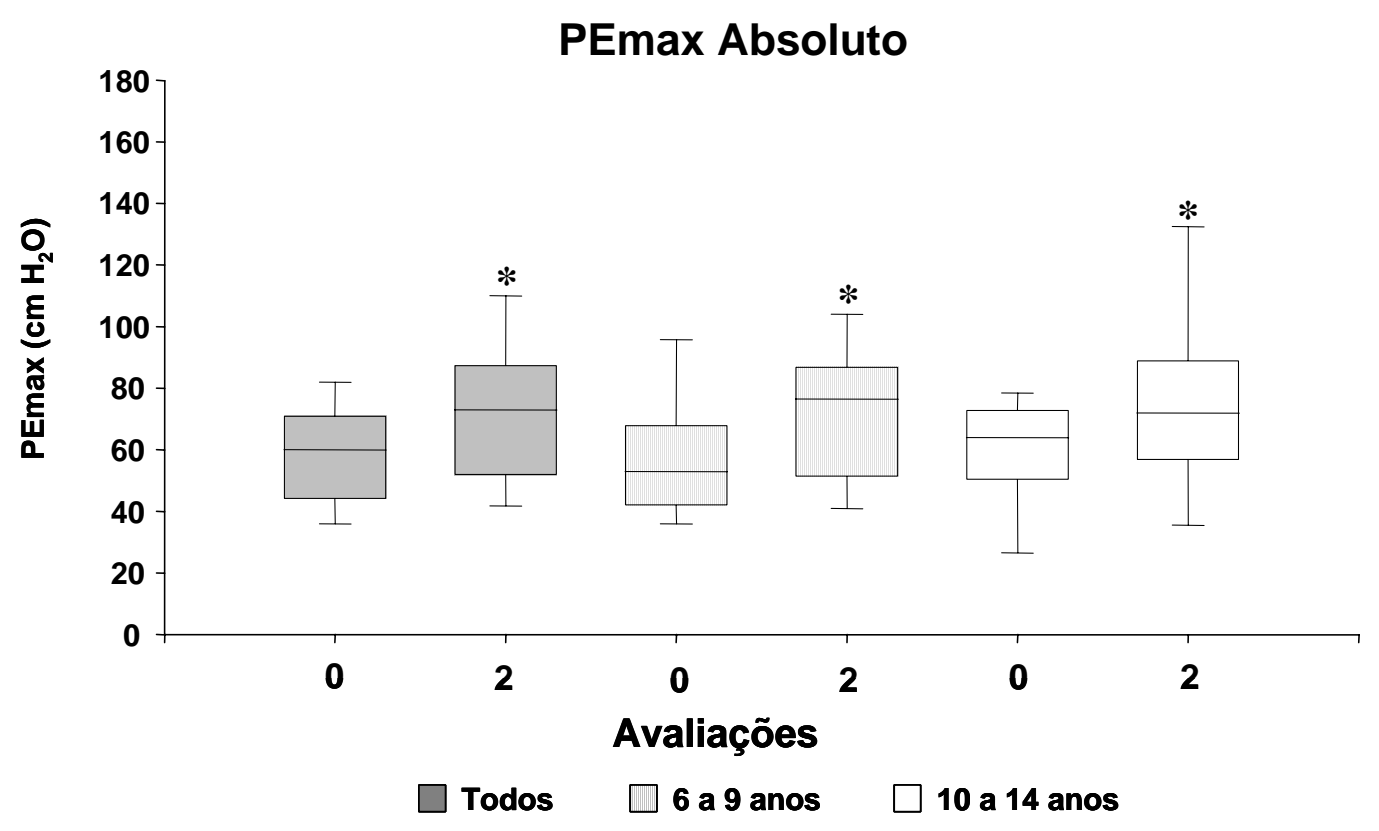

FIGURA 13 - Gráfico dos valores absolutos da PEmax, considerando as avaliações 0 e 2. Para o grupo total $(\mathrm{N}=39)$, os de 6 a 9 anos $(\mathrm{N}=25)$ e para os de 10 a $14(\mathrm{~N}=14)$. Valores calculados pela mediana. $* \neq 0 \mathrm{p} \leq 0,05$ 
TABELA 6 - PEmax Relativo dos pacientes que fizeram as três primeiras avaliações: início (0), 5 meses de treinamento (1) e 10 meses de treinamento (2). Todos, $\mathrm{N}=39 ; 6$ a $9, \mathrm{~N}=25$ e 10 a $14, \mathrm{~N}=14$

\section{PEmax RELATIVO (\% do predito)}

\begin{tabular}{|c|c|c|c|c|c|c|c|c|c|}
\hline & \multicolumn{3}{|c|}{6 a 14 anos $(p=0,001)$} & \multicolumn{3}{|c|}{6 a 9 anos $(p=0,012)$} & \multicolumn{3}{|c|}{10 a 14 anos $(p=0,028)$} \\
\hline & $\mathbf{0}$ & 1 & 2 & $\mathbf{0}$ & 1 & 2 & $\mathbf{0}$ & 1 & 2 \\
\hline Mediana & 61,5 & 80,8 & $82,8 *$ & 87,6 & 98,1 & $95,5^{*}$ & 52,8 & 54,7 & $55,6^{*}$ \\
\hline $5 \%$ & 31,5 & 36,1 & 40,2 & 45,3 & 39,4 & 47,4 & 17,1 & 23,9 & 22,6 \\
\hline $95 \%$ & 121,9 & 138,7 & 162,9 & 122,2 & 146,1 & 166,5 & 70,2 & 101,7 & 138,1 \\
\hline
\end{tabular}

\section{PEmax Relativo}

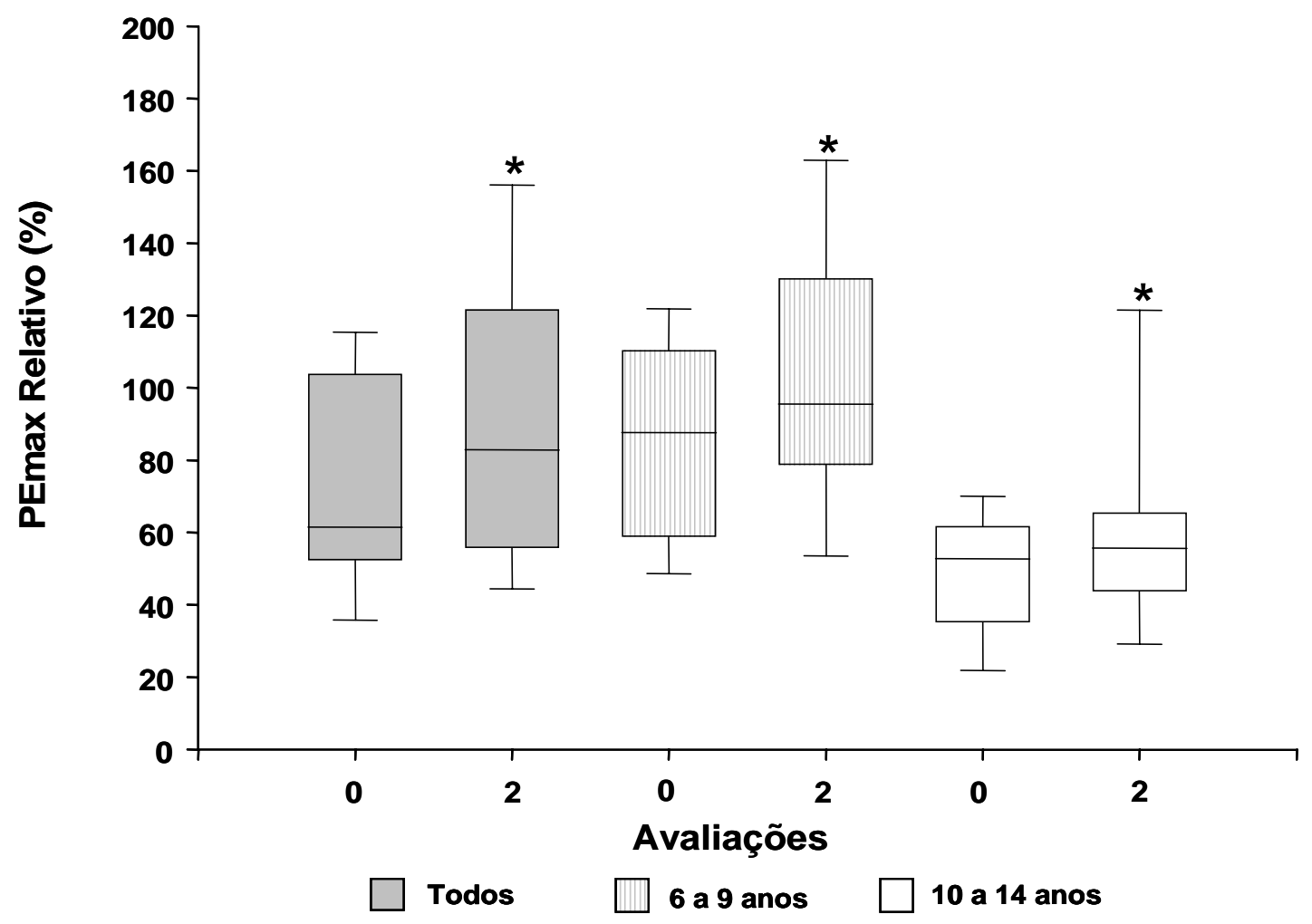

FIGURA 14 - Gráfico da PEmax em valores percentuais ao predito, considerando as avaliações 0 e 2. Para o grupo total $(\mathrm{N}=39)$, os de 6 a 9 anos $(\mathrm{N}=25)$ e para os de 10 a $14(\mathrm{~N}=14)$. Valores calculados pela mediana.

$* \neq 0 \quad \mathrm{p} \leq 0,05$ 
Os resultados a seguir, comparam o perfil de duas $(0$ e 2$)$ das três primeiras avaliações ao longo de um ano de treinamento. Cada ponto do gráfico foi calculado pela melhor das três avaliações consideradas válidas para VEF1 e CVF e a melhor de cinco avaliações das consideradas válidas para PEmax.

As linhas dos gráficos sobrepostos comparam os valores de cada paciente, distribuídos pelas faixas etárias no tempo inicial (0) com o resultado dos mesmos pacientes depois de 10 meses de treinamento (2). Os valores apresentados na curva das avaliações do momento inicial, devem ser comparados com os valores na mesma faixa etária da curva que representa 10 meses de treinamento.

Para a CVF em valores absolutos, as linhas de representação dos perfis seguem paralelas ao longo das faixas etárias, com valores maiores a favor do grupo póstreinamento (Figura 15). Para valores relativos, a diferença dos valores nas faixas etárias iniciais vai diminuindo e aos 14 anos as linhas se encontram (Figura 16).

Para os valores do VEF1, as diferenças são discretamente maiores, em favor do grupo depois de 10 meses de treinamento nas faixas etárias menores e seguem lado a lado com tendência de aproximação com o aumento das idades (Figura 17). Para valores relativos, os parâmetros são muito semelhantes aos da curva da CVF (Figura 18).

Em PEmax para valores absolutos, as linhas que representam o perfil dos pacientes, apresentam as mesmas tendências ao longo da idade, porém com valores iniciais maiores para o grupo depois de um ano de treinamento com discreto declínio desta diferença para os mais velhos (Figura 19). As curvas que estabelecem o perfil para PEmax em valores do percentual do predito, seguem um contínuo declínio a partir dos 6 anos, com vantagem para o grupo com 10 meses de treinamento, com diminuição desta tendência para os mais velhos (Figura 20). 


\section{CVF}

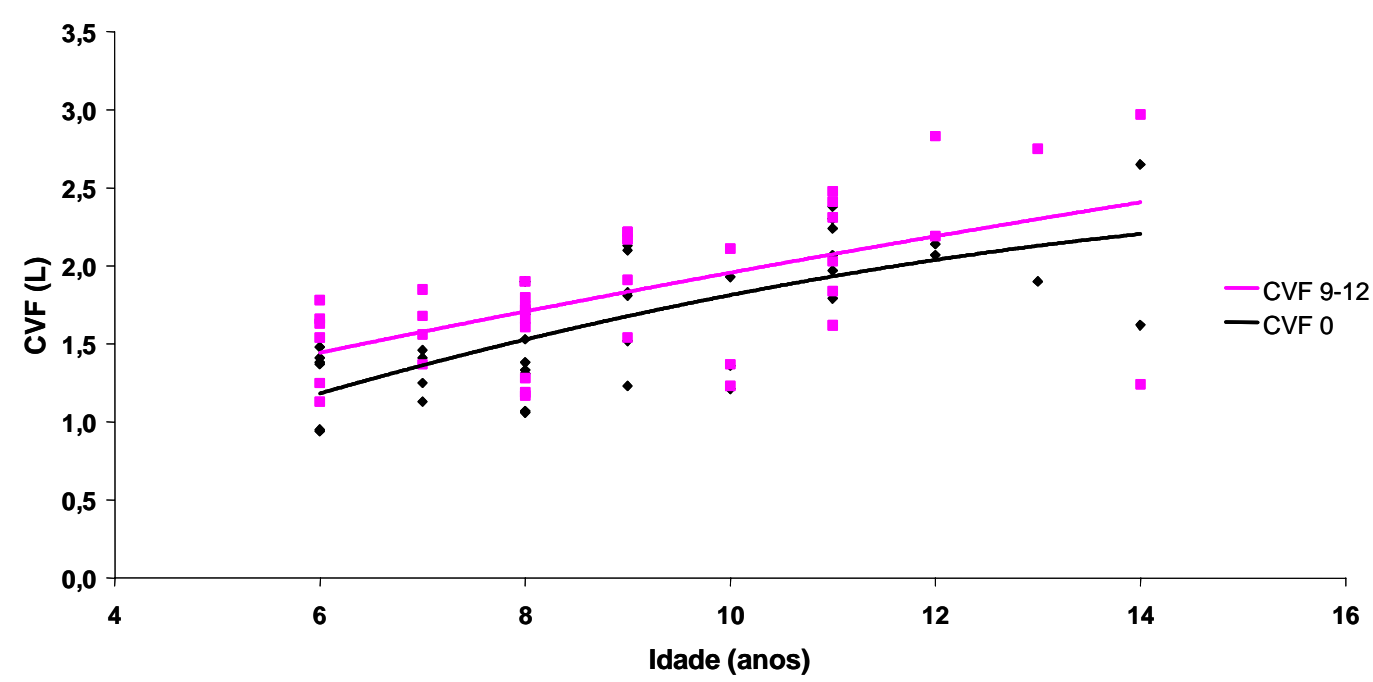

FIGURA 15 - Avaliação da CVF em litros para o grupo de pacientes antes e após 10 meses de treinamento. Foram avaliadas 39 pacientes com DMD com idades entre 6 e 14 anos.

\section{CVF Relativo}

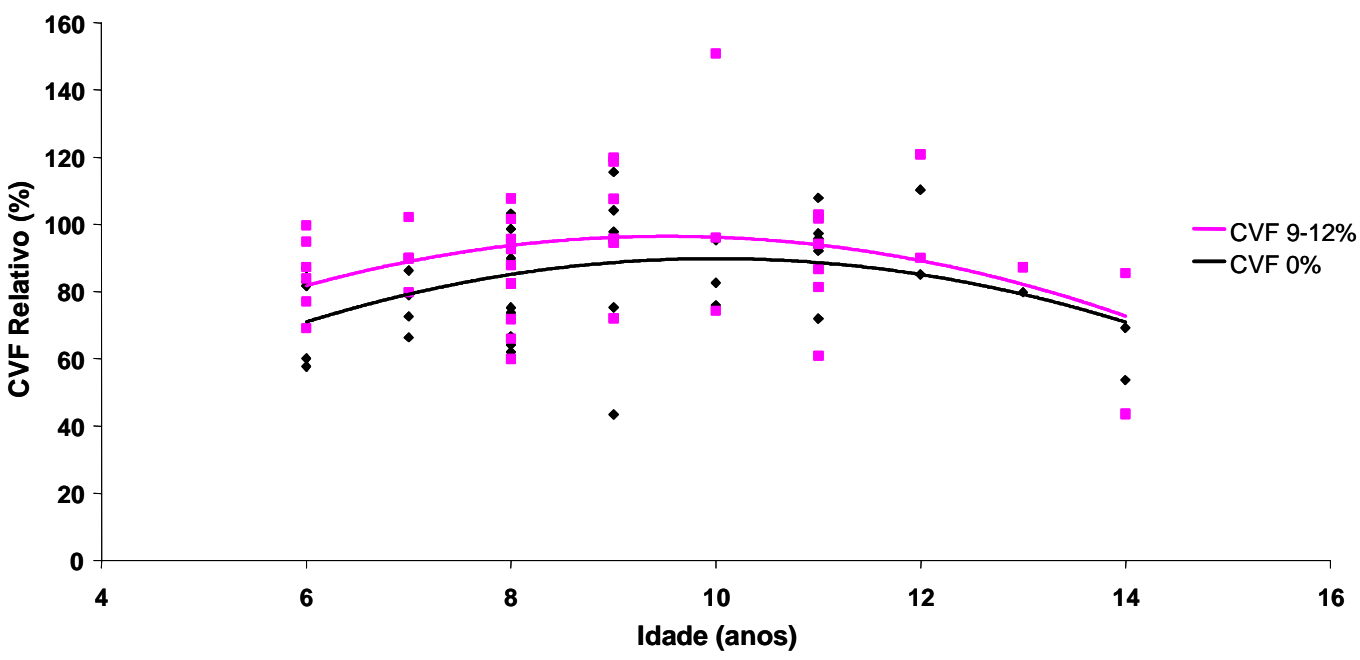

FIGURA 16 - Avaliação da CVF em valores percentuais aos do predito para o grupo de pacientes antes e após 10 meses de treinamento Foram avaliadas 39 pacientes com DMD com idades entre 6 e 14 anos. 


\section{VEF 1}

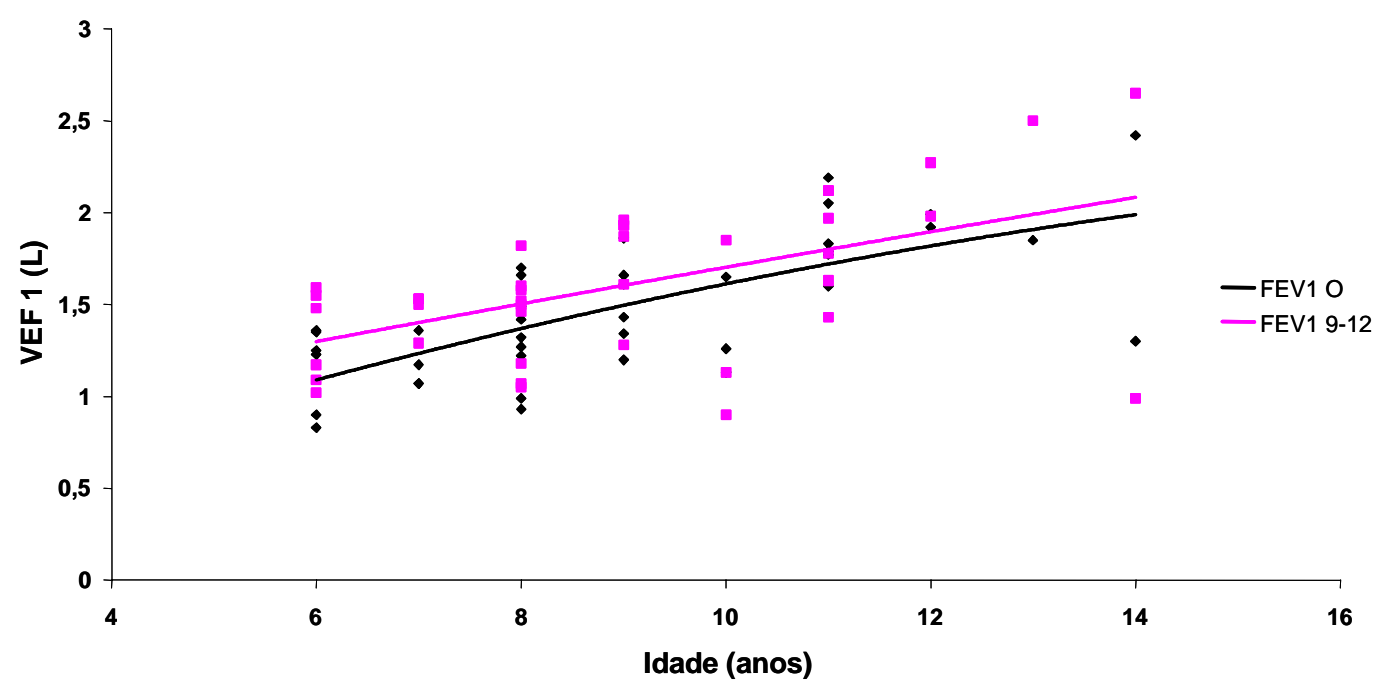

FIGURA 17 - Avaliação da VEF1 em litros para o grupo de pacientes antes e após 10 meses de treinamento. Foram avaliadas 39 pacientes com DMD com idades entre 6 e 14 anos.

VEF 1 Relativo

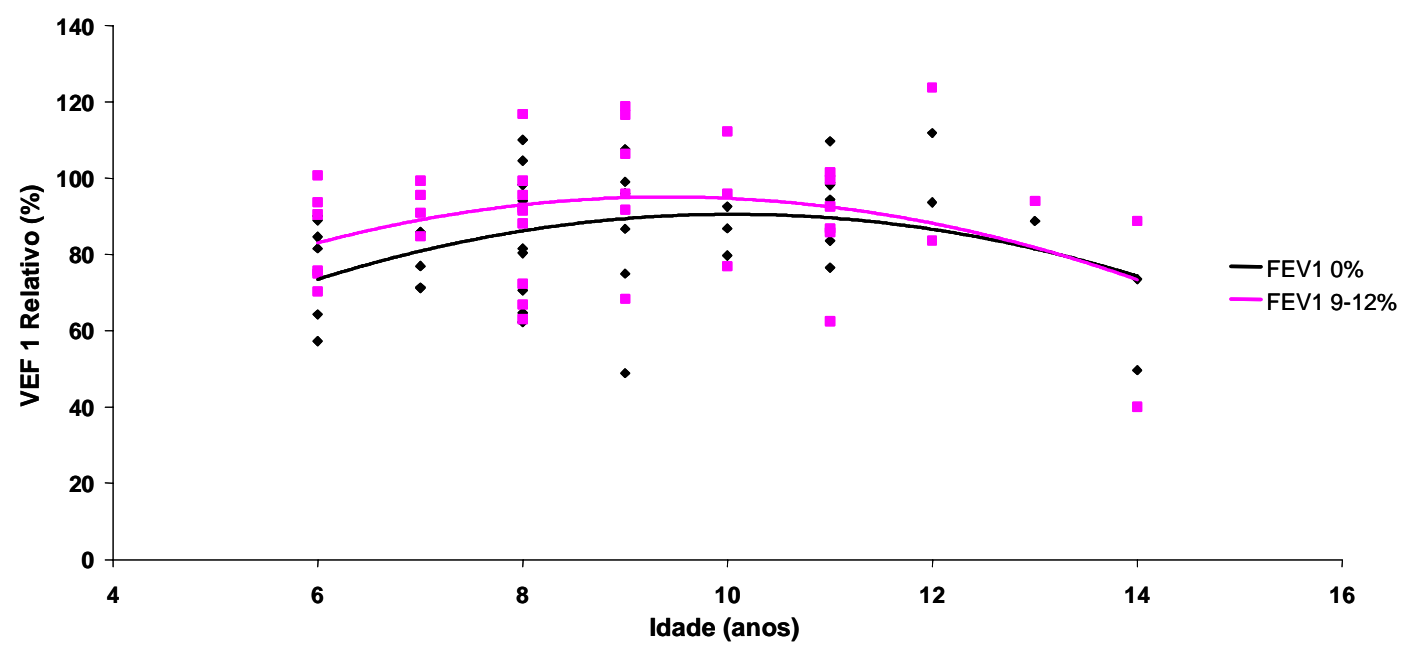

FIGURA 18 - Avaliação da VEF1 em porcentagem do predito para o grupo de pacientes antes e após 10 meses de treinamento Foram avaliadas 39 pacientes com DMD com idades entre 6 e 14 anos. 


\section{PEmax}

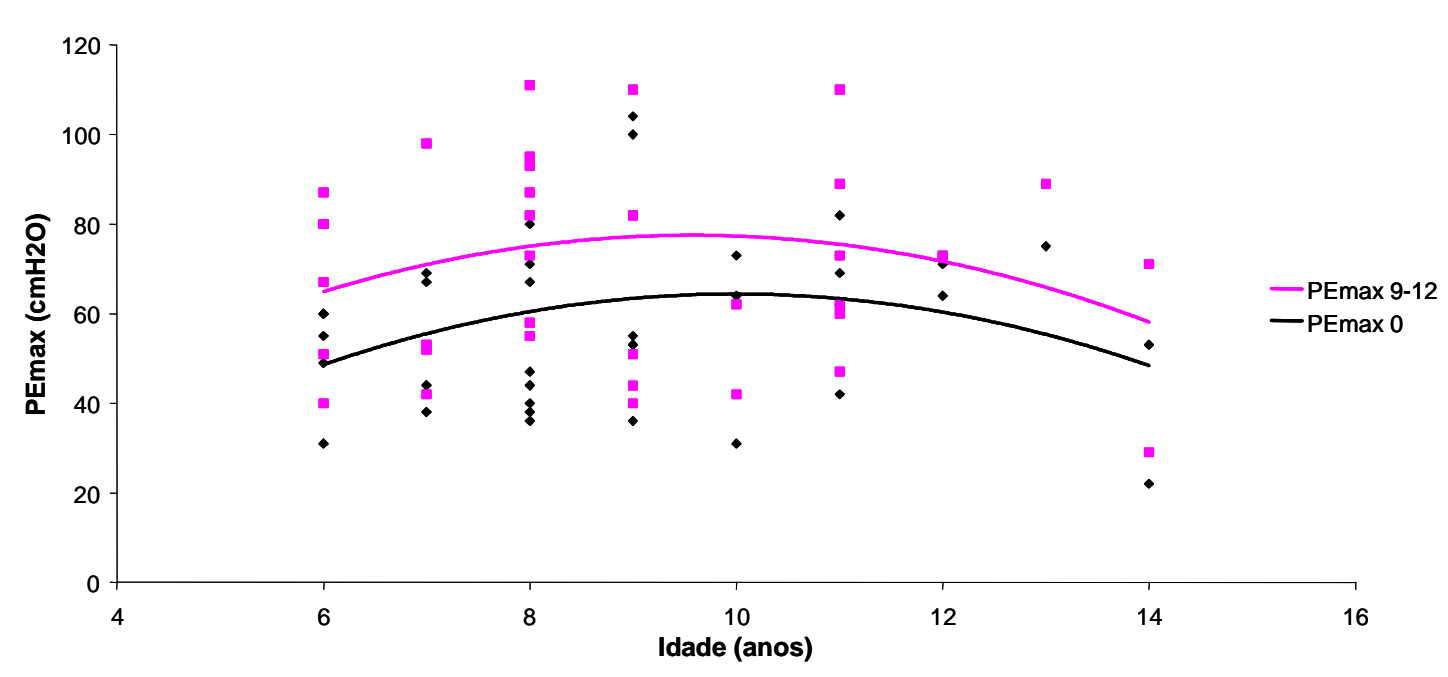

FIGURA 19 - Avaliação da PEmax em valores absolutos para o grupo de pacientes antes e após 10 meses de treinamento Foram avaliadas 39 pacientes com DMD com idades entre 6 e 14 anos.

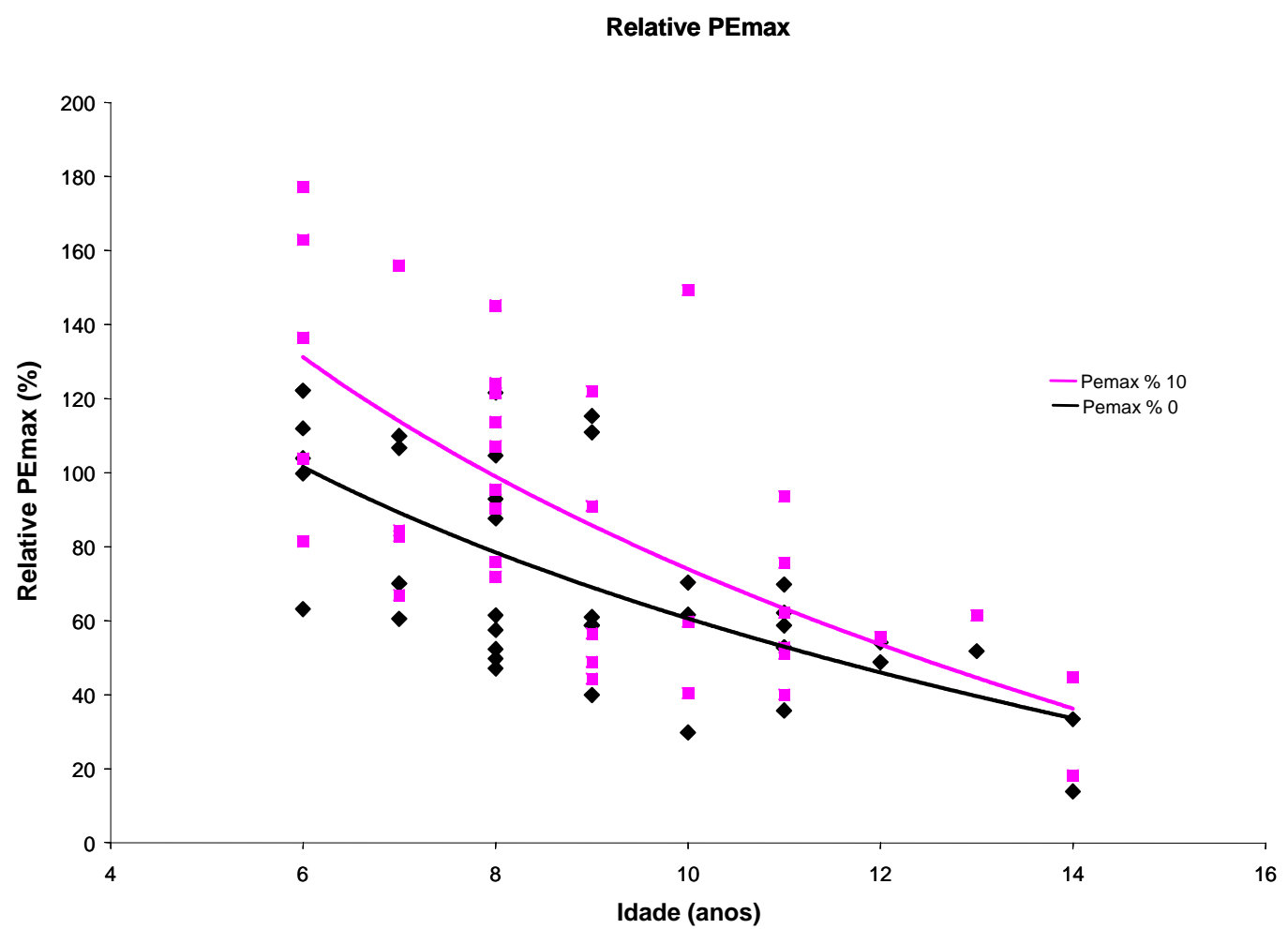

FIGURA 20 - Avaliação da PEmax em valores percentuais aos do predito para o grupo de pacientes antes e após 10 meses de treinamento. Foram avaliadas 39 pacientes com DMD com idades entre 6 e 14 anos. 


\subsection{Análise do perfil para amostra com $\mathrm{N}=70$}

Setenta pacientes de 6 a 14 anos que realizaram a avaliação no tempo inicial e pelo menos mais uma das duas seguintes. Ou seja, o tempo inicial (0) e mais a avaliação aos 5 meses (1) e/ou a avaliação de 10 meses (2). Este grupo foi subdividido em dois subgrupos, o primeiro de 6 a 9 anos, com $\mathrm{N}=41$ no momento inicial e o segundo de 10 a 14 anos, com $\mathrm{N}=29$ no momento inicial. $\mathrm{O}$ " $\mathrm{N}$ " dos pacientes para cada idade por ocasião da prova inicial de capacidade respiratória foi:

\begin{tabular}{|cccccccccc|}
\hline Idade & 6 & 7 & 8 & 9 & 10 & 11 & 12 & 13 & 14 \\
\hline $\mathbf{N}=$ & 10 & 7 & 12 & 12 & 6 & 11 & 8 & 2 & 2 \\
\hline
\end{tabular}

Para CVF em valores absolutos houve um aumento constante nos resultados da avaliação 0 para a avaliação 2, com significância para os grupos de 6 a 14 anos e 6 a 9 anos (Tabela 7 e Figura 21). Os dados preditos, foram semelhantes aos absolutos e com as mesmas significâncias (Tabela 8 e Figura 22).

Os resultados do VEF1, para valores absolutos e relativos, seguem o mesmo padrão dos resultados para a CVF, para os três grupos etários, sendo que para valores relativos encontramos significância apenas no grupo de 6 a 14 anos (Tabelas 9 e 10, Figuras 23 e 24).

Para PEmax em valores absolutos, foram os índices que mais se elevaram neste grupo $(\mathrm{N}=70)$. Aumentaram com significância da avaliação inicial (0) para a segunda avaliação (2) nos três grupos etários (Tabela 11 e Figura 25). Os índices relativos aumentam com significância nos grupos etários de 6 a 9 e 6 a 14 anos, quando se compara a avaliação 0 com a avaliação 1 (Tabela 12 e Figura 26). 
TABELA 7 - Avaliação da CVF em litros para o grupo de pacientes com pelo menos mais uma das avaliações ( 1 e/ou 2$)$, além da avaliação inicial (0), com um $\mathrm{N}=70$, divididos em dois grupos, um de 6 a 9 anos $(\mathrm{N}=41)$ e outro de 10 a 14 anos $(\mathrm{N}=29)$. Os dados foram expressos pela média

\begin{tabular}{|c|c|c|c|c|c|c|c|c|c|}
\hline & \multicolumn{3}{|c|}{$\begin{array}{c}\text { CVF } 6 \text { a } 14 \text { anos } \\
(p=0,001)\end{array}$} & \multicolumn{3}{|c|}{$\begin{array}{c}\text { CVF } 6 \text { a } 9 \text { anos } \\
\quad(p=0,001)\end{array}$} & \multicolumn{3}{|c|}{$\begin{array}{c}\text { CVF } 10 \text { a } 14 \text { anos } \\
(p=0,884)\end{array}$} \\
\hline & 0 & 1 & 2 & 0 & 1 & 2 & 0 & 1 & 2 \\
\hline $\mathbf{X}$ & 1,4 & 1,5 & $1,5^{*}$ & 1,3 & $1,4^{*}$ & $1,5^{*}$ & 1,6 & 1,6 & 1,7 \\
\hline SD & 0,4 & 0,3 & 0,4 & 0,3 & 0,3 & 0,3 & 0,4 & 0,3 & 0,6 \\
\hline EP & 0,0 & 0,0 & 0,1 & 0,0 & 0,0 & 0,0 & 0,1 & 0,1 & 0,1 \\
\hline $\mathbf{N}$ & 70 & 59 & 49 & 41 & 33 & 32 & 29 & 26 & 17 \\
\hline
\end{tabular}
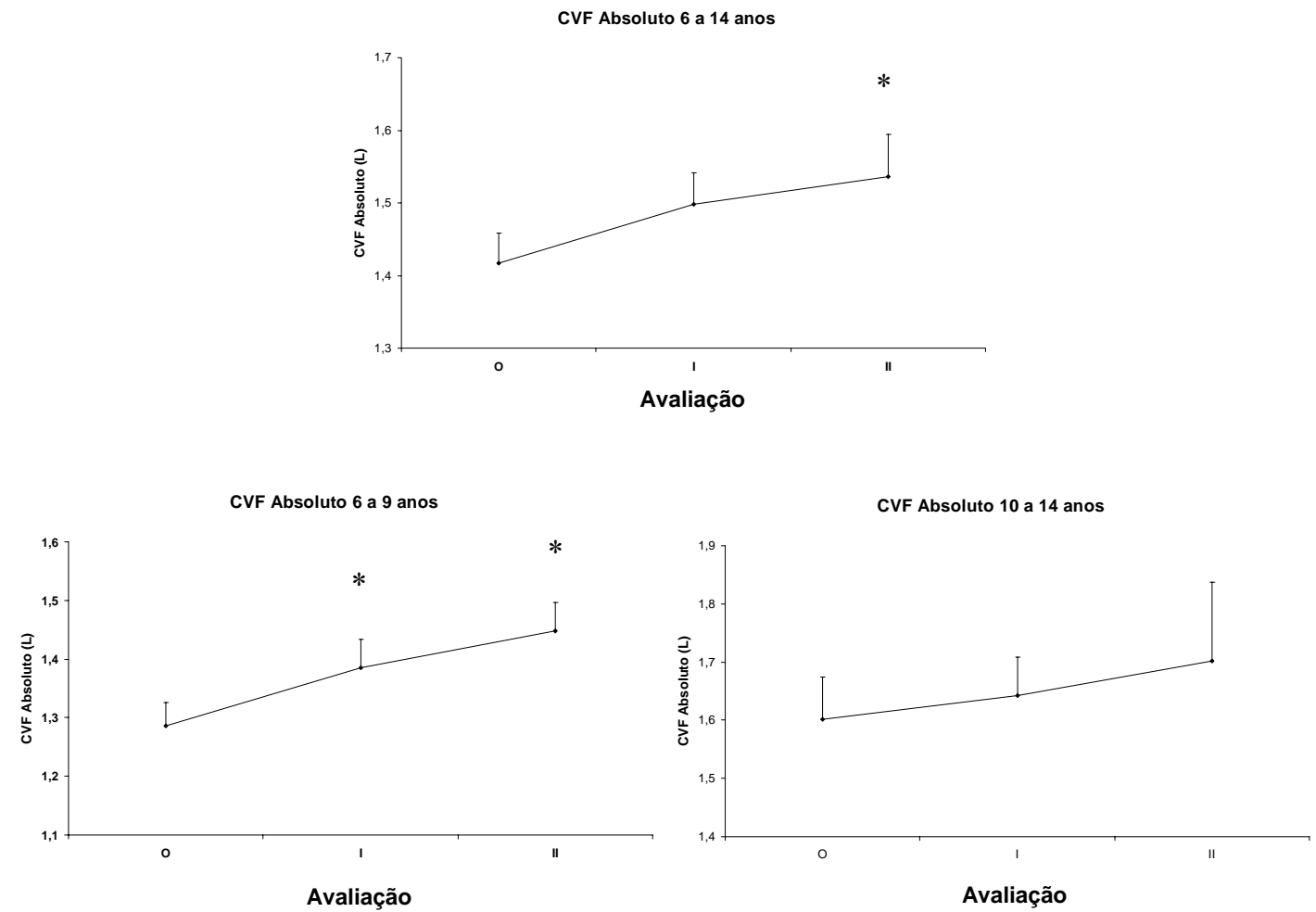

FIGURA 21 - Avaliação da CVF em litros para o grupo de pacientes com pelo menos mais uma das avaliações ( 1 e/ou 2 ), além da avaliação inicial (0), com um $\mathrm{N}=70$, divididos em dois grupos, um de 6 a 9 anos $(\mathrm{N}=41)$ e outro de 10 a 14 anos $(\mathrm{N}=29)$. Os dados foram expressos pela média. $* \neq 0, p \leq 0,05$ 
TABELA 8 - Avaliação da CVF em valores percentuais do predito, para o grupo de pacientes com pelo menos mais uma das avaliações (1 e/ou 2), além da avaliação inicial (0), com um $\mathrm{N}=70$, divididos em dois, um de 6 a 9 $\operatorname{anos}(\mathrm{N}=41)$ e outro de 10 a $14 \operatorname{anos}(\mathrm{N}=29)$

\begin{tabular}{cccccccccc}
\hline & \multicolumn{3}{c}{$\begin{array}{c}\text { CVF \% - 6 a 14 anos } \\
(\mathrm{p}=0,024)\end{array}$} & \multicolumn{3}{c}{$\begin{array}{c}\text { CVF \% - 6 a 9 anos } \\
(\mathrm{p}=0,006)\end{array}$} & \multicolumn{3}{c}{$\begin{array}{c}\text { CVF \% - 10 a 14 anos } \\
(\mathrm{p}=0,586)\end{array}$} \\
\hline & $\mathbf{0}$ & $\mathbf{1}$ & $\mathbf{2}$ & $\mathbf{0}$ & $\mathbf{1}$ & $\mathbf{2}$ & $\mathbf{0}$ & $\mathbf{1}$ & $\mathbf{2}$ \\
\hline $\mathbf{X}$ & $\mathbf{8 1 , 8}$ & $\mathbf{8 3 , 6}$ & $\mathbf{8 8 , 0 *}$ & $\mathbf{8 1 , 1}$ & $\mathbf{8 6 , 2 *}$ & $\mathbf{8 8 , 0}$ & $\mathbf{8 0 , 9}$ & $\mathbf{8 0 , 9}$ & $\mathbf{8 7 , 8}$ \\
$\mathbf{S D}$ & 17,3 & 14,6 & 17,7 & 15,6 & 12,3 & 15,0 & 20,2 & 16,4 & 26,8 \\
$\mathbf{E P}$ & 2,1 & 1,9 & 2,5 & 2,4 & 2,1 & 2,6 & 3,8 & 3,2 & 6,5 \\
$\mathbf{N}$ & 70 & 59 & 49 & 41 & 33 & 32 & 29 & 26 & 17 \\
\hline$* \neq 0 \mathrm{P} \leq 0,05$ & & & & & & & & &
\end{tabular}
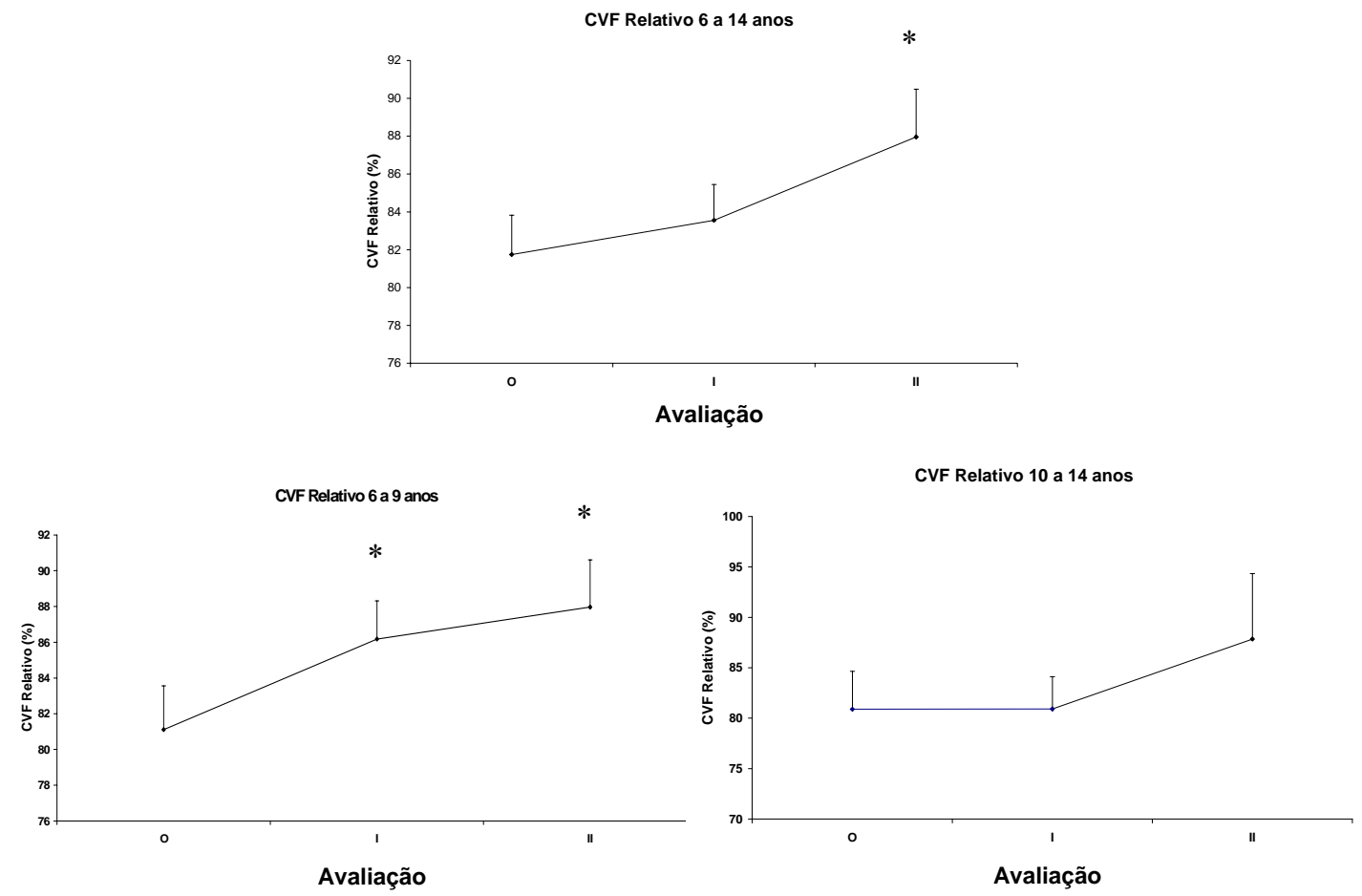

FIGURA 22 - Avaliação da CVF em valores percentuais do predito, para o grupo de pacientes com pelo menos mais uma das avaliações (1 e/ou 2), além da avaliação inicial (0), com um $\mathrm{N}=70$, divididos em dois, um de 6 a 9 $\operatorname{anos}(\mathrm{N}=41)$ e outro de 10 a 14 anos $(\mathrm{N}=29) . * \neq 0, \mathrm{p} \leq 0,05$ 
TABELA 9 - Avaliação da VEF1 em litros, para o grupo de pacientes com pelo menos mais uma das avaliações (1 e/ou 2), além da avaliação inicial (0), com um $\mathrm{N}=70$, divididos em dois, um de 6 a 9 anos $(\mathrm{N}=41)$ e outro de 10 a 14 anos $(\mathrm{N}=29)$

\begin{tabular}{|c|c|c|c|c|c|c|c|c|c|}
\hline & \multicolumn{3}{|c|}{$\begin{array}{c}\text { VEF1 }-6 \text { a } 14 \text { anos } \\
\quad(p=0,001)\end{array}$} & \multicolumn{3}{|c|}{$\begin{array}{c}\text { VEF1 }-6 \text { a } 9 \text { anos } \\
\quad(p=0,001)\end{array}$} & \multicolumn{3}{|c|}{$\begin{array}{c}\text { VEF1- } 10 \text { a } 14 \text { anos } \\
\quad(p=0,884)\end{array}$} \\
\hline & 0 & 1 & 2 & 0 & 1 & 2 & 0 & 1 & 2 \\
\hline$X$ & 1,4 & 1,5 & $1,5^{*}$ & 1,3 & $1,4^{*}$ & $1,4^{*}$ & 1,6 & 1,6 & 1,7 \\
\hline SD & 0,4 & 0,3 & 0,4 & 0,3 & 0,3 & 0,3 & 0,4 & 0,3 & 0,6 \\
\hline EP & 0,0 & 0,0 & 0,1 & 0,0 & 0,0 & 0,0 & 0,1 & 0,1 & 0,1 \\
\hline $\mathbf{N}$ & 70 & 59 & 49 & 41 & 33 & 32 & 29 & 26 & 17 \\
\hline
\end{tabular}
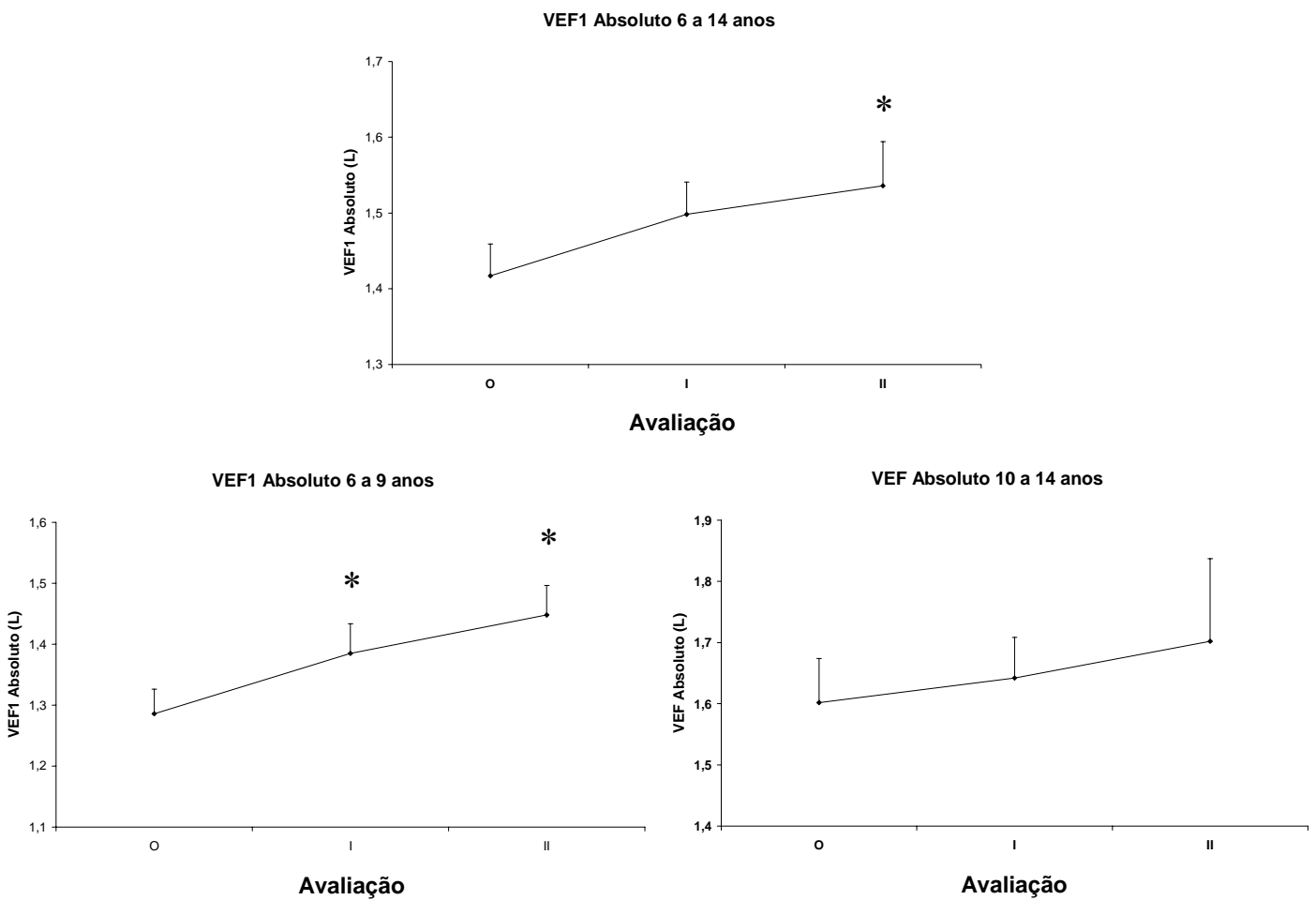

FIGURA 23 - Avaliação da VEF1 em litros, para o grupo de pacientes com pelo menos mais uma das avaliações (1 e/ou 2), além da avaliação inicial (0), com um $\mathrm{N}=70$, divididos em dois, um de 6 a 9 anos $(\mathrm{N}=41)$ e outro de 10 a 14 anos $(\mathrm{N}=29) . * \neq 0, \mathrm{p} \leq 0,05$ 
TABELA 10 - Avaliação da VEF1 em valores percentuais do predito, para o grupo de pacientes com pelo menos mais uma das avaliações (1 e/ou 2), além da avaliação inicial ( 0 ), com um $\mathrm{N}=70$, dividido em dois grupos, um de 6 a 9 anos $(\mathrm{N}=41)$ e outro de 10 a 14 anos $(\mathrm{N}=29)$

\begin{tabular}{cccccccccc}
\hline & $\begin{array}{c}\text { VEF1 \% }-6 \text { a 14 anos } \\
(\mathrm{p}=0,024)\end{array}$ & \multicolumn{3}{c}{$\begin{array}{c}\text { VEF1 \% - 6 a 9 anos } \\
(\mathrm{p}=0,113)\end{array}$} & \multicolumn{3}{c}{$\begin{array}{c}\text { VEF1\% - 10 a 14 anos } \\
(\mathrm{p}=0,732)\end{array}$} \\
\hline & $\mathbf{0}$ & $\mathbf{1}$ & $\mathbf{2}$ & $\mathbf{0}$ & $\mathbf{1}$ & $\mathbf{2}$ & $\mathbf{0}$ & $\mathbf{1}$ & $\mathbf{2}$ \\
\hline $\mathbf{X}$ & $\mathbf{8 1 , 8}$ & $\mathbf{8 3 , 6}$ & $\mathbf{8 8 , 0}$ & $\mathbf{8 1 , 7}$ & $\mathbf{8 5 , 4}$ & $\mathbf{8 9 , 2}$ & $\mathbf{8 1 , 8}$ & $\mathbf{8 1 , 1}$ & $\mathbf{8 5 , 6}$ \\
$\mathbf{S D}$ & 17,3 & 14,6 & 17,7 & 16,0 & 14,3 & 14,8 & 19,3 & 14,8 & 22,4 \\
$\mathbf{E P}$ & 2,1 & 1,9 & 2,5 & 2,5 & 2,5 & 2,6 & 3,6 & 2,9 & 5,4 \\
$\mathbf{N}$ & 70 & 59 & 49 & 41 & 33 & 32 & 29 & 26 & 17 \\
\hline
\end{tabular}

$* \neq 0 \mathrm{P} \leq 0,05$
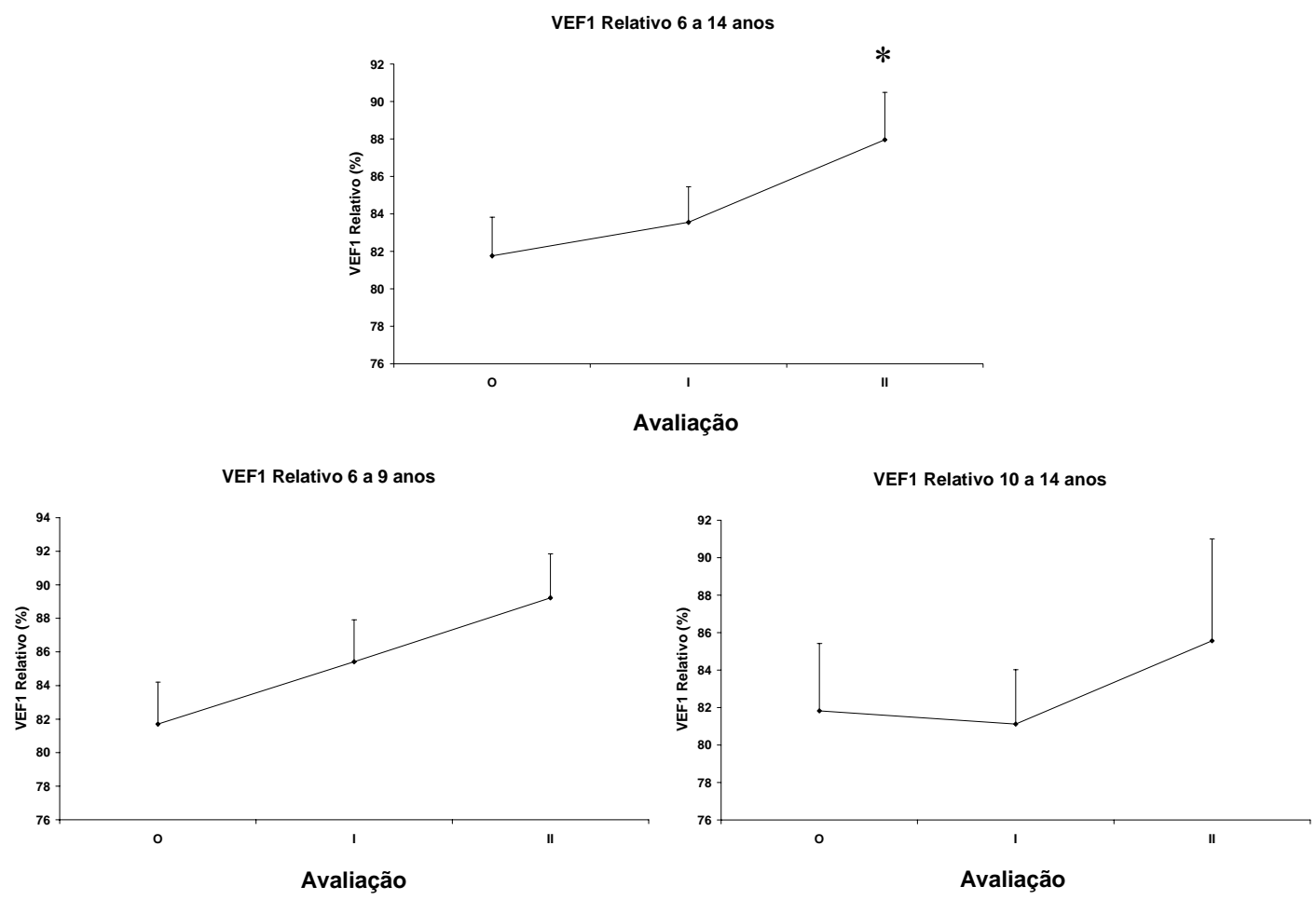

FIGURA 24 - Avaliação da VEF1 em valores percentuais do predito, para o grupo de pacientes com pelo menos mais uma das avaliações (1 e/ou 2), além da avaliação inicial ( 0 ), com um $\mathrm{N}=70$, dividido em dois grupos, um de 6 a 9 anos $(\mathrm{N}=41)$ e outro de 10 a 14 anos $(\mathrm{N}=29) .{ }^{*} \neq 0, \mathrm{p} \leq 0,05$ 
TABELA 11 - Avaliação da PEmax em valores absolutos, para o grupo de pacientes com pelo menos mais uma das avaliações (1 e/ou 2), além da avaliação inicial (0), com um $\mathrm{N}=70$, dividido em dois grupos, um de 6 a $9 \operatorname{anos}(\mathrm{N}=41)$ e outro de 10 a $14 \operatorname{anos}(\mathrm{N}=29)$

\begin{tabular}{|c|c|c|c|c|c|c|c|c|c|}
\hline & \multicolumn{3}{|c|}{$\begin{array}{c}\text { PEmax - 6 a } 14 \text { anos } \\
(p=0,001)\end{array}$} & \multicolumn{3}{|c|}{$\begin{array}{c}\text { PEmax }-6 \text { a } 9 \text { anos } \\
\quad(p=0,003)\end{array}$} & \multicolumn{3}{|c|}{$\begin{array}{c}\text { PEmax - } 10 \text { a } 14 \text { anos } \\
(p=0,032)\end{array}$} \\
\hline & 0 & 1 & 2 & 0 & 1 & 2 & $\mathbf{0}$ & 1 & 2 \\
\hline $\mathbf{X}$ & 57,2 & $66,2 *$ & $69,1^{*}$ & 56,8 & 65,9 & $68,5^{*}$ & 57,8 & 66,5 & $70,2^{*}$ \\
\hline SD & 19,5 & 17,9 & 24,8 & 21,4 & 16,0 & 22,4 & 16,9 & 20,3 & 29,4 \\
\hline EP & 2,3 & 2,4 & 3,6 & 3,3 & 2,9 & 4,0 & 3,1 & 4,1 & 7,1 \\
\hline $\mathbf{N}$ & 70 & 56 & 48 & 41 & 31 & 31 & 29 & 25 & 17 \\
\hline
\end{tabular}

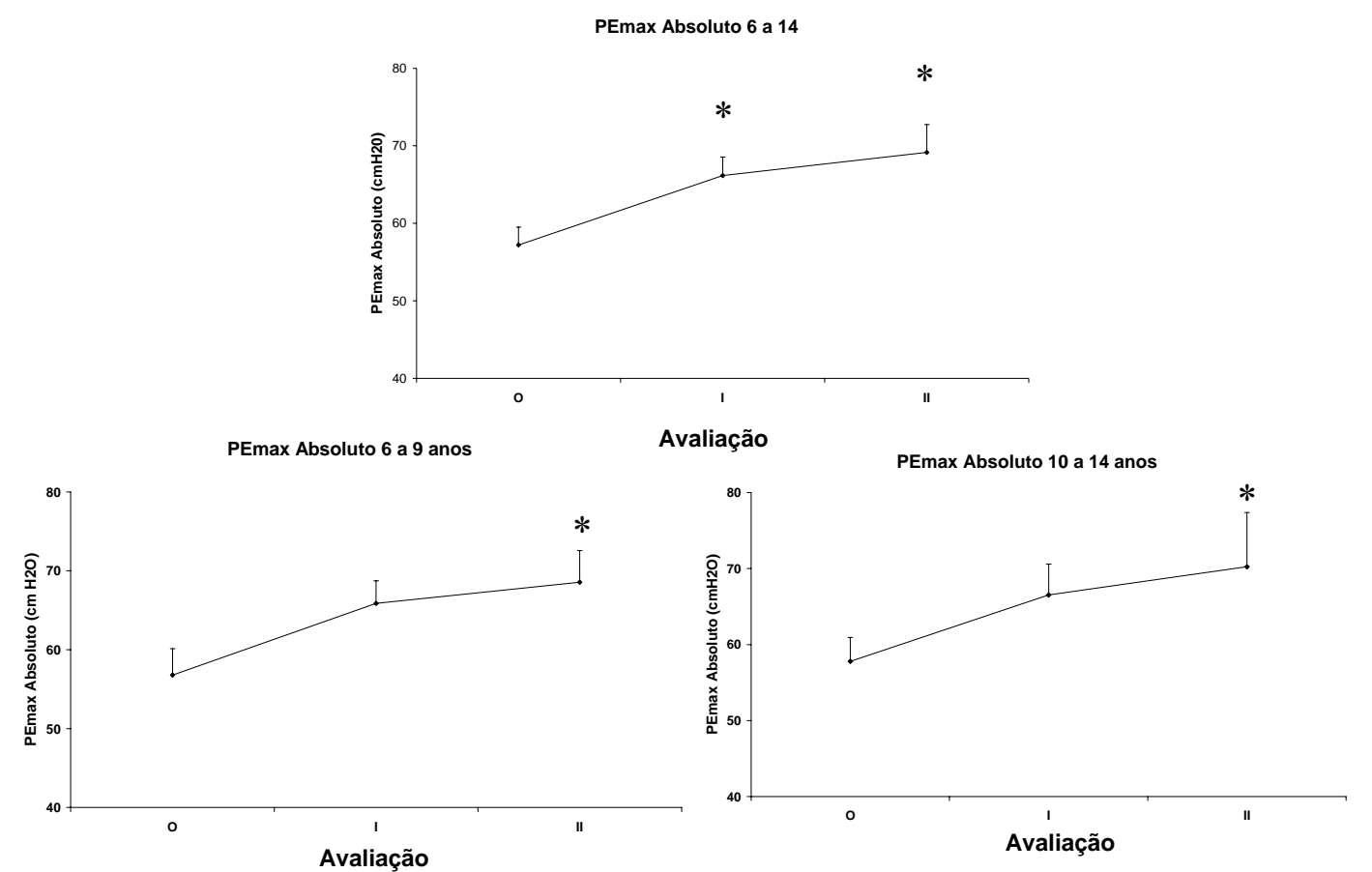

FIGURA 25 - Avaliação da PEmax em valores absolutos, para o grupo de pacientes com pelo menos mais uma das avaliações (1 e/ou 2), além da avaliação inicial (0), com um $\mathrm{N}=70$, dividido em dois grupos, um de 6 a $9 \operatorname{anos}(\mathrm{N}=41)$ e outro de 10 a $14 \operatorname{anos}(\mathrm{N}=29) .{ }^{*} \mathrm{p} \leq 0,05$ 
TABELA 12 - Avaliação da PEmax em valores proporcionais ao predito, para o grupo de pacientes com pelo menos mais uma das avaliações $(1 \mathrm{e} / \mathrm{ou}$ 2), além da avaliação inicial (0), com um $\mathrm{N}=70$, dividido em dois grupos, um de 6 a 9 anos $(\mathrm{N}=41)$ e outro de 10 a 14 anos $(\mathrm{N}=29)$

\begin{tabular}{cccccccccc}
\hline & \multicolumn{3}{c}{$\begin{array}{c}\text { PEmax \% - 6 a 14 anos } \\
(\mathrm{p}=0,034)\end{array}$} & \multicolumn{3}{c}{$\begin{array}{c}\text { PEmax \% - 6 a 9 anos } \\
(\mathrm{p}=0,024)\end{array}$} & \multicolumn{3}{c}{ PEmax \% - 10 a 14 anos } \\
$(\mathrm{p}=0,334)$ & \\
\hline & $\mathbf{0}$ & $\mathbf{1}$ & $\mathbf{2}$ & $\mathbf{0}$ & $\mathbf{1}$ & $\mathbf{2}$ & $\mathbf{0}$ & $\mathbf{1}$ & $\mathbf{2}$ \\
\hline $\mathbf{X}$ & $\mathbf{6 6 , 6}$ & $\mathbf{7 5 , 2}$ & $\mathbf{8 6 , 8 *}$ & $\mathbf{5 6 , 8}$ & $\mathbf{6 5 , 9}$ & $\mathbf{6 8 , 5 *}$ & $\mathbf{4 7 , 8}$ & $\mathbf{5 5 , 0}$ & $\mathbf{5 8 , 1}$ \\
$\mathbf{S D}$ & 30,1 & 32,7 & 40,9 & 21,4 & 16,0 & 22,4 & 15,3 & 19,7 & 28,9 \\
$\mathbf{E P}$ & 3,6 & 4,4 & 5,9 & 3,3 & 2,9 & 4,0 & 2,8 & 3,9 & 7,0 \\
$\mathbf{N}$ & 70 & 59 & 49 & 41 & 33 & 32 & 29 & 26 & 17 \\
\hline
\end{tabular}
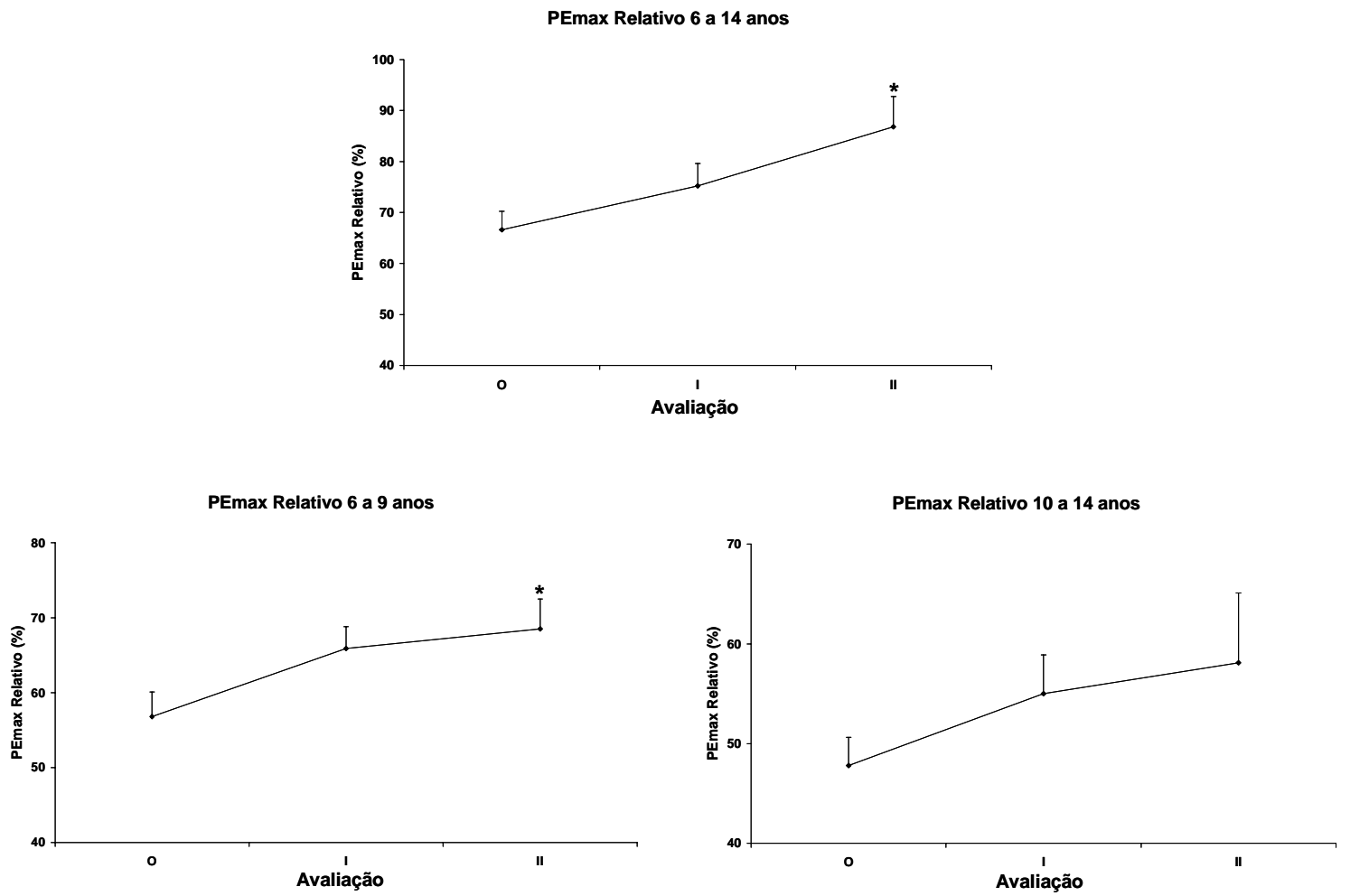

FIGURA 26 - Avaliação da PEmax em valores proporcionais ao predito, para o grupo de pacientes com pelo menos mais uma das avaliações (1 e/ou 2), além da avaliação inicial (0), com um $\mathrm{N}=70$, dividido em dois grupos, um de 6 a 9 anos $(\mathrm{N}=41)$ e outro de 10 a 14 anos $(\mathrm{N}=29)$. $* \mathrm{p} \leq 0,05$ 
Os gráficos a seguir, comparam os perfis dos pacientes que fizeram a avaliação inicial (0) com o perfil dos mesmos pacientes depois de um 10 meses de treinamento (2), com $\mathrm{N}=70$ para a linha que representa o tempo inicial e $\mathrm{N}=49$ para a linha que representa 10 meses de treinamento. Lembrando que nesta análise estão os pacientes que fizeram a avaliação inicial e mais uma das duas seguintes (1 ou 2). Cada ponto do gráfico representa a melhor das três avaliações consideradas válidas para VEF1 e CVF e a melhor de cinco avaliações das consideradas válidas para PEmax. As linhas dos gráficos comparam o resultado das avaliações dos pacientes, distribuídos pelas faixas etárias. Os valores apresentados na curva das avaliações do momento inicial, foram comparados com os valores na mesma faixa etária da curva que representa 10 meses de treinamento. Os gráficos mostram que para CVF, tanto para valores absolutos como para percentuais do predito, as diferenças se tornaram maiores em favor dos resultados após 10 meses de treinamento, especialmente para CVF em litros nas faixas etárias superiores aos 11 anos (Figuras 27 e 28).

Para o VEF1 em litros, a melhora dos resultados em favor do grupo que treinou se manteve constante ao longo da idade, com discreta melhora nas idades mais avançadas. Para valores relativos, a melhora do grupo que treinou, apresentou tendência de aproximação dos resultados com o momento inicial, ao longo da idade (Figuras 29 e 30).

Em PEmax para valores absolutos, as linhas que representam o perfil dos pacientes, apresentaram as mesmas tendências ao longo da idade, porém com valores iniciais maiores para o grupo depois de 10 meses de treinamento com declínio desta diferença para os mais velhos (Figura 31). Os valores do percentual do predito, para PEmax, também foram maiores para os pacientes depois de 10 meses de treinamento com a mesma tendência de aproximação dos valores com o aumento da idade (Figura 32). 


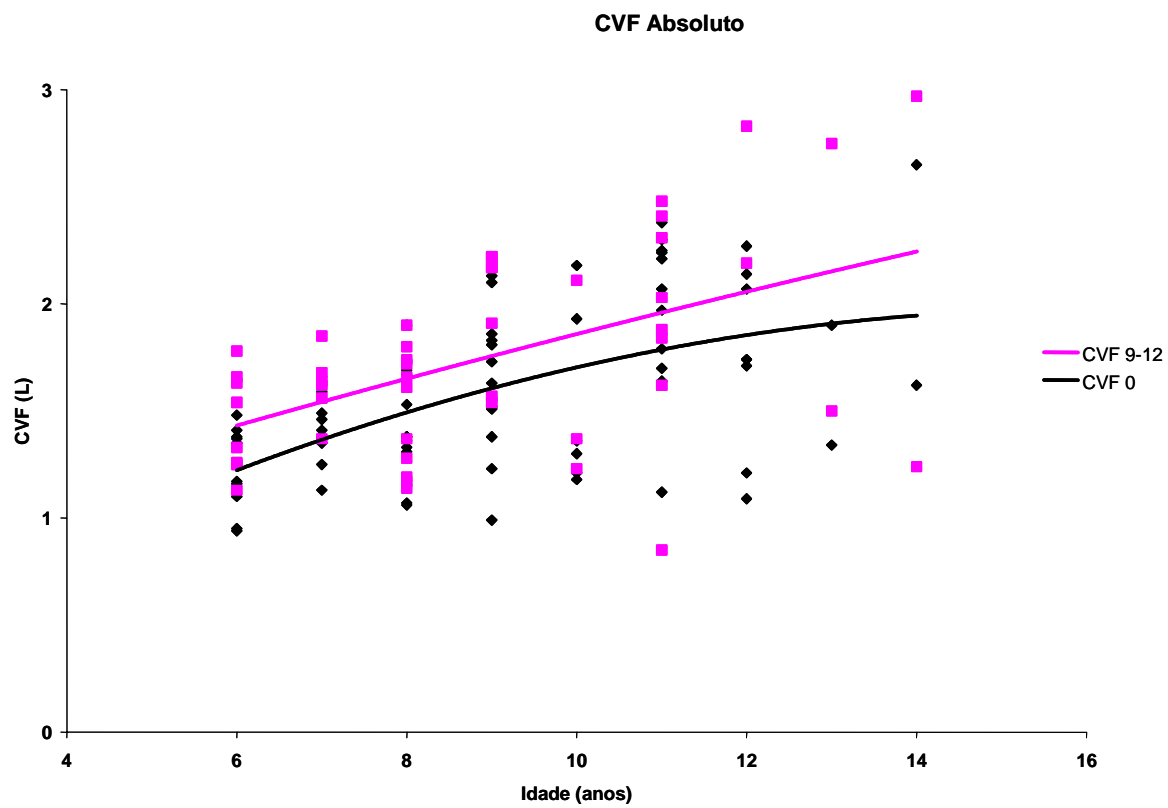

FIGURA 27 - Avaliação da CVF em litros antes e após 1 ano de treinamento. Foram avaliados 70 pacientes com DMD com idades entre 6 e 14 anos. Cada ponto do gráfico representa o melhor valor de cada paciente para este índice.

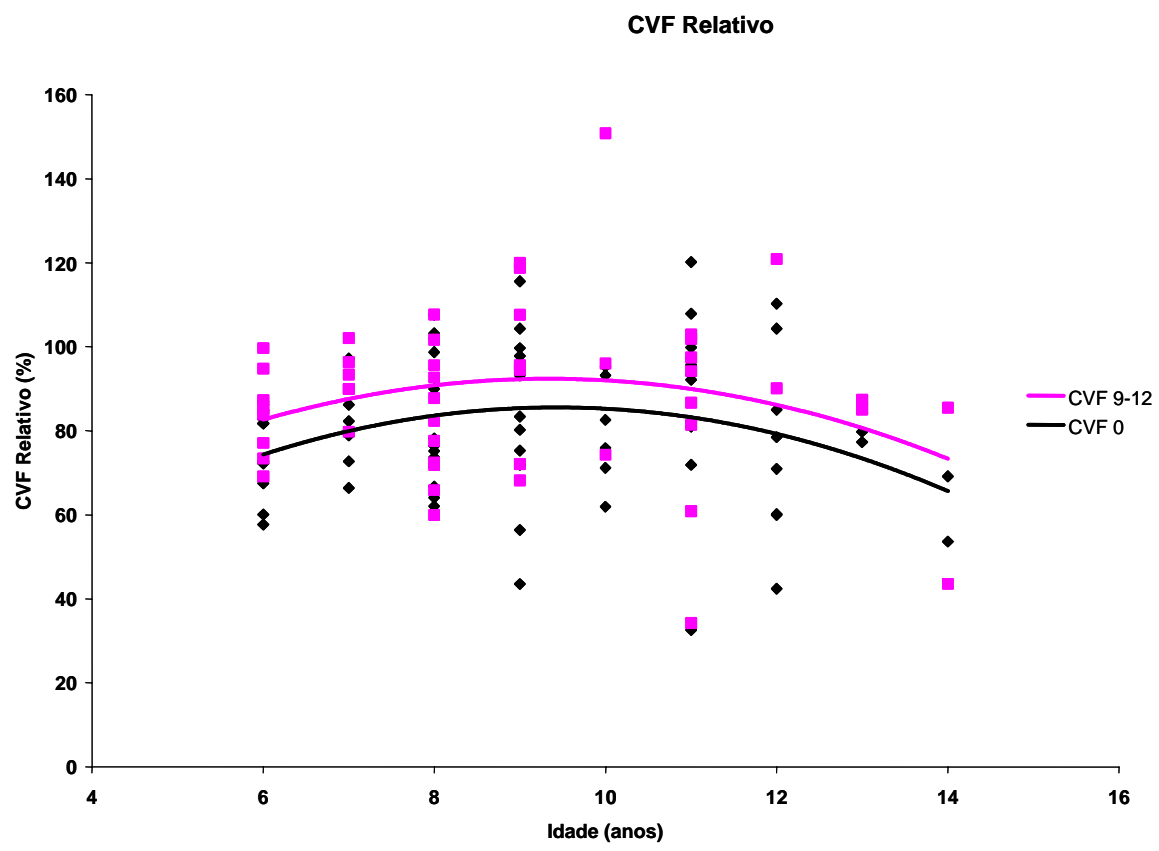

FIGURA 28 - Avaliação da CVF em valores percentuais ao predito antes e após 1 ano de treinamento. Foram avaliados 70 pacientes com DMD com idades entre 6 e 14 anos. Cada ponto do gráfico representa o melhor valor de cada paciente para este índice. 


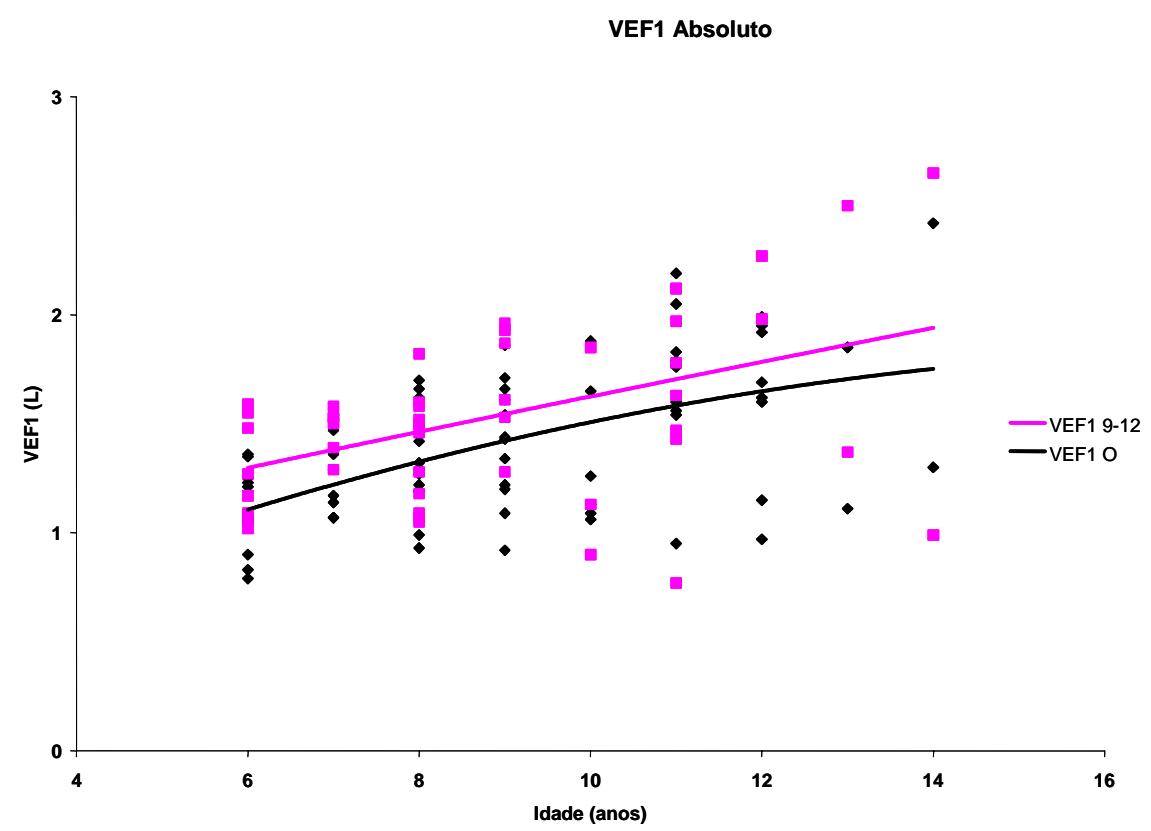

FIGURA 29 - Avaliação da VEF1 em litros antes e após 1 ano de treinamento. Foram avaliados 70 pacientes com DMD com idades entre 6 e 14 anos. Cada ponto do gráfico representa o melhor valor de cada paciente para este índice.

VEF1 Relativo

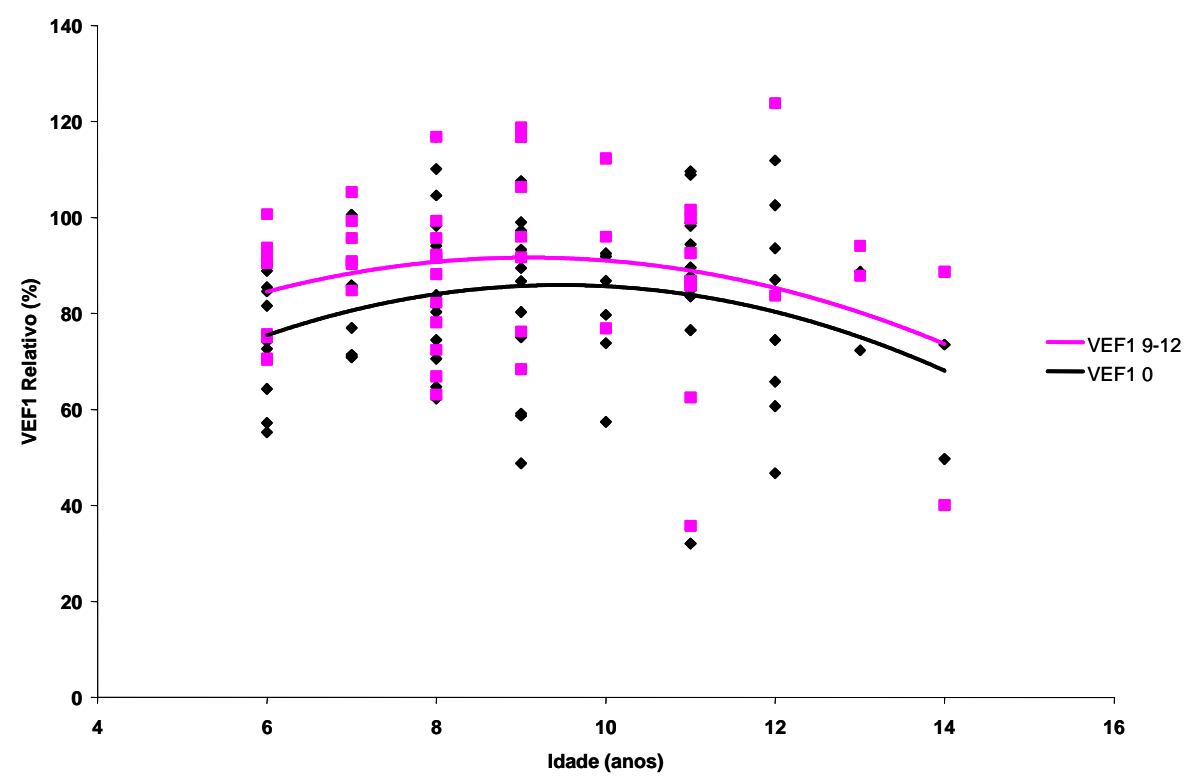

FIGURA 30 - Avaliação da VEF1 em valores percentuais do predito antes e após 1 ano de treinamento. Foram avaliadas 70 pacientes com DMD com idades entre 6 e 14 anos. Cada ponto do gráfico representa o melhor valor de cada paciente para este índice. 


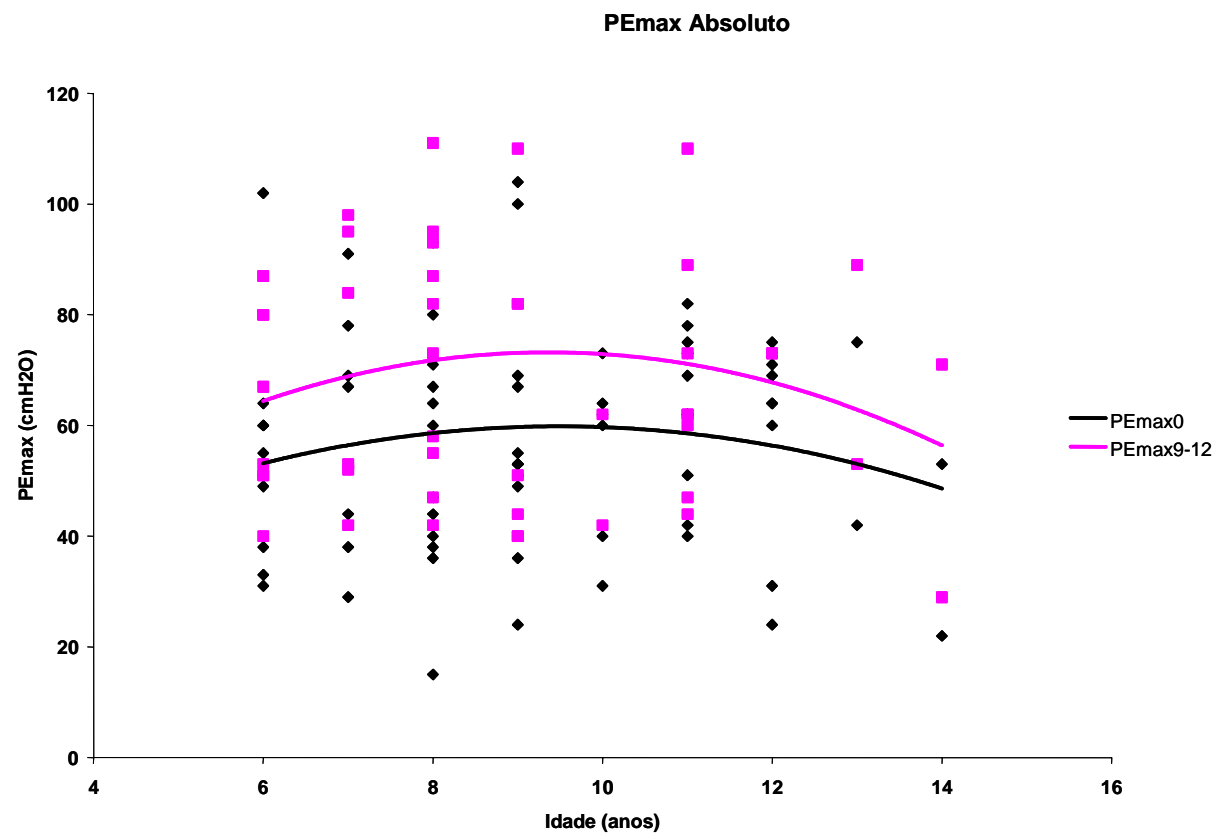

FIGURA 31 - Avaliação da PEmax em valores absolutos antes e após 1 ano de treinamento. Foram avaliados 70 pacientes com DMD com idades entre 6 e 14 anos. Cada ponto do gráfico representa o melhor valor de cada paciente para este índice.

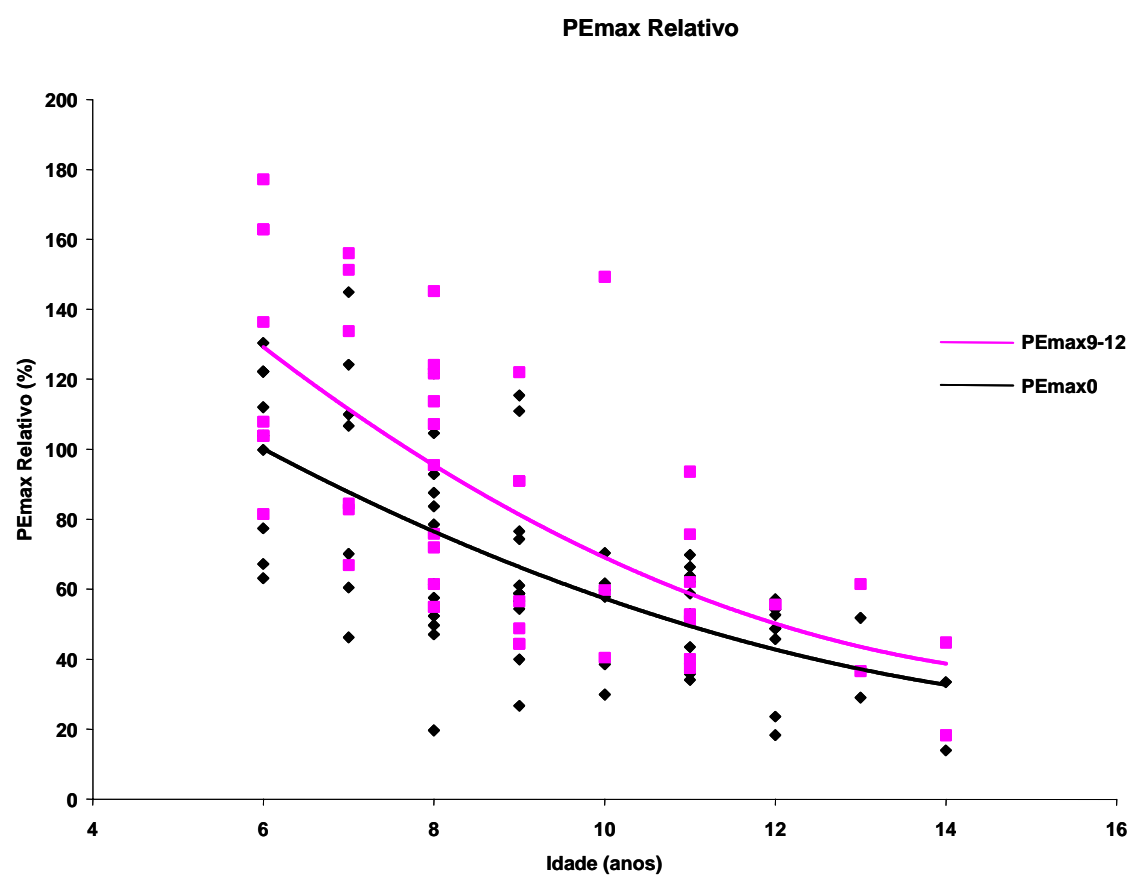

FIGURA 32 - Avaliação da PEmax em valores percentuais aos do predito antes e após 1 ano de treinamento. Foram avaliadas 70 pacientes com DMD com idades entre 6 e 14 anos. Cada ponto do gráfico representa o melhor valor de cada paciente para este índice. 


\subsection{Análise do perfil para amostra com $\mathrm{N}=18$}

Analisamos os resultados de 18 pacientes que fizeram as quatro avaliações além da inicial, no período de 20 meses (após 5 meses, 10 meses, 15 meses e 20 meses). O "N" dos pacientes para cada idade por ocasião da prova inicial de capacidade respiratória foi:

\begin{tabular}{|cccccccccc|}
\hline Idade & 6 & 7 & 8 & 9 & 10 & 11 & 12 & 13 & 14 \\
\hline $\mathbf{N}=$ & 1 & 2 & 3 & 3 & 3 & 3 & 2 & 1 & 2 \\
\hline
\end{tabular}

Os valores absolutos obtidos para a CVF atingem seu pico na avaliação 3 (aos 15 meses de treinamento), mas, ao final dos 20 meses de treinamento mantiveram-se com resultados superiores aos do início. Em relação à CVF proporcional ao predito, não foram observadas variações significativas nos valores das avaliações (Tabela 13 e Figura 33).

Para VEF1 em valores absolutos, os pacientes apresentaram nas avaliações 3 e 4, resultados superiores aos da avaliação inicial, com significância, chegando ao final dos 20 meses de treinamento, num nível superior ao momento inicial. Em números proporcionais ao predito, não foram observadas variações significativas nos resultados das avaliações (Tabela 14 e Figura 34).

Para PEmax em valores absolutos o pico se estabeleceu depois de 10 meses de treinamento (avaliação 2). Quanto ao predito, os pacientes atingiram os 20 meses de treinamento com valores discretamente inferiores aos do início do projeto (Tabela $15 \mathrm{e}$ Figura 35). 
TABELA 13 - Avaliação da CVF absoluta (L) e relativa (\%) dos pacientes com todas as avaliações $(0,1,2,3$, e 4$)$ no período de dois anos de treinamento, $\mathrm{N}=18$. Valores calculados pela mediana

\begin{tabular}{|c|c|c|c|c|c|c|c|c|c|c|}
\hline & \multicolumn{5}{|c|}{ CVF ABSOLUTO } & \multicolumn{5}{|c|}{ CVF RELATIVO } \\
\hline & $\mathbf{0}$ & 1 & 2 & 3 & 4 & $\mathbf{0}$ & 1 & 2 & 3 & 4 \\
\hline mediana & 1,78 & 1,85 & $1,87^{*}$ & $1,88 *$ & $1,85^{*}$ & 85,6 & 85,2 & 94,7 & $\mathbf{8 8 , 4}$ & 90,6 \\
\hline $5 \%$ & 1,16 & 1,17 & 1,29 & 1,32 & 1,19 & 52,7 & 68,8 & 65,4 & 64,0 & 63,5 \\
\hline $95 \%$ & 2,29 & 2,49 & 2,80 & 2,92 & 2,88 & 106,9 & 103,4 & 138,8 & 113,7 & 106,2 \\
\hline
\end{tabular}

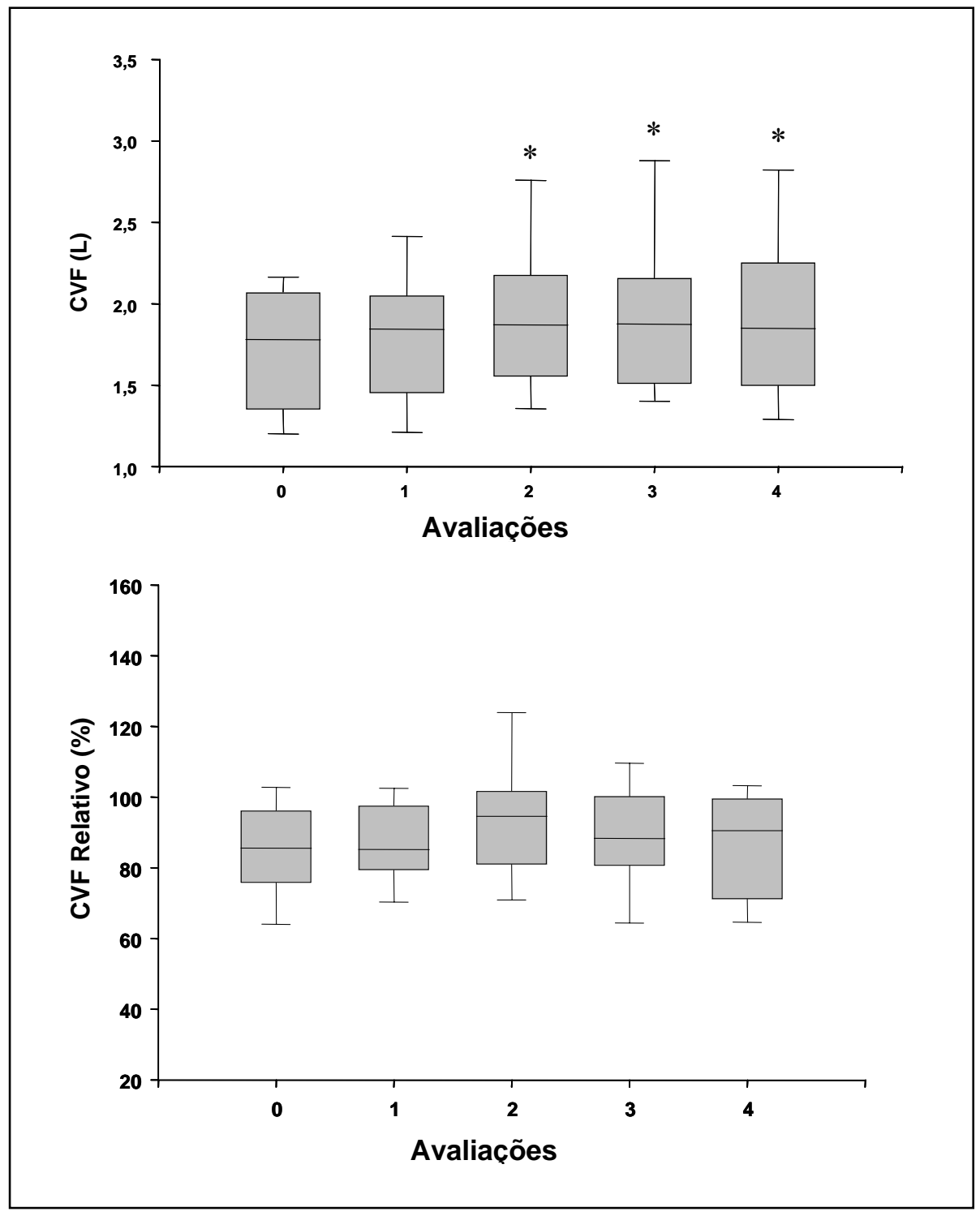

FIGURA 33 - Avaliação da CVF absoluta (L) e relativa (\%) dos pacientes com todas as avaliações $(0,1,2,3$, e 4$)$ no período de dois anos de treinamento, $\mathrm{N}=18$. Valores calculados pela mediana. 
TABELA 14 - Resultado do VEF1 em valores absolutos e percentuais do predito, dos pacientes com todas as avaliações $(0,1,2,3$, e 4$)$ no período de dois anos de treinamento, $\mathrm{N}=18$. Dados expressos pela mediana

\begin{tabular}{|c|c|c|c|c|c|c|c|c|c|c|}
\hline & \multicolumn{5}{|c|}{ VEF1 ABSOLUTO } & \multicolumn{4}{|c|}{ VEF1 RELATIVO } & \multirow[b]{2}{*}{4} \\
\hline & $\mathbf{O}$ & 1 & 2 & 3 & 4 & $\mathbf{0}$ & 1 & 2 & 3 & \\
\hline mediana & 1,57 & 1,70 & 1,62 & $1,65 *$ & $1,62 *$ & 87,75 & 86,90 & 94,90 & 93,60 & 91,95 \\
\hline $5 \%$ & 1,07 & 1,09 & 0,99 & 1,191 & 1,13 & 57,72 & 66,92 & 64,86 & 62,10 & 67,42 \\
\hline $95 \%$ & 2,11 & 2,16 & 2,40 & 2,52 & 2,59 & 111,18 & 110,86 & 121,00 & 119,98 & 110,52 \\
\hline
\end{tabular}

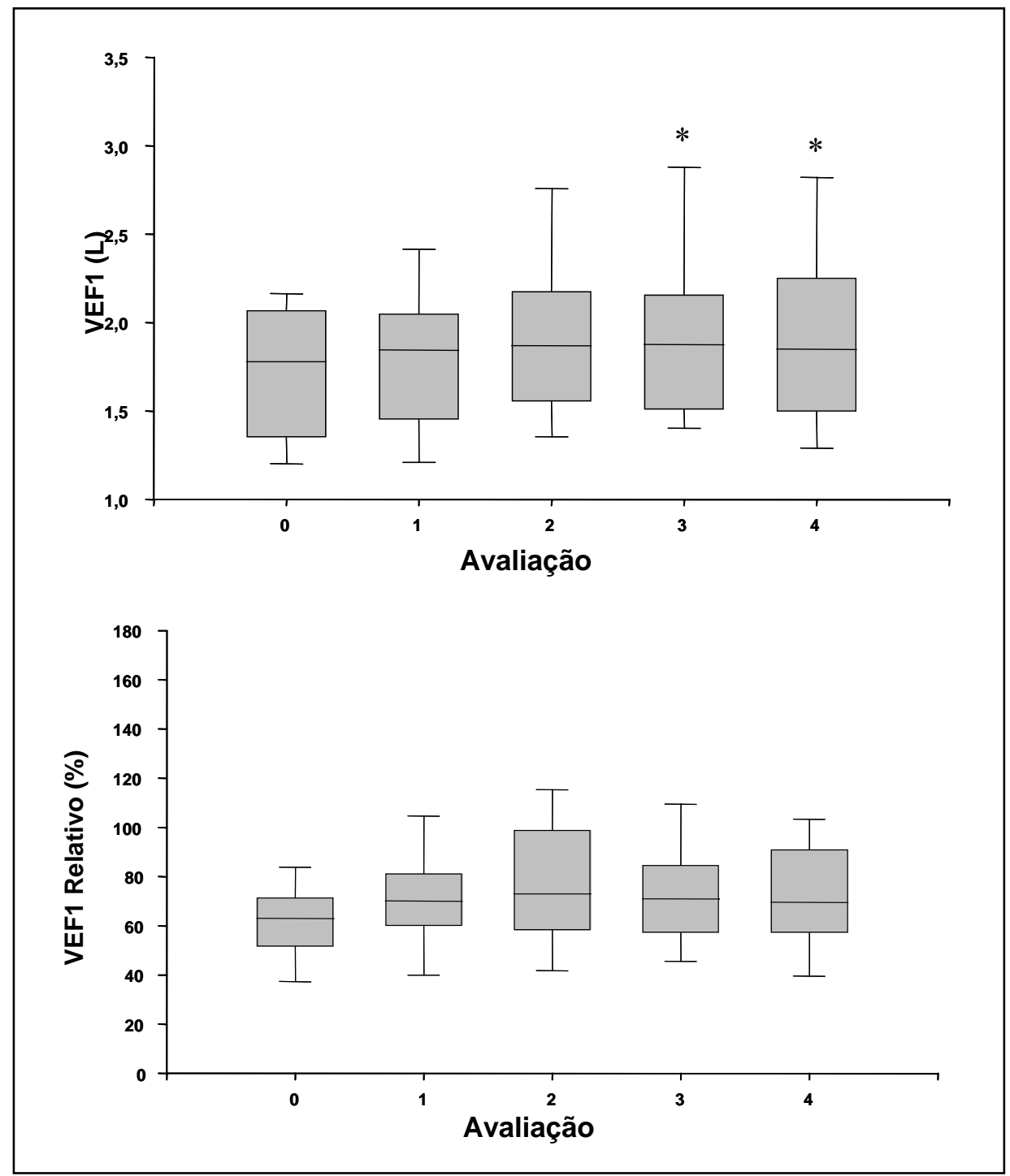

FIGURA 34 - Resultado do VEF1 absoluto (L) e RELATIVO (\%) dos pacientes com todas as avaliações (0,1,2,3, e 4) no período de dois anos de treinamento, $\mathrm{N}=18$. Valores calculados pela mediana. 
TABELA 15 - Resultado da PEmax em valores absolutos e percentuais do predito, dos pacientes com todas as avaliações $(0,1,2,3$, e 4$)$ no período de dois anos de treinamento, $\mathrm{N}=18$. Dados expressos pela mediana

\begin{tabular}{ccccccccccc}
\hline & \multicolumn{4}{c}{ PEmax ABSOLUTO } & \multicolumn{5}{c}{ PEmax RELATIVO } \\
\hline & $\mathbf{0}$ & $\mathbf{1}$ & $\mathbf{2}$ & $\mathbf{3}$ & $\mathbf{4}$ & $\mathbf{0}$ & $\mathbf{1}$ & $\mathbf{2}$ & $\mathbf{3}$ & $\mathbf{4}$ \\
\hline mediana & $\mathbf{6 3 , 0}$ & $\mathbf{7 0 , 0}$ & $\mathbf{7 3 , 0} *$ & $\mathbf{7 1 , 0}$ & $\mathbf{6 9 , 5}$ & $\mathbf{6 1 , 2}$ & $\mathbf{8 2 , 0}$ & $\mathbf{6 8 , 7}$ & $\mathbf{6 1 , 7}$ & $\mathbf{6 0 , 4}$ \\
$\mathbf{5 \%}$ & 33,8 & 30,0 & 40,8 & 38,6 & 37,0 & 37,4 & 29,3 & 40,0 & 34,2 & 28,8 \\
$\mathbf{9 5 \%}$ & 92,8 & 108,2 & 137,4 & 136,4 & 129,8 & 117,7 & 115,4 & 130,1 & 121,5 & 120,6 \\
\hline$* 0, \mathrm{p} \leq 0,05$ & & & & & & & & & &
\end{tabular}

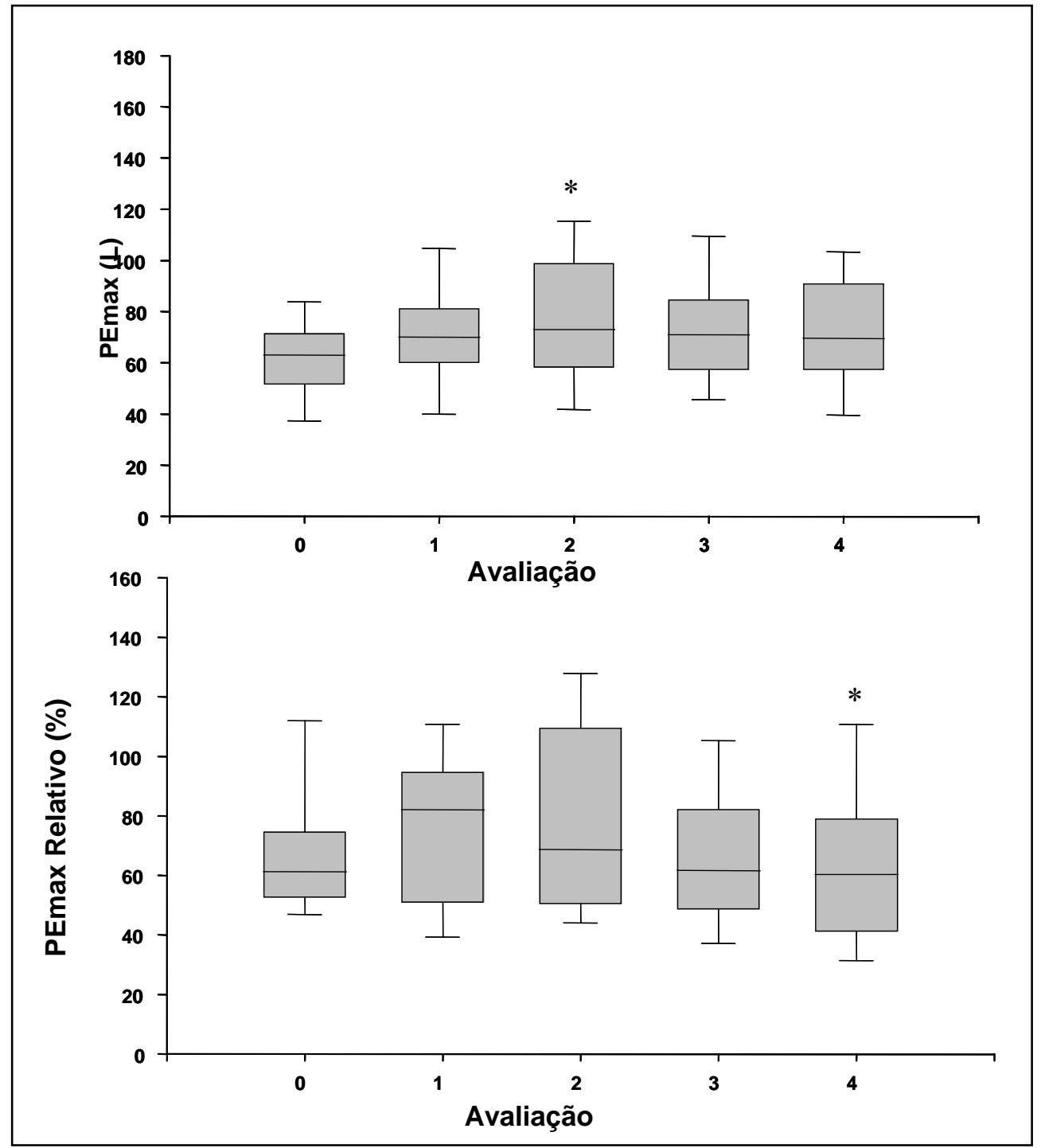

FIGURA 35 - Resultado da PEmax em valores absolutos e percentuais do predito, dos pacientes com todas as avaliações $(0,1,2,3$, e 4$)$ no período de dois anos de treinamento, $\mathrm{N}=18$. Valores calculados pela mediana. 


\subsection{Análise pelo índice de adesão}

Dos 85 pacientes que participaram da avaliação inicial, 70 aderiram ao projeto em diferentes níveis: 1 (parcial), 2 (satisfatória) e 3 (total).

A quantidade de pacientes para cada nível de adesão ficou assim distribuída:

Para $\mathrm{N}=70$

\begin{tabular}{|cccc|}
\hline Adesão & $\mathbf{1}$ & $\mathbf{2}$ & $\mathbf{3}$ \\
\hline $\mathbf{N}=$ & 22 & 30 & 18 \\
\hline
\end{tabular}

Para $\mathrm{N}=39$

\begin{tabular}{|cccc|}
\hline Adesão & $\mathbf{1}$ & $\mathbf{2}$ & $\mathbf{3}$ \\
\hline $\mathbf{N}=$ & 10 & 16 & 13 \\
\hline
\end{tabular}

Para $\mathrm{N}=18$

\begin{tabular}{|cccc|}
\hline Adesão & $\mathbf{1}$ & $\mathbf{2}$ & $\mathbf{3}$ \\
\hline $\mathbf{N}=$ & 2 & 6 & 10 \\
\hline
\end{tabular}

Os níveis 1 e 2 de adesão significavam que os exercícios foram realizados de maneira correta e em quantidade satisfatória, portanto, estavam dentro do desejado. O nível 1, embora realizados corretamente, o paciente não conseguiu a regularidade esperada.

Obtivemos para N=39 aproximadamente $70 \%$ de um bom nível de adesão ao projeto (níveis 2 e 3). Deste grupo comparamos os resultados das avaliações de CVF, VEF1 e PEmax em porcentagem do predito dos pacientes com índice de adesão 1 com o resultado dos mesmo índices dos pacientes com nível 3 de adesão, depois de 10 meses de treinamento e percebemos que as linhas do grupo 3 de adesão apontaram para melhores resultados do que as do grupo de adesão 1. Deste grupo, 13 
pacientes apresentaram índice 3 de adesão e destes, apenas 2 reduziram seus valores de CVF relativo, apenas 1 reduziu seus valores para VEF1 relativo e 3 reduziram os valores de PEmax relativo (Figuras 36 a 41).

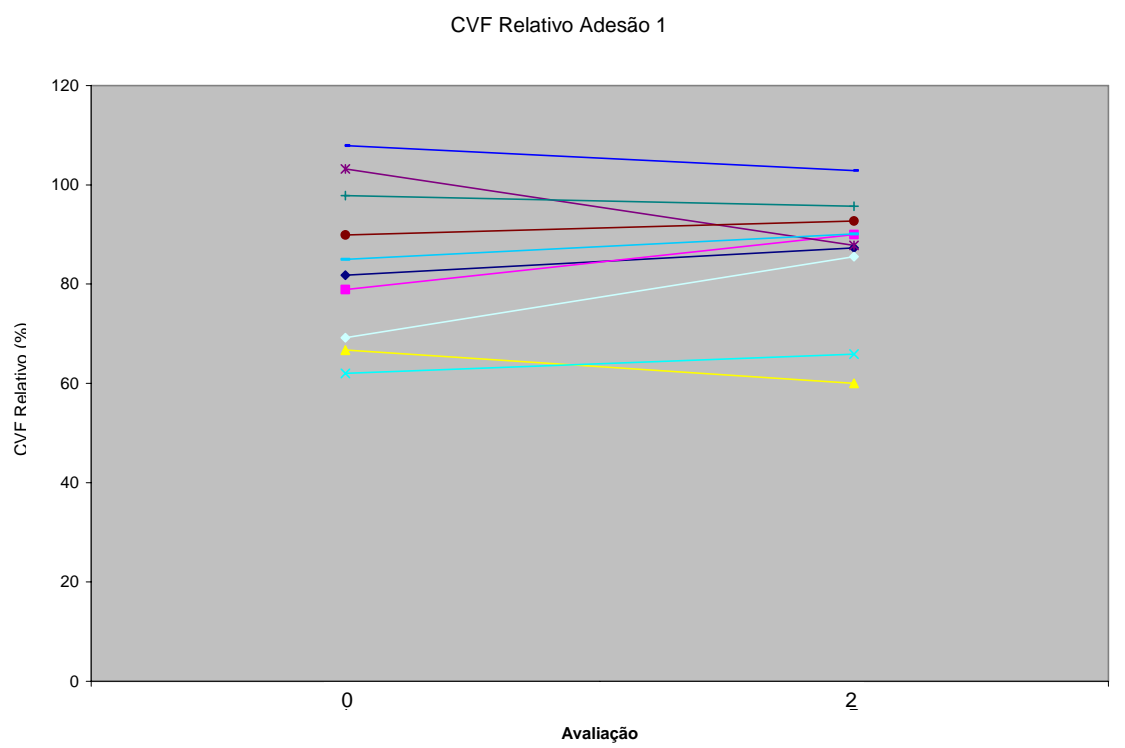

FIGURA 36 - Resultados da CVF em valores percentuais ao predito no momento inicial (0) e após 10 meses de treinamento (2). Foram avaliados 10 pacientes com DMD com idades entre 6 e 14 anos com índice de adesão 1 (baixo) ao projeto.

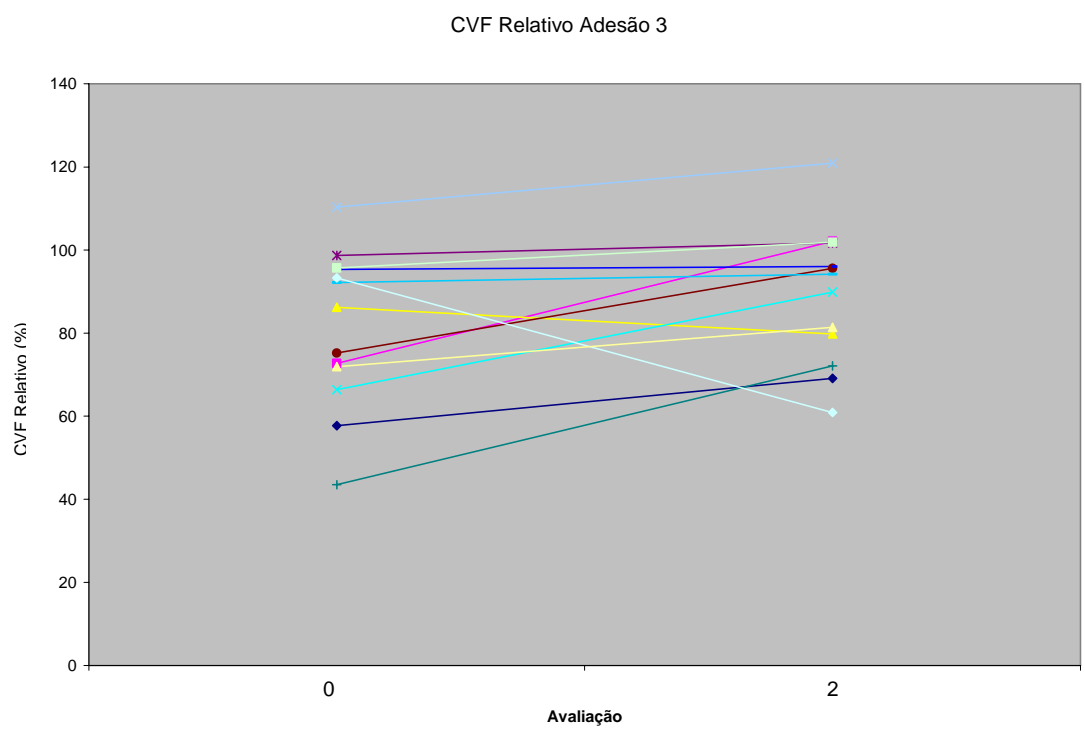

FIGURA 37 - Resultados da CVF em valores percentuais ao predito no momento inicial (0) e após 10 meses de treinamento (2). Foram avaliados 13 pacientes com DMD com idades entre 6 e 14 anos com índice de adesão 3 (total) ao projeto. 


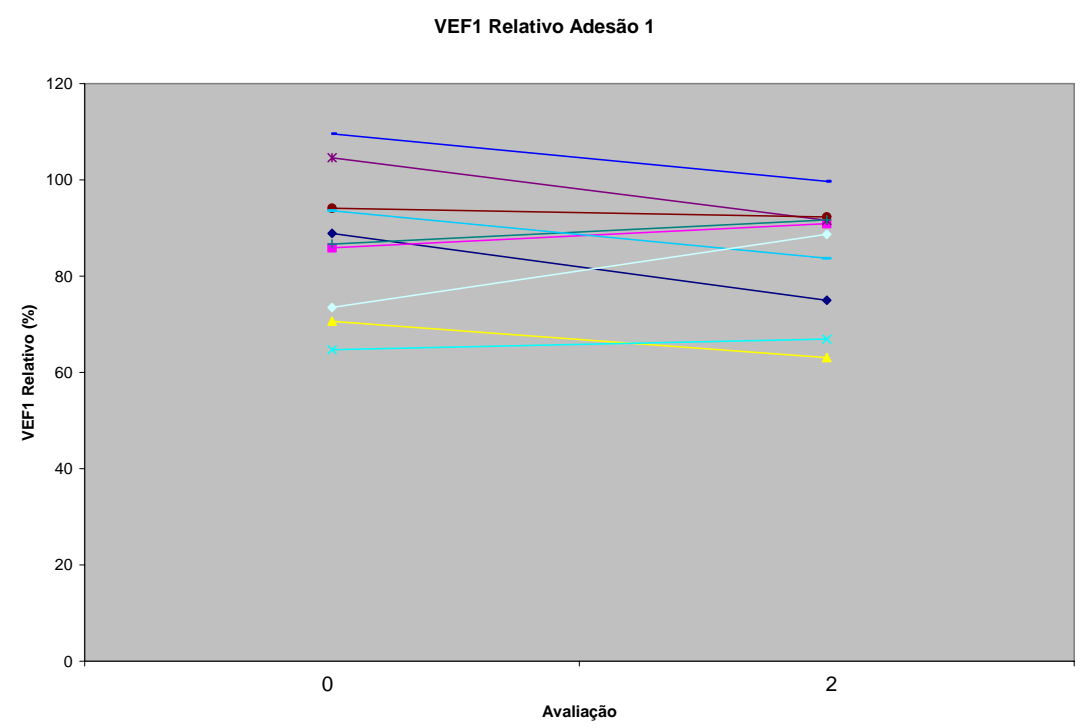

FIGURA 38 - Resultados do VEF1 em valores percentuais ao predito no momento inicial (0) e após 10 meses de treinamento (2). Foram avaliados 10 pacientes com DMD com idades entre 6 e 14 anos com índice de adesão 1 (baixo) ao projeto.

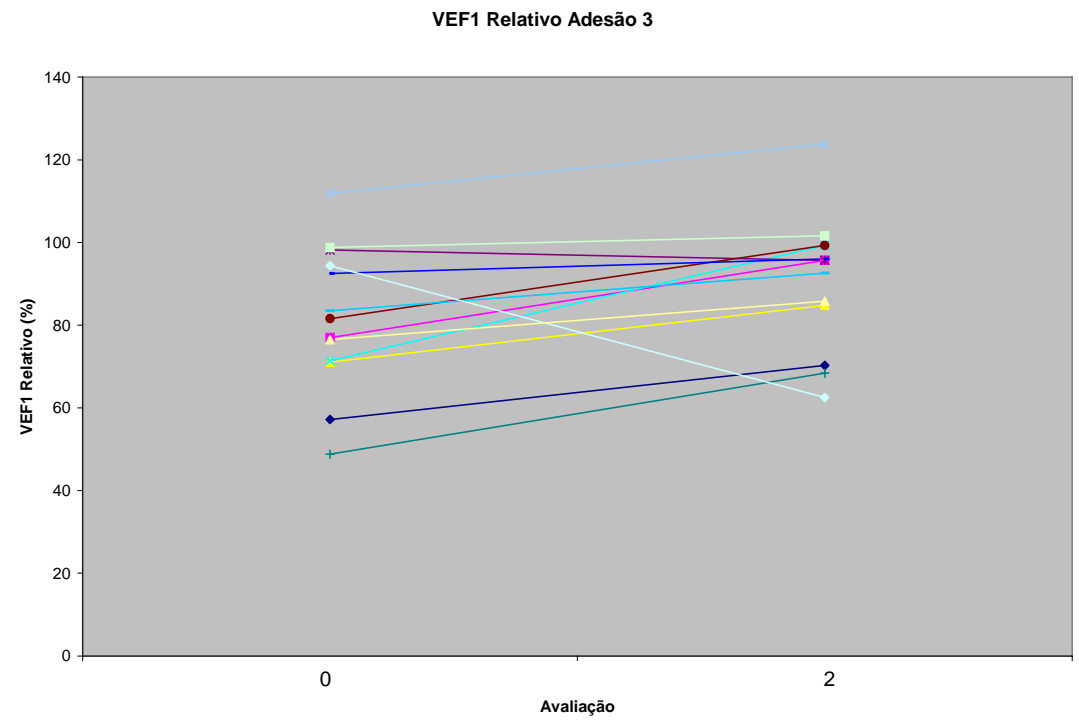

FIGURA 39 - Resultados do VEF1 em valores percentuais ao no momento inicial (0) e após 10 meses de treinamento (2). Foram avaliados 13 pacientes com DMD com idades entre 6 e 14 anos com índice de adesão 3 (total) ao projeto. 
PEmax Relativo Adesão 1

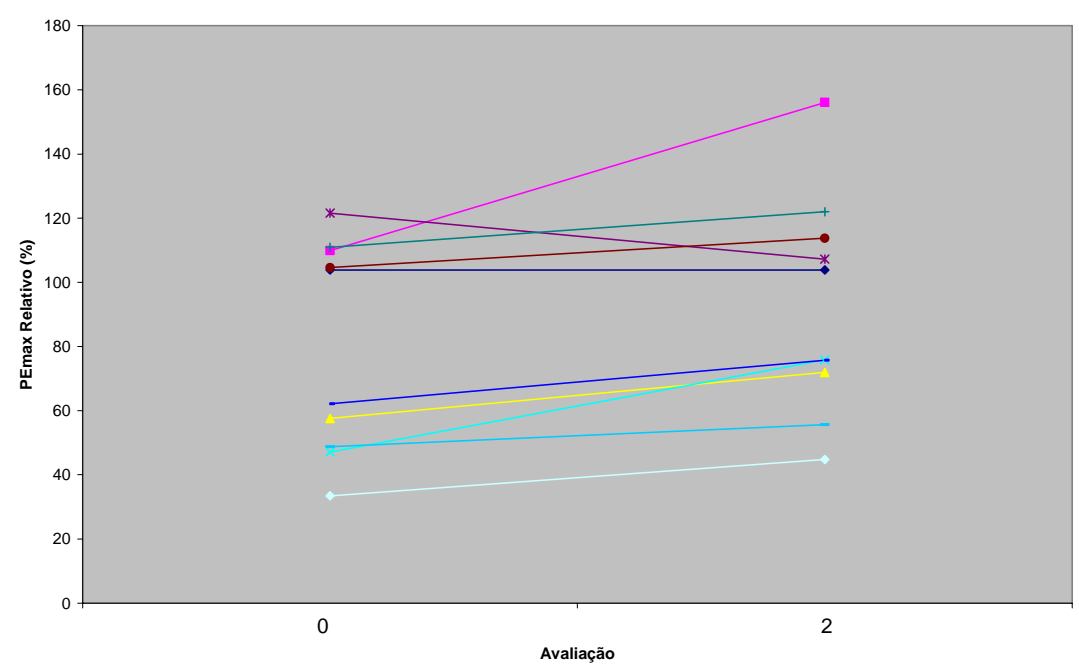

FIGURA 40 - Resultados da PEmax em valores percentuais ao predito no momento inicial (0) e após 10 meses de treinamento (2). Foram avaliados 10 pacientes com DMD com idades entre 6 e 14 anos com índice de adesão 1 (baixo) ao projeto.

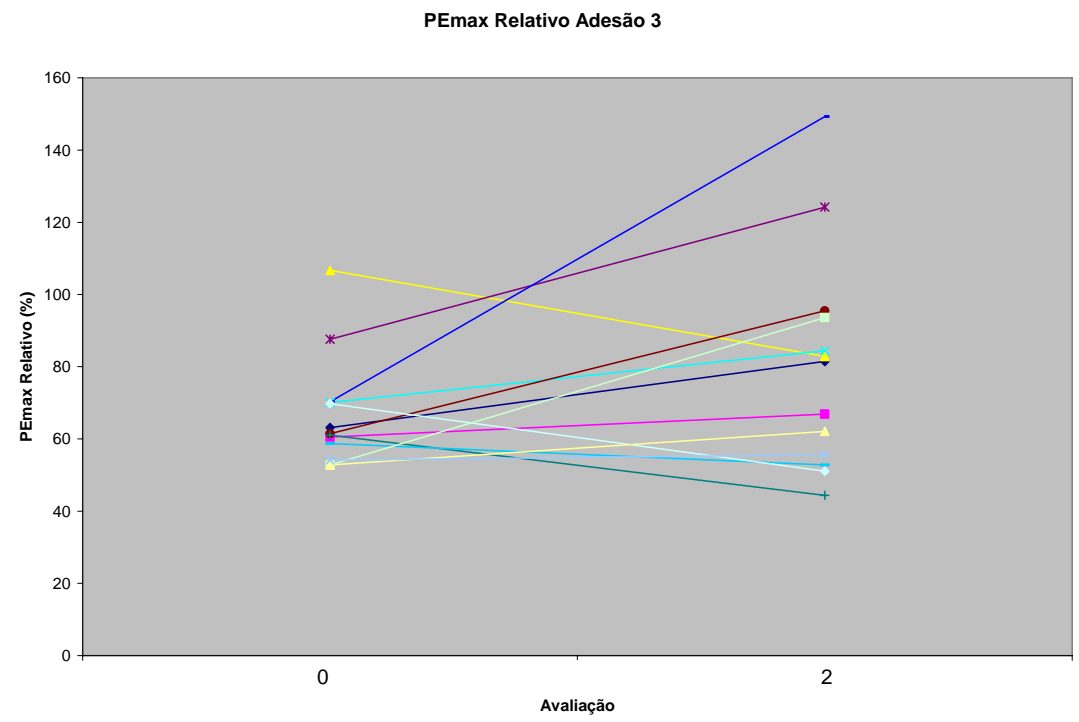

FIGURA 41 - Resultados da PEmax em valores percentuais ao predito no momento inicial (0) e após 10 meses de treinamento (2). Foram avaliados 13 pacientes com DMD com idades entre 6 e 14 anos com índice de adesão 3 (total) ao projeto. 
Os parâmetros de função pulmonar em pacientes com DMD atingem seu índice máximo para valores absolutos aos 14 anos de idade (Hahn et al., 1997; Tangsrud et al., 2001). Entretanto no estudo realizado por Carvalho em 2004, foi observado que o pico máximo de função pulmonar dos pacientes brasileiros com DMD ocorreu entre os 11 e 12 anos de idade. Estes dados parecem mais compatíveis com o quadro clínico dos pacientes de DMD, visto que o início da perda da função pulmonar deveria ocorrer simultaneamente com o início do comprometimento da capacidade de deambulação, que é por volta dos 10 anos de idade (Rideau et al., 1983).

As referências apresentam para os valores absolutos um padrão com fase ascendente, platô e fase descendente, relacionados com o crescimento corpóreo dos pacientes. Desta forma, para se averiguar o efeito da aplicação das técnicas de ioga na capacidade respiratória em pacientes com DMD, temos que levar em consideração, que os valores das provas de função pulmonar (CVF e VEF1) aumentam naturalmente para valores absolutos (em litros) até o período entre $11 \mathrm{e}$ 12 anos de idade e para a força expiratória (PEmax) até os 9 anos de idade (Carvalho, 2004).

No entanto, valores de CVF, VEF1 e PEmax, corrigidos em porcentagem do predito, apresentam uma diminuição constante dos resultados ao longo da idade a partir dos 5 anos (Tangsrud et al., 2001; Hahn et al., 1997; Carvalho, 2004). 
Por este motivo, todos os resultados positivos obtidos em porcentagem do predito, tem grande significado enquanto que para valores absolutos, somente consideramos positivo os aumento nos valores para os grupos de maior faixa etária (10 a 14 anos de idade).

\subsection{CVF e VEF1}

Os pacientes com distrofia muscular de Duchenne (DMD), que participaram do treinamento de ioga, apresentaram ao longo de 10 meses melhora em todas as avaliações dos testes de função pulmonar (CVF e VEF1), tanto para valores absolutos (em litros) como para os valores relativos (percentuais do predito), nos 3 grupos etários ( 6 a 14 anos, 6 a 9 anos e 10 a 14 anos) e nas 3 diferentes análises $(\mathrm{N}=39, \mathrm{~N}=70$ e $\mathrm{N}=18)$. Este aumento é verificado inclusive nos índices para os quais as referências previamente descritas apontam queda significativa nos valores (porcentagem do predito para CVF e VEF1), relacionada com a idade dos pacientes (Tangsrud et al., 2001; Carvalho, 2004/2006).

Griggs (1990) sugere que a CVF é um parâmetro da função pulmonar útil para monitorar a progressão da DMD, tendo a vantagem de ser preciso e reprodutível embora seja menos sensível para se detectar a fraqueza muscular do que PEmax. A obtenção adequada da CVF depende de um esforço inspiratório e expiratório, requerendo força muscular para se atingir os valores máximos. O que é compatível com os nossos resultados que apontam melhora da CVF e melhora da força expiratória (PEmax). 
$\mathrm{Na}$ análise dos valores com 70 pacientes, os resultados foram semelhantes aos da análise com 39 pacientes, inclusive nas significâncias, com exceção às tendências das curvas que determinaram os perfis dos pacientes em valores proporcionais ao predito de CVF e VEF1, onde se percebeu no $\mathrm{N}=39$ uma tendência de aproximação dos resultados das avaliações com o decorrer da idade e nas curvas de $\mathrm{N}=70$ uma tendência de melhora com o decorrer da idade (Figuras 16, 18, 28 e 30).

$\mathrm{Na}$ análise com 18 pacientes ao longo de 20 meses, os dados mostraram a triste realidade da DMD. Os valores absolutos e relativos de CVF e VEF1 dos pacientes que praticaram as técnicas de ioga e que apresentaram aumento de resultados nas avaliações ao longo de 15 meses, começaram a estabilizar seus índices de capacidade respiratória, muito embora a manutenção dos resultados para estes pacientes fosse positivo.

Todos os resultados obtidos neste trabalho para CVF foram muito semelhantes aos do VEF1, inclusive as significâncias. A manobra para a obtenção do VEF1 depende ainda mais da musculatura expiratória do que para a CVF (Carvalho, 2004), o que reforça a importância de termos iniciado nosso trabalho com as técnicas relacionadas com esta musculatura.

\subsection{PEmax}

Os resultados dos testes realizados no período de 10 meses de treinamento para a força expiratória máxima (PEmax), também apresentaram melhora para valores absolutos (litros) nos três grupos etários (6 a 14 anos, 6 a 9 anos e 10 a 14 
anos) e nas três diferentes análises $(\mathrm{N}=39, \mathrm{~N}=70$ e $\mathrm{N}=18)$. Para valores relativos (porcentagem do predito), verificamos melhora em todos os grupos etários nas análises com $\mathrm{N}=39$. Esta melhora para o grupo que participou do treinamento dos exercícios respiratórios de ioga, foi registrada para PEmax em valores absolutos (cmH2O) inclusive para os pacientes com mais de 9 anos, considerada por Carvalho (2004) como a idade de pico para este índice e também para valores relativos (porcentagem do predito) em que as referências apontam queda constante a partir dos 5 anos de idade (Carvalho, 2004/2006; Hahn A et al., 1997).

Os dados do grupo de 18 pacientes (avaliação ao longo de 20 meses) seguiram a mesma tendência dos resultados dos grupos de $\mathrm{N}=39$ e $\mathrm{N}=70$, evoluíram significativamente nas três primeiras avaliações, seguido de queda ou, manutenção dos resultados na avaliação 4 (20 meses de treinamento).

A análise dos resultados da PEmax com os três diferentes grupos $(\mathrm{N}=39$, $\mathrm{N}=70$ e $\mathrm{N}=18$ ) apresentou os melhores resultados da aplicação das técnicas respiratórias de ioga para os pacientes com DMD, principalmente quando se leva em consideração que a melhoria da força expiratória tem relação com a melhoria dos outros índices avaliados e que a força expiratória foi o índice de declínio mais precocemente apresentado em pacientes com DMD (Brooke et al., 1987; Hahn et al., 1997; Carvalho, 2004).

Observamos no grupo de 39 pacientes, aumento da PEmax em valores absolutos e relativos (Tabelas 5 e 6) na faixa etária de 10 a 14 anos, em que segundo as referência para estes pacientes, o declínio se mostrou bastante acentuado. $\mathrm{O}$ aumento maior para valores absolutos não contradisse o aumento menor nos valores relativos (Tabela 6), uma vez que houve redução da intensidade do declive, conforme apontou a comparação das linhas de perfis (Figuras 19 e 20). 
$\mathrm{Na}$ análise dos valores com 70 pacientes, os resultados foram semelhantes aos da análise com 39 pacientes, inclusive nas significâncias.

$\mathrm{Na}$ análise de PEmax em valores proporcionais ao predito com 18 pacientes, após 20 meses de treinamento, os resultados dos testes foram discretamente menores do que os valores iniciais, porém, com valores ainda bem superiores aos do declínio previsto pela doença.

\subsection{PImax}

Observamos que PImax não apresentou resultados significantes em nenhuma das análises verificadas neste trabalho. Os resultados variaram de acordo com o $\mathrm{N}$ e o grupo etário estudado, não demonstrando coerência nos resultados que nos permitisse qualquer conclusão.

Uma das possibilidades da PImax não ter alterado significativamente, pode ter sido a dificuldade das crianças em executar o movimento de sucção no aparelho.

Diversos estudos tem avaliado o efeito do treinamento muscular inspiratório e os efeitos observados foram controversos, mostrando não haver aumento (Stern et al., 1989) ou pequeno aumento não significativo (Smithet al., 1988).

As curvas de perfil estabelecidas nas análises com N=39 e $\mathrm{N}=70$, também demonstraram a evolução da capacidade respiratória destes pacientes por serem comparados os perfis do momento inicial do grupo com os perfis do mesmo grupo após 10 meses de treinamento (Figuras 15 a 20 e 27 a 32). 
Os exercícios de ioga comprovaram sua eficiência quando foram relacionados com o índice de adesão do paciente. Para os resultados de CVF, VEF1 e PEmax, em percentual do predito, os pacientes de nível 3 de adesão foram os que apresentaram maior evolução numérica nos resultados das avaliações respiratórias depois de 10 meses de treinamento, quando comparados com os pacientes de nível de adesão 1 . Lembrando que para valores proporcionais ao predito, para estes pacientes, manutenção de valores significou ganho.

Para a escolha das técnicas respiratórias de ioga, levamos em consideração que a evolução do comprometimento motor dos pacientes com DMD, evolui para o andar digitígrado, hiper-extensão da coluna vertebral, ante versão do quadril e escoliose grave (Giggs et al., 1981; Rideau et al., 1984) até atingir a perda da capacidade de deambulação, aproximadamente aos 10 anos de idade (Smith et al., 1981). Em consequência destas alterações, o paciente apresenta um abdome flácido com redução da força dos músculos expiratórios e conseqüente diminuição da força expiratória (PEmax) (Campbell e Green, 1953). Por este motivo, escolhemos para este trabalho, exercícios que atuam principalmente na musculatura expiratória forçada. O kapalabhati pela determinação do ritmo rápido de expiração e agnisara pela intensidade da contração da musculatura abdominal.

Outro aspecto importante para a escolha destes exercícios de ioga, foi o fato de poderem ser feitos sentados ou mesmo deitados, se necessário. Os exercícios não necessitaram de ajuda externa para sua execução, puderam ser feitos pelos pacientes com autonomia, sem necessidade de nenhum aparato, o único pré-requisito é não executá-los após as refeições, por causa do desconforto que podem ocasionar pelo envolvimento da região abdominal. 
O primeiro exercício a ser ensinado foi o kapalabhati. Por ser o primeiro, foi treinado por mais tempo (Figura 2). Na primeira avaliação depois de 5 meses de treinamento, observamos melhora com significância dos resultados para PEmax em valores absolutos (cm H20) para o grupo total nas análises com $\mathrm{N}=39$ e $\mathrm{N}=70$. Considerando-se que a primeira avaliação foi feita no período de 5 meses a partir da avaliação inicial e que na faixa etária superior a 9 anos o crescimento corpóreo não compensa o declínio da função pulmonar dos pacientes com DMD, provavelmente devido à perda da força muscular, (Brooke et al., 1987; Hahn et al., 1997; Carvalho, 2004) pudemos atribuir a este primeiro exercício (kapalabhati), uma ação de destaque na melhora dos resultados.

Contudo, tememos que com a evolução da doença, as crianças percam a motivação em realizar os exercícios respiratórios de ioga, pois tem em mente que "melhoria" signifique poder realizar movimentos de membros superiores e inferiores como as crianças normais e não reconheçam inicialmente a importância de se manter a condição respiratória como prevenção. Observamos que as crianças que se envolveram mais com a execução diária dos exercícios, foram as que melhoraram mais e as que tiveram os cuidadores mais próximos e atentos ao curso desta doença. Esperamos que para o futuro estes exercícios de comprovada eficiência e que não dependem de auxílio externo para sua execução, possam fazer parte da rotina destes pacientes, como contribuição para a melhoria da qualidade de vida destas crianças e para que suas dificuldades futuras possam ser amenizadas. 
- Os três exercícios respiratórias de ioga (kapalabhati, uddiyana e agnisara) foram aplicadas com sucesso em crianças com DMD.

- Notou-se melhora dos parâmetros de CVF e VEF1 nas três análises e particularmente no subgrupo dos pacientes de 10 a 14 anos, onde estes parâmetros mostram franco declínio em pacientes com DMD, como evolução natural da doença.

- Observou-se especial melhora da PEmax em valores absolutos e relativos, com destaque para a melhora do subgrupo de 10 a 14 anos.

- Sugere-se que os exercícios respiratórios de ioga propostos no projeto, com ênfase na técnica de kapalabhati, sejam incorporados à prática clínica destes pacientes com benefícios da função respiratória, retardando o seu declínio. 


\section{ANEXOS}




\section{Anexo I - Ficha de acompanhamento da prática individual}
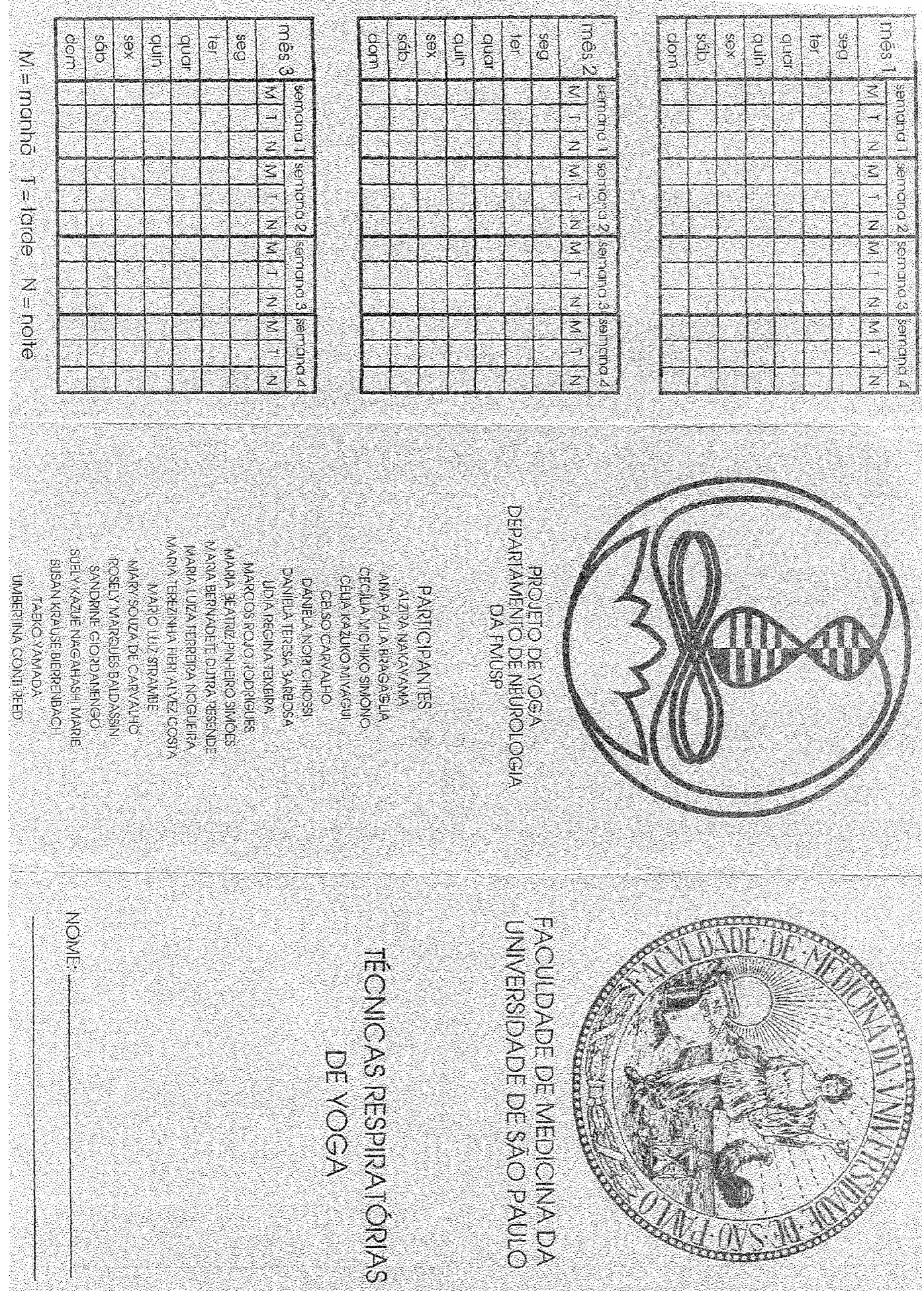

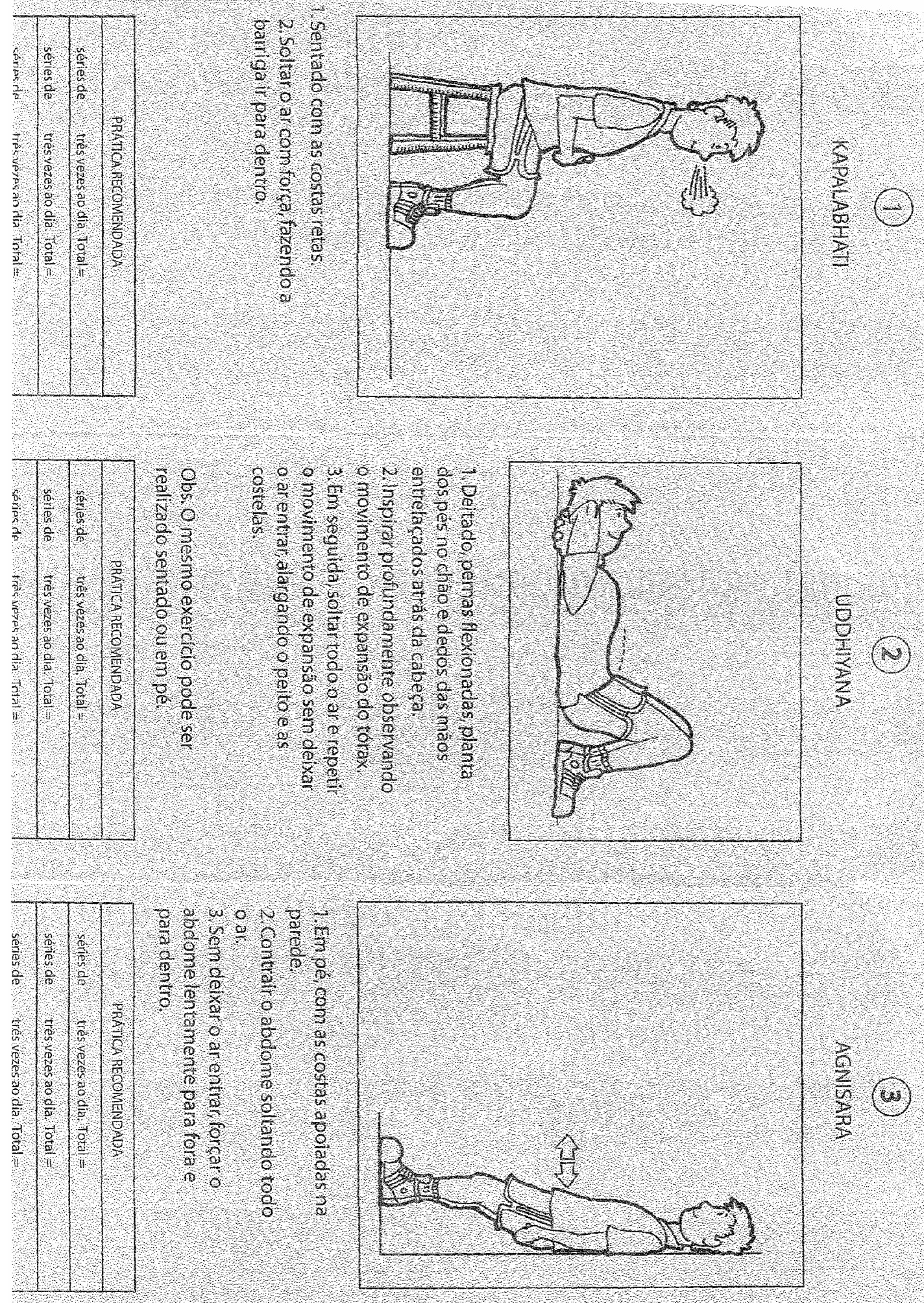

$\frac{3}{\frac{2}{5}}$

(w) 
Anexo II - Relação dos pacientes com o número dos registros no Hospital das

Clínicas, dados antropométricos, idade e índice de adesão ao projeto

\begin{tabular}{|c|c|c|c|c|c|c|c|}
\hline & Paciente & HC - RG & Peso & Estatura & $\begin{array}{c}\text { Idade } \\
\text { Início } \\
\text { no projeto }\end{array}$ & $\begin{array}{c}\text { Grupo } \\
\mathrm{N}=\end{array}$ & $\begin{array}{l}\text { *Indice } \\
\text { de } \\
\text { adesão }\end{array}$ \\
\hline 1 & $\mathrm{ACA}$ & 3295546-J & 31,9 & 121,0 & 8 & 18 & 3 \\
\hline 2 & $A L M$ & 3334901-A & 27,9 & 129,5 & 12 & 18 & 3 \\
\hline 3 & A L S & 2871613-E & 26,3 & 122,0 & 13 & 70 & 1 \\
\hline 4 & A M O & 13445981-C & 48,0 & 159,6 & 11 & 85 & \\
\hline 5 & A N V & $13436125-F$ & 30,0 & 157,9 & 11 & 70 & 1 \\
\hline 6 & $A O M$ & $13616165-C$ & 21,0 & 121,0 & 9 & 70 & 2 \\
\hline 7 & AOS & 3371103-K & 38,3 & 133,0 & 11 & 70 & 3 \\
\hline 8 & B F S J & 3338951-J & 19,0 & 112,0 & 6 & 85 & \\
\hline 9 & B S M & 13451274-A & 23,5 & 120,0 & 6 & 39 & 2 \\
\hline 10 & $C L C$ & 3355013-D & 28,0 & 136,0 & 9 & 85 & \\
\hline 11 & CMS & |-6091592 & 33,2 & 134,0 & 11 & 39 & 1 \\
\hline 12 & C S & 13481564-G & 49,5 & 136,0 & 12 & 85 & \\
\hline 13 & C S C & 3375221-E & 22,0 & 125,0 & 7 & 18 & 3 \\
\hline \#14 & D H M S & 13474658-D & 22,5 & 116,0 & 6 & 70 & 1 \\
\hline 15 & $\mathrm{DA} E \mathrm{~A}$ & 3276354-B & 38,0 & 133,0 & 11 & 18 & 3 \\
\hline 16 & D B O & 13482813-F & 37,8 & 126,0 & 8 & 39 & 1 \\
\hline 17 & D G E & 3276716-G & 27,0 & 120,0 & 8 & 18 & 2 \\
\hline 18 & D GP S & ו-13602245 & 135 & 120,0 & 7 & 70 & 3 \\
\hline 19 & $\mathrm{DH} \mathrm{T} T$ & I-3317075 & 22,5 & 116,0 & 11 & 39 & 2 \\
\hline 20 & D S S & 33278677-D & 26,5 & 120,0 & 12 & 70 & 2 \\
\hline 21 & E A Y & 3353249-B & 29,6 & 123,0 & 8 & 18 & 3 \\
\hline 22 & E C M & 13595372-C & 21,8 & 115,0 & 6 & 70 & 2 \\
\hline 23 & E S G & 13649593-B & 26,0 & 132,0 & 11 & 70 & 2 \\
\hline 24 & FAS & 3309346-A & 36,0 & 157,7 & 11 & 18 & 3 \\
\hline 25 & FHLS & 13443344-B & 39,0 & 123,0 & 9 & 70 & 1 \\
\hline 26 & FNP & 13446034-B & 27,5 & 127,0 & 9 & 18 & 1 \\
\hline 27 & FP P & 3320285-E & 40,0 & 150,0 & 12 & 70 & 1 \\
\hline 28 & FPSS & 13448000-E & 32,0 & 130,0 & 8 & 39 & 1 \\
\hline 29 & F S A & |-13451327 & 23,0 & 117,0 & 7 & 70 & 2 \\
\hline 30 & F Z T & 13452014-K & 22,5 & 124,0 & 7 & 39 & 1 \\
\hline 31 & G B C S & $13616162-F$ & 26,0 & 122,0 & 8 & 70 & 2 \\
\hline 32 & G G P & $3370122-K$ & 28,5 & 124,5 & 8 & 85 & \\
\hline 33 & G L N B & 3303321-IU & 22,0 & 125,0 & 7 & 70 & 1 \\
\hline 34 & G R S & $3230044-E$ & 29,7 & 133,0 & 7 & 85 & \\
\hline 35 & $G \vee R$ & 3349744-G & 41,3 & 132,0 & 9 & 39 & 2 \\
\hline 36 & G Y & 3296445-J & 26,5 & 122,0 & 9 & 39 & 2 \\
\hline 37 & HS M & $13499235-C$ & 28,0 & 132,0 & 10 & 18 & 3 \\
\hline 38 & I B Q & $13490606-\mathrm{G}$ & 22,5 & 118,0 & 6 & 18 & 2 \\
\hline 39 & I C B M B & 3227976-F & 54,3 & 149,0 & 12 & 85 & \\
\hline 40 & J B S & 6066810-E & 60,2 & 150,0 & 11 & 85 & \\
\hline 41 & J C T J & 13594143-B & 22,5 & 121,0 & 7 & 39 & 3 \\
\hline 42 & $\mathrm{JFN}$ & 13589518-D & 47,0 & 137,0 & 9 & 18 & 2 \\
\hline \#43 & JFS & 15596639-J & 25,0 & 121,0 & 8 & 39 & 1 \\
\hline 44 & J J O & 13590670-G & 16,0 & 110,0 & 8 & 70 & 1 \\
\hline 45 & $J L A F$ & $3357435-C$ & 23,0 & 120,0 & 7 & 18 & 3 \\
\hline
\end{tabular}


ANEXO II (...continuação)

\begin{tabular}{|c|c|c|c|c|c|c|c|}
\hline & Paciente & HC - RG & Peso & Estatura & $\begin{array}{c}\text { Idade } \\
\text { Início } \\
\text { no projeto }\end{array}$ & $\begin{array}{c}\text { Grupo } \\
\mathbf{N}=\end{array}$ & $\begin{array}{c}\text { *Indice } \\
\text { de } \\
\text { adesão }\end{array}$ \\
\hline 46 & $\mathrm{JLOJS}$ & 13604814-F & 33,0 & 122,0 & 9 & 70 & 2 \\
\hline \#47 & J P O & 13585094-B & 23,0 & 119,5 & 6 & 39 & 2 \\
\hline 48 & $\mathrm{JVCA}$ & 6066113-H & 24,0 & 116,0 & 6 & 39 & 3 \\
\hline 49 & J B S & 6066810-E & 28,0 & 126,0 & 8 & 85 & \\
\hline 50 & L A R M & 13588310-C & 31,0 & 141,0 & 11 & 70 & 2 \\
\hline 51 & L B F & 3360077-A & 34,0 & 138,0 & 8 & 39 & 1 \\
\hline 52 & L C N & $13452100-C$ & 29,0 & 125,0 & 11 & 70 & 2 \\
\hline 53 & L E M G C & $3341081-K$ & 24,0 & 113,7 & 14 & 39 & 1 \\
\hline 54 & LFM & 3207624-C & 27,5 & 127,0 & 8 & 85 & \\
\hline 55 & L H M & $3360677-\mathrm{J}$ & 28,0 & 134,0 & 9 & 85 & \\
\hline 56 & L M S & 3355317-J & 21,0 & 126,0 & 11 & 85 & \\
\hline 57 & LNS & 3000637-B & 72,0 & 165,0 & 13 & 85 & \\
\hline 58 & LR S & 13445304-D & 27,0 & 126,0 & 8 & 39 & 2 \\
\hline 59 & MCS & 13487695-E & 30,0 & 124,5 & 9 & 70 & 3 \\
\hline 60 & M F & 3372753-K & 22,9 & 124,0 & 6 & 70 & 2 \\
\hline 61 & MR S & 13440663-K & 31,0 & 141,0 & 13 & 18 & 2 \\
\hline 62 & M S R S & $882002164-G$ & 17,2 & 115,0 & 6 & 70 & 3 \\
\hline 63 & P C P & 13592994-H & 48,5 & 142,0 & 12 & 70 & 1 \\
\hline \#64 & $\mathrm{PHF}$ & 5165302-J & 43,8 & 156,0 & 11 & 39 & 3 \\
\hline 65 & R B A & 13441034-E & 26,8 & 149,7 & 9 & 18 & 3 \\
\hline 66 & R B C & 13670781-D & 29,3 & 131,0 & 9 & 70 & 2 \\
\hline 67 & R D M & 3335790-K & 20,0 & 114,0 & 10 & 18 & 2 \\
\hline 68 & RDS & 3321782-E & 26,0 & 137,0 & 12 & 70 & 1 \\
\hline 69 & RF S & $13469697-G$ & 22,5 & 118,0 & 10 & 70 & 3 \\
\hline 70 & $\mathrm{R} K \mathrm{~A}$ & 13486859-A & 38,0 & 134,0 & 10 & 70 & 2 \\
\hline 71 & $\mathrm{R} M$ & 44101501-A & 27,0 & 119,0 & 8 & 39 & 2 \\
\hline 72 & R M M S & 3351568-F & 28,2 & 150,0 & 12 & 85 & \\
\hline 73 & R S F & 3368834-J & 18,5 & 117,0 & 10 & 18 & 2 \\
\hline 74 & R S S & $136366853-A$ & 21,5 & 130,0 & 9 & 70 & 3 \\
\hline 75 & R SC & 3222121-F & 43,0 & 140,0 & 11 & 85 & \\
\hline 76 & TFN & $13435288-\mathrm{H}$ & 21,0 & 120,0 & 6 & 39 & 2 \\
\hline 77 & $T L J$ & 3342393-K & 20,0 & 126,0 & 9 & 39 & 2 \\
\hline 78 & $\mathrm{TSF}$ & 3205744-C & 37,0 & 150,0 & 12 & 70 & 1 \\
\hline 79 & VAN & $3264264-\mathrm{H}$ & 24,0 & 125,0 & 8 & 70 & 1 \\
\hline 80 & WAS & 3365940-K & 32,0 & 140,0 & 10 & 70 & 1 \\
\hline 81 & W B S & 3262281-D & 49,7 & 142,0 & 12 & 18 & 1 \\
\hline 82 & WF N & 3305788-B & 40,0 & 137,0 & 11 & 18 & 3 \\
\hline 83 & W S M & $13466054-F$ & 20,5 & 121,5 & 6 & 39 & 1 \\
\hline 84 & W S S & 13452216-A & 37,5 & 142,5 & 12 & 70 & 2 \\
\hline 85 & W S T T & 3317073-K & 42,4 & 153,0 & 14 & 39 & 2 \\
\hline
\end{tabular}

(*) Adesão: 1 - comprometimento insatisfatório com a prática diária.

2 - realização satisfatória do sugerido como prática diária.

3 - comprometimento total com a prática sugerida. 
Anexo III - Relação das datas de introdução dos exercícios.

\begin{tabular}{|c|c|c|c|c|c|}
\hline & PACIENTE & KAPALABHATI & UDDIYANA & AGNISARA & Idade \\
\hline 1 & $A C A$ & $20 / 05 / 03$ & $12 / 08 / 03$ & $4 / 11 / 03$ & 8 \\
\hline 2 & $A L M$ & $29 / 04 / 03$ & 07/10/03 & $27 / 01 / 04$ & 12 \\
\hline 3 & $A L S$ & $29 / 04 / 03$ & $08 / 07 / 03$ & $24 / 08 / 04$ & 13 \\
\hline 4 & A MO & 06/05/03 & $17 / 02 / 04$ & não fez & 11 \\
\hline 5 & A N V & $01 / 07 / 03$ & não fez & não fez & 9 \\
\hline 6 & $\mathrm{AOM}$ & $16 / 03 / 04$ & $20 / 04 / 04$ & $06 / 07 / 04$ & 7 \\
\hline 7 & AOS & 10/06/03 & $15 / 07 / 03$ & $02 / 03 / 04$ & 11 \\
\hline 8 & B F S J & $12 / 08 / 03$ & 04/11/03 & $27 / 09 / 05$ & 6 \\
\hline 9 & B S M & $13 / 05 / 03$ & $19 / 08 / 03$ & $16 / 03 / 04$ & 7 \\
\hline 10 & C L C & $20 / 05 / 03$ & 18/1103 & $17 / 02 / 04$ & 9 \\
\hline 11 & CMS & $23 / 03 / 04$ & 29/06/04 & $24 / 08 / 04$ & 13 \\
\hline 12 & C S & 24/06/03 & não fez & não fez & 12 \\
\hline 13 & C S C & 19/08/03 & $17 / 02 / 04$ & 28/09/04 & 7 \\
\hline 14 & CSN & $30 / 03 / 04$ & não fez & não fez & 11 \\
\hline 15 & $D A A$ & 01/07/03 & 05/08/03 & 03/02/04 & 11 \\
\hline 16 & D B O & 06/05/03 & $30 / 09 / 03$ & não fez & 11 \\
\hline 17 & D G E & 08/04/03 & 06/10/03 & $27 / 01 / 04$ & 8 \\
\hline 18 & D GPS & $20 / 01 / 04$ & $02 / 03 / 04$ & $20 / 07 / 04$ & 7 \\
\hline 19 & $\mathrm{DH} \mathrm{T} T$ & $29 / 04 / 03$ & $04 / 11 / 03$ & $10 / 02 / 04$ & 6 \\
\hline 20 & D S S & $29 / 04 / 03$ & 01/07/03 & $11 / 11 / 03$ & 8 \\
\hline 21 & E A Y & $15 / 07 / 03$ & $27 / 01 / 04$ & $20 / 07 / 04$ & 8 \\
\hline 22 & E C M & $21 / 10 / 03$ & $13 / 04 / 04$ & $25 / 10 / 05$ & 6 \\
\hline 23 & E S G & 03/07/04 & $23 / 11 / 04$ & $23 / 11 / 04$ & 11 \\
\hline 24 & FAS & 08/07/03 & $13 / 10 / 03$ & $20 / 11 / 04$ & 11 \\
\hline 25 & FHLS & $27 / 05 / 03$ & $09 / 12 / 03$ & não fez & 9 \\
\hline 26 & F N P & $15 / 04 / 03$ & $13 / 05 / 03$ & 03/06/03 & 9 \\
\hline 27 & F P P & 09/08/03 & não fez & não fez & 12 \\
\hline 28 & FPSS & 06/05/03 & $25 / 11 / 03$ & não fez & 8 \\
\hline 29 & F S A & 08/04/03 & 07/10/03 & $20 / 07 / 04$ & 7 \\
\hline 30 & F Z T & $20 / 05 / 03$ & $22 / 07 / 03$ & não fez & 7 \\
\hline 31 & G B C S & $15 / 06 / 04$ & $04 / 04 / 06$ & $12 / 09 / 06$ & 8 \\
\hline 32 & G G P & $29 / 04 / 03$ & não fez & não fez & 8 \\
\hline 33 & GIL N B & $22 / 04 / 03$ & $24 / 06 / 03$ & $21 / 09 / 04$ & 7 \\
\hline 34 & G R S & $31 / 08 / 04$ & $31 / 08 / 04$ & não fez & 7 \\
\hline 35 & $G \vee R$ & 29/07/03 & 09/12/03 & $13 / 07 / 04$ & 9 \\
\hline 36 & G Y & 08/04/03 & 29/04/03 & 01/07/03 & 9 \\
\hline 37 & HS M & 23/09/03 & $21 / 10 / 03$ & $25 / 11 / 03$ & 10 \\
\hline 38 & I B Q & 10/06/03 & $13 / 01 / 04$ & $13 / 01 / 04$ & 6 \\
\hline 39 & I C B M B & 06/05/03 & não fez & não fez & 12 \\
\hline 40 & J B S & 19/07/05 & 04/10/05 & 04/10/05 & 11 \\
\hline 41 & $\mathrm{JCT}$ & $02 / 12 / 03$ & $02 / 12 / 03$ & $02 / 12 / 03$ & 7 \\
\hline 42 & $\mathrm{~J} F \mathrm{~N}$ & $21 / 10 / 03$ & $27 / 01 / 04$ & $25 / 05 / 04$ & 9 \\
\hline 43 & $\mathrm{JFS}$ & 02/09/03 & 08/03/05 & não fez & 8 \\
\hline 44 & J JO & $11 / 11 / 03$ & $20 / 01 / 04$ & $27 / 04 / 04$ & 8 \\
\hline 45 & $\mathrm{JL} A F$ & 03/06/03 & $02 / 12 / 03$ & $16 / 03 / 04$ & 7 \\
\hline 46 & $\mathrm{~J} \mathrm{LOJ} \mathrm{S}$ & 29/04/03 & $13 / 05 / 03$ & $02 / 12 / 03$ & 9 \\
\hline 47 & J P O & 08/07/03 & $30 / 09 / 03$ & $02 / 03 / 04$ & 6 \\
\hline 48 & $\mathrm{~J} \vee C A$ & $22 / 04 / 03$ & $06 / 04 / 04$ & $06 / 04 / 04$ & 6 \\
\hline
\end{tabular}


ANEXO III (...continuação)

\begin{tabular}{llrrrr}
\hline & PACIENTE & KAPALABHATI & UDDIYANA & AGNISARA & Idade \\
\hline $\mathbf{4 9}$ & J W A C & $14 / 09 / 04$ & $14 / 09 / 04$ & $09 / 11 / 04$ & 8 \\
$\mathbf{5 0}$ & L A R M & $17 / 06 / 03$ & $22 / 07 / 03$ & $02 / 09 / 03$ & 13 \\
$\mathbf{5 1}$ & L B F & $27 / 05 / 03$ & $19 / 08 / 03$ & $28 / 09 / 04$ & 11 \\
$\mathbf{5 2}$ & L C N & $22 / 04 / 03$ & $27 / 05 / 03$ & $17 / 02 / 04$ & 8 \\
$\mathbf{5 3}$ & L E M G C & $10 / 06 / 03$ & $22 / 07 / 03$ & $31 / 08 / 04$ & 6 \\
$\mathbf{5 4}$ & L F M & $17 / 06 / 03$ & $02 / 09 / 03$ & $21 / 09 / 04$ & 8 \\
$\mathbf{5 5}$ & L H M & $13 / 05 / 03$ & $20 / 05 / 03$ & não fez & 9 \\
$\mathbf{5 6}$ & L M S & $10 / 06 / 03$ & $11 / 11 / 03$ & não fez & 11 \\
$\mathbf{5 7}$ & L N S & $22 / 06 / 04$ & $22 / 06 / 04$ & não fez & 14 \\
$\mathbf{5 8}$ & L R S & $22 / 04 / 03$ & $21 / 10 / 03$ & $11 / 09 / 04$ & 9 \\
$\mathbf{5 9}$ & M C S & $03 / 06 / 03$ & $05 / 08 / 03$ & $09 / 08 / 03$ & 8 \\
$\mathbf{6 0}$ & M F & $20 / 05 / 03$ & $22 / 07 / 03$ & $20 / 04 / 04$ & 8 \\
$\mathbf{6 1}$ & M R S & $06 / 05 / 03$ & $09 / 09 / 03$ & $08 / 11 / 03$ & 6 \\
$\mathbf{6 2}$ & P B R & $22 / 07 / 03$ & $02 / 12 / 03$ & $27 / 01 / 04$ & 12 \\
$\mathbf{6 3}$ & P C P & $22 / 01 / 04$ & $13 / 04 / 04$ & $01 / 06 / 04$ & 11 \\
$\mathbf{6 4}$ & P H F & $08 / 07 / 03$ & $30 / 03 / 04$ & $10 / 08 / 04$ & 13 \\
$\mathbf{6 5}$ & R B A & $13 / 05 / 03$ & $12 / 08 / 03$ & $09 / 12 / 03$ & 9 \\
$\mathbf{6 6}$ & R B C & $19 / 04 / 05$ & $20 / 09 / 05$ & $13 / 12 / 05$ & 9 \\
$\mathbf{6 7}$ & R D M & $24 / 06 / 03$ & $29 / 07 / 03$ & $26 / 08 / 03$ & 10 \\
$\mathbf{6 8}$ & R D S & $29 / 07 / 03$ & $27 / 01 / 04$ & $09 / 03 / 04$ & 12 \\
$\mathbf{6 9}$ & R F S & $30 / 09 / 03$ & $02 / 12 / 03$ & $27 / 01 / 04$ & 10 \\
$\mathbf{7 0}$ & R K A & $12 / 08 / 03$ & $21 / 10 / 03$ & $25 / 05 / 04$ & 10 \\
$\mathbf{7 1}$ & R M & $06 / 05 / 03$ & $20 / 05 / 03$ & $26 / 08 / 03$ & 8 \\
$\mathbf{7 2}$ & R M M S & $06 / 04 / 04$ & não fez & não fez & 12 \\
$\mathbf{7 3}$ & R S F & $15 / 04 / 03$ & $29 / 04 / 03$ & $24 / 06 / 03$ & 10 \\
$\mathbf{7 4}$ & R S S & $05 / 10 / 04$ & $30 / 11 / 04$ & $26 / 04 / 05$ & 9 \\
$\mathbf{7 5}$ & R SC & $16 / 12 / 03$ & $30 / 08 / 05$ & não fez & 11 \\
$\mathbf{7 6}$ & T F N & $22 / 04 / 03$ & $18 / 11 / 03$ & $03 / 02 / 04$ & 6 \\
$\mathbf{7 7}$ & T L J & $24 / 06 / 03$ & $16 / 12 / 03$ & $14 / 09 / 04$ & 9 \\
$\mathbf{7 8}$ & T S F & $29 / 04 / 03$ & não fez & não fez & 12 \\
$\mathbf{7 9}$ & V A N & $29 / 04 / 03$ & $27 / 05 / 03$ & $09 / 12 / 03$ & 8 \\
$\mathbf{8 0}$ & W A S & $24 / 06 / 03$ & $09 / 12 / 03$ & não fez & 10 \\
$\mathbf{8 1}$ & W B S & $29 / 07 / 03$ & $04 / 11 / 03$ & $20 / 01 / 04$ & 12 \\
$\mathbf{8 2}$ & W F M & $29 / 07 / 03$ & $07 / 10 / 03$ & $19 / 10 / 04$ & 11 \\
$\mathbf{8 3}$ & W S M & $24 / 06 / 03$ & $14 / 10 / 03$ & $09 / 03 / 04$ & 6 \\
$\mathbf{8 4}$ & W S S & $03 / 06 / 03$ & $08 / 06 / 04$ & $08 / 06 / 04$ & 12 \\
$\mathbf{8 5}$ & W S T T & $29 / 04 / 03$ & $04 / 11 / 03$ & $10 / 02 / 04$ & 14 \\
\hline & & & & &
\end{tabular}


Anexo IV - Resultados das avaliações da capacidade vital forçada

\begin{tabular}{|c|c|c|c|c|c|}
\hline & CVF 0 & CVF 1 & CVF 2 & CVF 3 & CVF 4 \\
\hline 1 & 1,7 & 1,8 & 1,8 & 1,8 & 1,8 \\
\hline 2 & 2,1 & 2,0 & 2,2 & 2,2 & 2,2 \\
\hline 3 & 1,3 & & 1,5 & & \\
\hline 4 & 1,5 & & & & \\
\hline 5 & 1,1 & & 0,9 & & \\
\hline 6 & 1,4 & 1,6 & & & \\
\hline 7 & 1,7 & 1,6 & & 1,8 & 1,7 \\
\hline 8 & 2,0 & 2,2 & & 2,0 & \\
\hline 9 & 1,0 & 1,1 & 1,3 & & 1,2 \\
\hline 10 & 1,3 & & & & \\
\hline 11 & 2,3 & 2,3 & 2,4 & & \\
\hline 12 & 1,6 & & & & \\
\hline 13 & 1,1 & 1,2 & 1,6 & 1,5 & 1,5 \\
\hline 14 & 1,1 & 1,2 & & & \\
\hline 15 & 2,0 & 2,1 & 2,0 & 2,0 & 2,0 \\
\hline 16 & 1,5 & 1,7 & 1,7 & & 1,7 \\
\hline 17 & 1,7 & 1,8 & 1,9 & 2,0 & 1,7 \\
\hline 18 & 1,1 & 1,2 & & & \\
\hline 19 & 1,8 & 2,0 & 1,6 & 1,8 & \\
\hline 20 & 2,3 & 2,1 & & 2,4 & \\
\hline 21 & 1,3 & 1,5 & 1,7 & 1,7 & 1,7 \\
\hline 22 & 1,2 & & 1,3 & & \\
\hline 23 & 1,6 & 1,6 & & & \\
\hline 24 & 2,4 & 2,4 & 2,3 & 2,4 & 2,5 \\
\hline 25 & 1,0 & 1,6 & & & \\
\hline 26 & 1,8 & 1,9 & 1,9 & 2,0 & 2,1 \\
\hline 27 & 1,7 & 1,6 & & & \\
\hline 28 & 1,3 & 1,5 & 1,3 & & \\
\hline 29 & 1,6 & & 1,6 & 1,7 & 1,8 \\
\hline 30 & 1,4 & 1,7 & 1,7 & 1,6 & \\
\hline 31 & 1,4 & & 1,4 & & \\
\hline 32 & 1,5 & & & & \\
\hline 33 & 1,5 & 1,6 & & 1,9 & \\
\hline 34 & 0,9 & & & & \\
\hline 35 & 1,5 & 1,9 & 2,2 & & \\
\hline 36 & 1,8 & 1,8 & 2,2 & 2,0 & \\
\hline 37 & 1,9 & 2,1 & 2,1 & 2,2 & 2,3 \\
\hline 38 & 1,4 & 1,4 & 1,7 & 1,8 & 1,8 \\
\hline 39 & 2,2 & & & & \\
\hline 40 & 1,8 & & & & \\
\hline 41 & 1,3 & 1,6 & 1,9 & 1,7 & \\
\hline 42 & 2,1 & 2,0 & 2,2 & 2,1 & 2,2 \\
\hline 43 & 1,1 & 1,6 & 1,2 & & \\
\hline 44 & 1,7 & & 1,1 & & \\
\hline 45 & 1,5 & 1,5 & 1,4 & 1,4 & 1,5 \\
\hline 46 & 1,7 & 1,8 & & & \\
\hline 47 & 1,4 & 1,6 & 1,8 & & \\
\hline 48 & 0,9 & 1,1 & 1,1 & 1,1 & \\
\hline
\end{tabular}


ANEXO IV (...continuação)

\begin{tabular}{|c|c|c|c|c|c|}
\hline & CVF 0 & CVF 1 & CVF 2 & CVF 3 & CVF 4 \\
\hline 49 & 1,4 & & & & \\
\hline 50 & 2,2 & & 1,9 & & \\
\hline 51 & 1,9 & 1,9 & 1,7 & 1,8 & \\
\hline 52 & 2,3 & 2,0 & & 2,2 & 2,2 \\
\hline 53 & 2,7 & 2,1 & 3,0 & 3,3 & \\
\hline 54 & 1,7 & & & & \\
\hline 55 & 1,4 & & & & \\
\hline 56 & 3,1 & & & & \\
\hline 57 & 0,8 & & & & \\
\hline 58 & 1,4 & 1,4 & 1,6 & & \\
\hline 59 & 1,5 & & 1,6 & 1,8 & \\
\hline 60 & 1,2 & 1,3 & & & \\
\hline 61 & 1,9 & 2,1 & 2,8 & 2,9 & 2,8 \\
\hline 62 & 1,2 & 1,3 & & & \\
\hline 63 & 1,1 & 1,6 & & 1,5 & \\
\hline 64 & 2,2 & 2,6 & 2,5 & & \\
\hline 65 & 1,2 & 1,4 & 1,5 & 1,5 & 1,4 \\
\hline 66 & 1,9 & 2,0 & & & \\
\hline 67 & 1,2 & 1,1 & 1,2 & 1,3 & 1,1 \\
\hline 68 & 1,7 & 2,1 & & & \\
\hline 69 & 1,2 & 1,2 & & 1,4 & 1,4 \\
\hline 70 & 1,3 & 1,5 & & & 1,5 \\
\hline 71 & 1,1 & 1,1 & 1,2 & 1,4 & \\
\hline 72 & 1,5 & & & & \\
\hline 73 & 1,4 & 1,6 & 1,4 & 1,5 & 1,3 \\
\hline 74 & 1,6 & 1,8 & & & \\
\hline 75 & 1,3 & & & & \\
\hline 76 & 1,5 & 1,4 & 1,6 & & \\
\hline 77 & 2,1 & 2,0 & 2,2 & & 2,2 \\
\hline 78 & 1,2 & 1,2 & & & \\
\hline 79 & 1,4 & 1,6 & & & \\
\hline 80 & 2,2 & 2,0 & & & \\
\hline 81 & 2,1 & 2,6 & 2,8 & 3,0 & 2,9 \\
\hline 82 & 2,1 & 2,0 & 1,8 & 1,8 & 1,9 \\
\hline 83 & 1,4 & 1,5 & 1,5 & 1,8 & \\
\hline 84 & 1,7 & 1,6 & & & \\
\hline 85 & 1,6 & 1,6 & 1,2 & 0,8 & \\
\hline$X$ & 1,6 & 1,7 & 1,7 & 1,8 & 1,8 \\
\hline DP & 0,4 & 0,4 & 0,5 & 0,5 & 0,5 \\
\hline EP & 0,0 & 0,0 & 0,1 & 0,1 & 0,1 \\
\hline $\mathbf{N}$ & 85 & 60 & 49 & 40 & 28 \\
\hline
\end{tabular}


Anexo V - Resultados das avaliações da capacidade vital forçada em porcentagem do predito

\begin{tabular}{|c|c|c|c|c|c|}
\hline & CVF 0\% & CVF 1\% & CVF 2\% & CVF 3\% & CVF 4\% \\
\hline 1 & 98,7 & 102,4 & 101,7 & 100,7 & 101,4 \\
\hline 2 & 110,3 & 100,5 & 120,9 & 116,9 & 102,7 \\
\hline 3 & 77,3 & & 85,1 & & \\
\hline 4 & 86,1 & & & & \\
\hline 5 & 32,6 & & 34,3 & & \\
\hline 6 & 54,5 & & & & \\
\hline 7 & 82,3 & 75 & & 86,1 & 75,9 \\
\hline 8 & 93,8 & 110,7 & & 93,7 & \\
\hline 9 & 60,1 & 67,4 & 77,1 & & 70,4 \\
\hline 10 & 61,6 & & & & \\
\hline 11 & 107,9 & 99,9 & 102,9 & & \\
\hline 12 & 85,4 & & & & \\
\hline 13 & 66,4 & 70,9 & 89,9 & 84,9 & 78,1 \\
\hline 14 & 67,5 & 68,5 & & & \\
\hline 15 & 95,7 & 97,7 & 101,9 & 99,2 & 96,2 \\
\hline 16 & 89,9 & 98,8 & 92,7 & & 93,2 \\
\hline 17 & 102 & 104 & 107,7 & 108,8 & 95,6 \\
\hline 18 & 67,5 & 68,5 & & & \\
\hline 19 & 97,3 & 109,4 & 86,7 & 91,9 & \\
\hline 20 & 104,3 & 80,8 & & 106,4 & \\
\hline 21 & 75,2 & 84,6 & 95,6 & 90,4 & 90,3 \\
\hline 22 & 72,2 & & 73,4 & & \\
\hline 23 & 81 & 77,5 & & & \\
\hline 24 & 71,9 & 72,4 & 81,4 & 81,7 & 71,8 \\
\hline 25 & 56,4 & 86,9 & & & \\
\hline 26 & 97,8 & 95,2 & 95,7 & 95,7 & 100,1 \\
\hline 27 & 60 & 57,6 & & & \\
\hline 28 & 66,7 & 79,7 & 60 & & \\
\hline 29 & 97,2 & & 96,4 & 98,6 & 99,2 \\
\hline 30 & 78,9 & 96,4 & 90 & 88,4 & \\
\hline 31 & 78,2 & & 77,6 & & \\
\hline 32 & 84 & & & & \\
\hline 33 & 82,3 & 80,7 & & 85,3 & \\
\hline 34 & 41,5 & & & & \\
\hline 35 & 75,3 & 89,8 & 107,6 & & \\
\hline 36 & 104,3 & 101,8 & 119,9 & 112,1 & \\
\hline 37 & 95,3 & 97,6 & 96 & 101,2 & 108,6 \\
\hline 38 & 82,8 & 81,7 & 94,8 & 99,5 & 99,5 \\
\hline 39 & 78,9 & & & & \\
\hline 40 & 64 & & & & \\
\hline 41 & 72,7 & 92,3 & 102,1 & 96,3 & \\
\hline 42 & 95 & 87,2 & 94,5 & 86,3 & 90,8 \\
\hline 43 & 62 & 90,1 & 65,9 & & \\
\hline 44 & 107,6 & & 72,5 & & \\
\hline 45 & 86,2 & 85,8 & 79,8 & 83,6 & 88,2 \\
\hline 46 & 99,7 & 100,9 & & & \\
\hline 47 & 81,7 & 91 & 99,7 & & \\
\hline
\end{tabular}


ANEXO V (...continuação)

\begin{tabular}{|c|c|c|c|c|c|}
\hline & CVF 0\% & CVF 1\% & CVF 2\% & CVF 3\% & CVF $4 \%$ \\
\hline 48 & 57,7 & 66,8 & 69,1 & 65,1 & \\
\hline 49 & 76,7 & & & & \\
\hline 50 & 120,2 & & 97,4 & & \\
\hline 51 & 103,2 & 98,2 & 87,8 & 87,9 & \\
\hline 52 & 99,8 & 89,1 & & 94,8 & 88,7 \\
\hline 53 & 69,2 & 72,4 & 85,5 & 85,8 & \\
\hline 54 & 92,9 & & & & \\
\hline 55 & 80,2 & & & & \\
\hline 56 & 95,1 & & & & \\
\hline 57 & 47,3 & & & & \\
\hline 58 & 73,7 & 76,2 & 82,4 & & \\
\hline 59 & 71,9 & & 68,2 & 67,8 & \\
\hline 60 & 72,7 & 78 & & & \\
\hline 61 & 79,8 & 82,8 & 87,4 & 100,1 & 97,8 \\
\hline 62 & 72,7 & 78,0 & & & \\
\hline 63 & 60,2 & 87,2 & & 79,6 & \\
\hline 64 & 92,2 & 96,9 & 94,2 & & \\
\hline 65 & 43,5 & 67,6 & 72,1 & 77,3 & 68,8 \\
\hline 66 & 93,2 & 97 & & & \\
\hline 67 & 75,9 & 70,6 & 74,3 & 71,9 & 64,9 \\
\hline 68 & 78,5 & 95,8 & & & \\
\hline 69 & 71,2 & 69,1 & & 83,2 & 79,3 \\
\hline 70 & 61,9 & 72,7 & & & 57,2 \\
\hline 71 & 64,1 & 67 & 71,8 & 82 & \\
\hline 72 & 52,3 & & & & \\
\hline 73 & 82,6 & 92,1 & 150,8 & 86,1 & 62,6 \\
\hline 74 & 83,4 & 88,7 & & & \\
\hline 75 & 54,5 & & & & \\
\hline 76 & 87 & 74,2 & 83,9 & & \\
\hline 77 & 115,6 & 110 & 118,8 & & 114,1 \\
\hline 78 & 42,4 & 40,2 & & & \\
\hline 79 & 76,4 & 76,3 & & & \\
\hline 80 & 93,2 & 83,4 & & & \\
\hline 81 & 85 & 84,6 & 90,1 & 63,7 & 76,3 \\
\hline 82 & 93,3 & 82,5 & 60,9 & 64,5 & 69,1 \\
\hline 83 & 81,8 & 87,6 & 87,3 & 94 & \\
\hline 84 & 70,9 & 64,1 & & & \\
\hline 85 & 53,6 & 51,6 & 43,6 & 25,2 & \\
\hline$X$ & 79,3 & 84,3 & 87,9 & 87,1 & 86,2 \\
\hline DP & 18,0 & 14,6 & 19,6 & 16,2 & 15,0 \\
\hline EP & 1,9 & 1,9 & 2,8 & 2,6 & 2,8 \\
\hline $\mathbf{N}$ & 85 & 60 & 49 & 40 & 28 \\
\hline
\end{tabular}


Anexo VI - Resultados das avaliações do volume expiratório forçado no $1^{\circ}$ minuto

\begin{tabular}{|c|c|c|c|c|c|}
\hline & VEF1 O & VEF1 1 & VEF1 2 & VEF1 3 & VEF1 4 \\
\hline 1 & 1,5 & 1,6 & 1,5 & 1,5 & 1,5 \\
\hline 2 & 1,9 & 1,8 & 2,0 & 2,0 & 2,1 \\
\hline 3 & 1,1 & & 1,4 & & \\
\hline 4 & 0,8 & & & & \\
\hline 5 & 1,0 & & 0,8 & & \\
\hline 6 & 1,2 & 1,5 & & & \\
\hline 7 & 1,5 & 1,4 & & 1,5 & 1,6 \\
\hline 8 & 1,8 & 2,1 & & 1,9 & \\
\hline 9 & 0,9 & 0,9 & 1,1 & & 1,0 \\
\hline 10 & 1,0 & & & & \\
\hline 11 & 2,1 & 1,9 & 2,0 & & \\
\hline 12 & 1,5 & & & & \\
\hline 13 & 1,1 & 1,2 & 1,5 & 1,3 & 1,3 \\
\hline 14 & 1,0 & 1,3 & & & \\
\hline 15 & 1,8 & 1,8 & 1,8 & 1,8 & 1,8 \\
\hline 16 & 1,4 & 1,5 & 1,5 & & 1,4 \\
\hline 17 & 1,7 & 1,8 & 1,8 & 1,9 & 1,6 \\
\hline 18 & 1,1 & 1,0 & & & \\
\hline 19 & 1,6 & 1,7 & 1,4 & 1,7 & \\
\hline 20 & 2,0 & 2,0 & & 2,2 & \\
\hline 21 & 1,3 & 1,5 & 1,6 & 1,5 & 1,5 \\
\hline 22 & 0,8 & & 1,1 & & \\
\hline 23 & 1,6 & 1,5 & & & \\
\hline 24 & 2,2 & 2,2 & 2,1 & 2,4 & 2,3 \\
\hline 25 & 0,9 & 1,4 & & & \\
\hline 26 & 1,4 & 1,6 & 1,6 & 1,7 & 1,8 \\
\hline 27 & 1,6 & 1,5 & & & \\
\hline 28 & 1,2 & 1,2 & 1,2 & & \\
\hline 29 & 1,5 & & 1,6 & 1,7 & 1,8 \\
\hline 30 & 1,4 & 1,6 & 1,5 & 1,5 & \\
\hline 31 & 1,3 & & 1,3 & & \\
\hline 32 & 1,5 & & & & \\
\hline 33 & 1,1 & 1,6 & & 1,6 & \\
\hline 34 & 0,8 & & & & \\
\hline 35 & 1,3 & 1,8 & 1,9 & & \\
\hline 36 & 1,7 & 1,6 & 1,9 & 1,8 & \\
\hline 37 & 1,7 & 1,8 & 1,9 & 1,9 & 2,0 \\
\hline 38 & 1,3 & 1,2 & 1,5 & 1,5 & 1,6 \\
\hline 39 & 2,0 & & & & \\
\hline 40 & 1,7 & & & & \\
\hline 41 & 1,2 & 1,3 & 1,5 & 1,5 & \\
\hline 42 & 1,9 & 1,9 & 1,9 & 2,0 & 1,9 \\
\hline 43 & 1,0 & 1,2 & 1,1 & & \\
\hline 44 & 1,6 & & 1,1 & & \\
\hline 45 & 1,1 & 1,1 & 1,3 & 1,3 & 1,2 \\
\hline 46 & 1,4 & 1,3 & & & \\
\hline 47 & 1,4 & 1,2 & 1,6 & & \\
\hline
\end{tabular}


ANEXO VI (...continuação)

\begin{tabular}{|c|c|c|c|c|c|}
\hline & VEF1 O & VEF1 1 & VEF1 2 & VEF1 3 & VEF1 4 \\
\hline 48 & 0,8 & 1,1 & 1,0 & & \\
\hline 49 & 1,3 & & & & \\
\hline 50 & 1,8 & & 1,5 & & \\
\hline 51 & 1,7 & 1,8 & 1,6 & 1,6 & \\
\hline 52 & 1,8 & 1,8 & & 1,8 & 1,9 \\
\hline 53 & 2,4 & 2,0 & 2,7 & 3,1 & \\
\hline 54 & 1,4 & & & & \\
\hline 55 & 1,4 & & & & \\
\hline 56 & 3,0 & & & & \\
\hline 57 & 0,7 & & & & \\
\hline 58 & 1,3 & 1,1 & 1,5 & & \\
\hline 59 & 1,1 & & 1,5 & 1,7 & \\
\hline 60 & 1,1 & 1,1 & & & \\
\hline 61 & 1,9 & 2,0 & 2,5 & 2,6 & 2,7 \\
\hline 62 & 1,1 & 1,1 & & & \\
\hline 63 & 1,0 & 1,2 & & 1,2 & \\
\hline 64 & 1,8 & 2,0 & 2,1 & & \\
\hline 65 & 1,2 & 1,2 & 1,3 & 1,4 & 1,3 \\
\hline 66 & 1,7 & 1,8 & & & \\
\hline 67 & 1,1 & 1,1 & 1,1 & 1,2 & 1,1 \\
\hline 68 & 1,7 & 1,9 & & & \\
\hline 69 & 1,1 & 1,0 & & 1,2 & 1,2 \\
\hline 70 & 1,1 & 1,3 & & & 1,3 \\
\hline 71 & 0,9 & 1,0 & 1,1 & 1,3 & \\
\hline 72 & 1,3 & & & & \\
\hline 73 & 1,3 & 1,3 & 0,9 & 1,4 & 1,2 \\
\hline 74 & 1,5 & 1,7 & & & \\
\hline 75 & 1,2 & & & & \\
\hline 76 & 1,2 & 1,3 & 1,6 & & \\
\hline 77 & 1,6 & 1,8 & 2,0 & & 2,0 \\
\hline 78 & 1,2 & 1,2 & & & \\
\hline 79 & 1,2 & 1,4 & & & \\
\hline 80 & 1,9 & 1,9 & & & \\
\hline 81 & 2,0 & 2,2 & 2,3 & 2,4 & 2,4 \\
\hline 82 & 1,8 & 1,8 & 1,6 & 1,6 & 1,7 \\
\hline 83 & 1,4 & 1,3 & 1,2 & 1,3 & \\
\hline 84 & 1,6 & 1,4 & & & \\
\hline 85 & 1,3 & 1,4 & 1,0 & 0,7 & \\
\hline $\mathrm{X}$ & 1,4 & 1,5 & 1,5 & 1,6 & 1,6 \\
\hline DP & 0,4 & 0,3 & 0,4 & 0,5 & 0,4 \\
\hline EP & 0,0 & 0,0 & 0,1 & 0,1 & 0,1 \\
\hline $\mathbf{N}$ & 85 & 60 & 49 & 40 & 28 \\
\hline
\end{tabular}


Anexo VII- Resultados das avaliações do volume expiratório forçado no $1^{\circ}$ minuto em porcentagem do predito

\begin{tabular}{|c|c|c|c|c|c|}
\hline & FEV1 0\% & FEV1 1\% & FEV1 2\% & FEV1 3\% & FEV1 4\% \\
\hline 1 & 98,2 & 100,5 & 95,7 & 98,5 & 95,4 \\
\hline 2 & 111,9 & 106,3 & 123,8 & 122,9 & 111,4 \\
\hline 3 & 72,3 & & 87,9 & & \\
\hline 4 & 54,9 & & & & \\
\hline 5 & 32,0 & & 35,7 & & \\
\hline 6 & 79,0 & & & & \\
\hline 7 & 84,9 & 72,8 & & 79,8 & 81 \\
\hline 8 & 99.0 & 119,6 & & 101.3 & \\
\hline 9 & 64,3 & 63,4 & 75,7 & & 65,7 \\
\hline 10 & 53,1 & & & & \\
\hline 11 & 109,6 & 95,2 & 99,7 & & \\
\hline 12 & 93,4 & & & & \\
\hline 13 & 71,4 & 75,8 & 99,3 & 80,6 & 82,7 \\
\hline 14 & 72,6 & 66,2 & & & \\
\hline 15 & 98,8 & 98,4 & 101,6 & 103,5 & 104 \\
\hline 16 & 94,1 & 99 & 92,3 & & 85,8 \\
\hline 17 & 110,1 & 113,9 & 116,8 & 115,6 & 99,5 \\
\hline 18 & 72,6 & 66,2 & & & \\
\hline 19 & 98,2 & 100,9 & 86,8 & 99,3 & \\
\hline 20 & 102,5 & 85,2 & & 107,4 & \\
\hline 21 & 81,6 & 90,9 & 99,3 & 93,2 & 92,2 \\
\hline 22 & 55,2 & & 70,6 & & \\
\hline 23 & 87,7 & 84,5 & & & \\
\hline 24 & 76,5 & 75,3 & 85,8 & 88,8 & 76,5 \\
\hline 25 & 58,7 & 88,3 & & & \\
\hline 26 & 86,7 & 94,9 & 91,7 & 95 & 93,6 \\
\hline 27 & 65,8 & 59,6 & & & \\
\hline 28 & 70,6 & 71 & 63,1 & & \\
\hline 29 & 100,6 & & 105,3 & 109,8 & 107,4 \\
\hline 30 & 85,9 & 103,1 & 90,9 & 89,8 & \\
\hline 31 & 83,8 & & 82,3 & & \\
\hline 32 & 92,9 & & & & \\
\hline 33 & 70,9 & 90,1 & & 84,6 & \\
\hline 34 & 42,4 & & & & \\
\hline 35 & 75,0 & 96,7 & 106,4 & & \\
\hline 36 & 107,6 & 106,3 & 116,7 & 114 & \\
\hline 37 & 92,5 & 97,1 & 96 & 102,1 & 105,7 \\
\hline 38 & 84,6 & 81,4 & 93,7 & 97,1 & 98,7 \\
\hline 39 & 81,3 & & & & \\
\hline 40 & 69,8 & & & & \\
\hline 41 & 77,0 & 86,1 & 95,7 & 96,9 & \\
\hline 42 & 96,1 & 93,3 & 96 & 94 & 91,7 \\
\hline 43 & 64,7 & 75,8 & 66,9 & & \\
\hline 44 & 116,8 & & 78,2 & & \\
\hline 45 & 71,1 & 75,9 & 84,8 & 83,6 & 76,9 \\
\hline 46 & 93,3 & 86,4 & & & \\
\hline 47 & 90,1 & 78,4 & 100,7 & & \\
\hline
\end{tabular}


ANEXO VII (...continuação)

\begin{tabular}{|c|c|c|c|c|c|}
\hline & FEV1 0\% & FEV1 1\% & FEV1 2\% & FEV1 3\% & FEV1 4\% \\
\hline 48 & 57,2 & 74,2 & 70,3 & & \\
\hline 49 & 82,3 & & & & \\
\hline 50 & 108,9 & & 86,4 & & \\
\hline 51 & 104,6 & 102,2 & 91,6 & 88,1 & \\
\hline 52 & 89,6 & 88,4 & & 90,3 & 88,6 \\
\hline 53 & 73,5 & 77,3 & 88,7 & 94,6 & \\
\hline 54 & 88,8 & & & & \\
\hline 55 & 80,3 & & & & \\
\hline 56 & 108,3 & & & & \\
\hline 57 & 42,0 & & & & \\
\hline 58 & 80,3 & 66,6 & 88,2 & & \\
\hline 59 & 59,1 & & 76,2 & 74,4 & \\
\hline 60 & 74,2 & 72,8 & & & \\
\hline 61 & 88,7 & 93,5 & 94,1 & 105,2 & 109,2 \\
\hline 62 & 74,2 & 72,8 & & & \\
\hline 63 & 60,7 & 73,2 & & 73,4 & \\
\hline 64 & 83,5 & 85,5 & 92,6 & & \\
\hline 65 & 48,8 & 62,2 & 68,4 & 79,4 & 73,1 \\
\hline 66 & 97,3 & 97,4 & & & \\
\hline 67 & 79,7 & 74 & 76,9 & 74,6 & 66,9 \\
\hline 68 & 87,0 & 97,6 & & & \\
\hline 69 & 73,8 & 67,2 & & 78,9 & 79,3 \\
\hline 70 & 57,4 & 72,4 & & & 57,9 \\
\hline 71 & 62,3 & 67,4 & 72,4 & 84,8 & \\
\hline 72 & 52,6 & & & & \\
\hline 73 & 86,8 & 82,5 & 112,3 & 93,2 & 68,2 \\
\hline 74 & 89,5 & 94,9 & & & \\
\hline 75 & 58,2 & & & & \\
\hline 76 & 81,6 & 76,2 & 90,5 & & \\
\hline 77 & 99,0 & 110,2 & 118,8 & & 118,4 \\
\hline 78 & 46,7 & 47,1 & & & \\
\hline 79 & 74,5 & 74,6 & & & \\
\hline 80 & 91,9 & 91,6 & & & \\
\hline 81 & 93,6 & 82,5 & 83,7 & 59,3 & 73,6 \\
\hline 82 & 94,4 & 82,9 & 62,5 & 66,3 & 69,8 \\
\hline 83 & 88,9 & 82,8 & 75 & 81,2 & \\
\hline 84 & 74,5 & 64,8 & & & \\
\hline 85 & 49,7 & 54,8 & 40,1 & 24,2 & \\
\hline $\mathbf{X}$ & 80,0 & 84,2 & 88,0 & 88,8 & 87,8 \\
\hline DP & 18,4 & 15,2 & 17,7 & 17,4 & 15,8 \\
\hline EP & 2,0 & 1,9 & 2,5 & 2,8 & 3,0 \\
\hline $\mathbf{N}$ & 85 & 60 & 49 & 40 & 28 \\
\hline
\end{tabular}


Anexo VIII - Resultados das avaliações da força expiratória máxima

\begin{tabular}{|c|c|c|c|c|c|}
\hline & PEmax0 & Pemax1 & Pemax2 & Pemax3 & Pemax4 \\
\hline 1 & 67 & 91 & 95 & 82 & 75 \\
\hline 2 & 71 & 60 & 73 & 60 & 55 \\
\hline 3 & 42 & & 53 & & \\
\hline 4 & 38 & & & & \\
\hline 5 & 51 & & 44 & & \\
\hline 6 & 57 & & & & \\
\hline 7 & 75 & 82 & & 82 & 95 \\
\hline 8 & 58 & 82 & & 73 & \\
\hline 9 & 49 & 60 & 67 & & 73 \\
\hline 10 & 53 & & & & \\
\hline 11 & 73 & 75 & 89 & & \\
\hline 12 & 60 & & & & \\
\hline 13 & 44 & 42 & 53 & 53 & 55 \\
\hline 14 & 38 & 49 & & & \\
\hline 15 & 62 & 95 & 110 & 104 & 95 \\
\hline 16 & 80 & 74 & 87 & & 82 \\
\hline 17 & 38 & 75 & 111 & 98 & 91 \\
\hline 18 & 38 & 49 & & & \\
\hline 19 & 42 & 60 & 47 & 55 & \\
\hline 20 & 75 & 67 & & 100 & \\
\hline 21 & 47 & 71 & 73 & 69 & 62 \\
\hline 22 & 33 & & 53 & & \\
\hline 23 & 62 & 73 & & & \\
\hline 24 & 62 & 67 & 73 & 62 & 58 \\
\hline 25 & 67 & 75 & & & \\
\hline 26 & 100 & 75 & 110 & 55 & 104 \\
\hline 27 & 31 & 31 & & & \\
\hline 28 & 44 & 29 & 55 & & \\
\hline 29 & 91 & & 95 & 107 & 100 \\
\hline 30 & 69 & 78 & 98 & & \\
\hline 31 & 60 & & 42 & & \\
\hline 32 & 73 & & & & \\
\hline 33 & 29 & 64 & & 82 & \\
\hline 34 & 22 & & & & \\
\hline 35 & 53 & 60 & 44 & & \\
\hline 36 & 104 & 71 & 82 & 87 & \\
\hline 37 & 73 & 111 & 155 & 158 & 160 \\
\hline 38 & 60 & 69 & 80 & 78 & 64 \\
\hline 39 & 69 & & & & \\
\hline 40 & 49 & & & & \\
\hline 41 & 38 & 55 & 42 & 60 & \\
\hline 42 & 53 & 104 & 82 & 78 & 82 \\
\hline 43 & 36 & 44 & 58 & & \\
\hline 44 & 15 & & 47 & & \\
\hline 45 & 67 & 64 & 52 & 71 & 98 \\
\hline 46 & 51 & 69 & & & \\
\hline 47 & 60 & 80 & 80 & & \\
\hline 48 & 31 & 67 & 40 & & \\
\hline
\end{tabular}


ANEXO VIII (...continuação)

\begin{tabular}{|c|c|c|c|c|c|}
\hline & Pemax0 & Pemax1 & Pemax2 & Pemax3 & Pemax4 \\
\hline 49 & 49 & & & & \\
\hline 50 & 78 & & 62 & & \\
\hline 51 & 93 & 89 & 82 & 91 & \\
\hline 52 & 40 & 78 & & 67 & 84 \\
\hline 53 & 53 & 55 & 71 & 55 & \\
\hline 54 & 60 & & & & \\
\hline 55 & 57 & & & & \\
\hline 56 & 67 & & & & \\
\hline 57 & 60 & & & & \\
\hline 58 & 40 & 62 & 68 & & \\
\hline 59 & 24 & & 40 & 58 & \\
\hline 60 & 31 & 67 & 40 & 53 & \\
\hline 61 & 75 & 78 & 89 & 93 & 87 \\
\hline 62 & 73 & & & & \\
\hline 63 & 60 & 71 & & 55 & \\
\hline 64 & 69 & 69 & 62 & & \\
\hline 65 & 55 & 47 & 40 & 33 & 40 \\
\hline 66 & 69 & 71 & & & \\
\hline 67 & 64 & 70 & 62 & 58 & 64 \\
\hline 68 & 64 & 58 & & & \\
\hline 69 & 62 & 71 & & 78 & 73 \\
\hline 70 & 60 & 73 & & & 49 \\
\hline 71 & 71 & 87 & 93 & 109 & \\
\hline 72 & 57 & & & & \\
\hline 73 & 31 & 22 & 42 & 47 & 35 \\
\hline 74 & 53 & 49 & & & \\
\hline 75 & 53 & & & & \\
\hline 76 & 55 & 53 & 87 & & \\
\hline 77 & 36 & 40 & 51 & & 49 \\
\hline 78 & 24 & 18 & & & \\
\hline 79 & 64 & 75 & & & \\
\hline 80 & 40 & & & & \\
\hline 81 & 64 & 73 & 73 & 71 & 87 \\
\hline 82 & 82 & 60 & 60 & 73 & 60 \\
\hline 83 & 51 & 53 & 51 & 49 & \\
\hline 84 & 69 & 87 & & & \\
\hline 85 & 22 & 60 & 29 & 22 & \\
\hline$X$ & 57 & 67 & 70 & 68 & 76 \\
\hline DP & 19 & 18 & 25 & 27 & 25 \\
\hline EP & 2 & 2 & 4 & 4 & 5 \\
\hline $\mathbf{N}$ & 85 & 58 & 49 & 40 & 28 \\
\hline
\end{tabular}


Anexo IX - Resultados das avaliações da força expiratória máxima em porcentagem do predito

\begin{tabular}{|c|c|c|c|c|c|}
\hline & Pemax\%0 & Pemax\%1 & Pemax\%2 & Pemax\%3 & Pemax\%4 \\
\hline 1 & 88 & 119 & 105 & 91 & 72 \\
\hline 2 & 49 & 41 & 46 & 38 & 32 \\
\hline 3 & 29 & & 33 & & \\
\hline 4 & 61 & & & & \\
\hline 5 & 43 & & 30 & & \\
\hline 6 & 65 & & & & \\
\hline 7 & 64 & 70 & & 63 & 66 \\
\hline 8 & 40 & 57 & & 50 & \\
\hline 9 & 100 & 122 & 107 & & 116 \\
\hline 10 & 59 & & & & \\
\hline 11 & 62 & 57 & 68 & & \\
\hline 12 & 96 & & & & \\
\hline 13 & 70 & 86 & 69 & 69 & 72 \\
\hline 14 & 49 & & & & \\
\hline 15 & 53 & 81 & 84 & 79 & 72 \\
\hline 16 & 105 & 97 & 97 & & 91 \\
\hline 17 & 50 & 83 & 123 & 94 & 88 \\
\hline 18 & 77 & 78 & & & \\
\hline 19 & 36 & 46 & 36 & 38 & \\
\hline 20 & 57 & 51 & & 69 & \\
\hline 21 & 61 & 93 & 81 & 77 & 60 \\
\hline 22 & 67 & & 84 & & \\
\hline 23 & 53 & 62 & & & \\
\hline 24 & 53 & 57 & 62 & 47 & 40 \\
\hline 25 & 74 & 72 & & & \\
\hline 26 & 111 & 83 & 122 & 53 & 100 \\
\hline 27 & 24 & 24 & & & \\
\hline 28 & 58 & 32 & 61 & & \\
\hline 29 & 145 & & 124 & 119 & 111 \\
\hline 30 & 110 & 115 & 128 & & \\
\hline 31 & 78 & & 55 & & \\
\hline 32 & 95 & & & & \\
\hline 33 & 46 & 102 & & 107 & \\
\hline 34 & 35 & & & & \\
\hline 35 & 59 & 67 & 42 & & \\
\hline 36 & 115 & 68 & 79 & 74 & \\
\hline 37 & 70 & 107 & 132 & 134 & 122 \\
\hline 38 & 122 & 110 & 127 & 102 & 84 \\
\hline 39 & 53 & & & & \\
\hline 40 & 42 & & & & \\
\hline 41 & 61 & 88 & 55 & 67 & \\
\hline 42 & 59 & 100 & 79 & 75 & 70 \\
\hline 43 & 47 & 58 & 64 & & \\
\hline 44 & 20 & & 61 & & \\
\hline 45 & 107 & 84 & 68 & 79 & 109 \\
\hline 46 & 57 & 77 & & & \\
\hline 47 & 122 & 127 & 127 & & \\
\hline
\end{tabular}


ANEXO IX (...continuação)

\begin{tabular}{|c|c|c|c|c|c|}
\hline & Pemax\%0 & Pemax\%1 & Pemax\%2 & Pemax\%3 & Pemax\%4 \\
\hline 48 & 63 & 120 & 64 & & \\
\hline 49 & 33 & 35 & 41 & 32 & \\
\hline 50 & 63 & 107 & 64 & 84 & \\
\hline 51 & 66 & & 53 & & \\
\hline 52 & 122 & 116 & 107 & 101 & \\
\hline 53 & 34 & 66 & & 51 & 58 \\
\hline 54 & 54 & & & & \\
\hline 55 & 78 & & & & \\
\hline 56 & 52 & 69 & & 71 & 51 \\
\hline 57 & 27 & & 39 & 56 & \\
\hline \multicolumn{6}{|l|}{58} \\
\hline 59 & 130 & & 81 & 64 & \\
\hline 60 & 52 & 49 & 56 & 54 & 51 \\
\hline 61 & 46 & & & & \\
\hline 62 & 95 & & & & \\
\hline 63 & 46 & 49 & & 35 & \\
\hline 64 & 59 & 59 & 47 & & \\
\hline 65 & 61 & 52 & 44 & 32 & 34 \\
\hline 66 & 77 & 79 & & & \\
\hline 67 & 62 & 67 & 60 & 49 & 49 \\
\hline 68 & 49 & 44 & & & \\
\hline 69 & 60 & 68 & & 66 & 62 \\
\hline 70 & 58 & 62 & & & 37 \\
\hline 71 & 93 & 114 & 122 & 121 & \\
\hline 72 & 45 & & & & \\
\hline 73 & 30 & 21 & 40 & 40 & 27 \\
\hline 74 & 59 & 54 & & & \\
\hline 75 & 112 & 84 & 139 & & \\
\hline 76 & 40 & & 57 & & 47 \\
\hline 77 & 24 & 24 & & & \\
\hline 78 & 18 & 12 & & & \\
\hline 79 & 84 & 98 & & & \\
\hline 80 & 39 & & & & \\
\hline 81 & 49 & 50 & 50 & 49 & 55 \\
\hline 82 & 70 & 51 & 46 & 50 & 41 \\
\hline 83 & 81 & 69 & 67 & 54 & \\
\hline 84 & 53 & 60 & & & \\
\hline 85 & 14 & 38 & 17 & 12 & \\
\hline$x$ & 65 & 71 & 75 & 68 & 69 \\
\hline DP & 29 & 27 & 33 & 28 & 28 \\
\hline EP & 3 & 3 & 5 & 4 & 5 \\
\hline $\mathbf{N}$ & 83 & 57 & 49 & 40 & 28 \\
\hline
\end{tabular}


Anexo X - Carta de aprovação pela Comissão de Ética da Faculdade de Medicina da Universidade de São Paulo

Hospital das Clinicas

da faculdade de Medicina da Universidade de São Paulo

CaIXA POSTAL, 8091 - SAO PAUlo - BRASIL

DIRETORIA CLÍNICA

Comissão de Ética para Análise de Projetos de Pesquisa

APROVACCÃO

A Comissão de Ética para Análise de Projetos de Pesquisa - CAPPesq da Diretoria Clínica do Hospital das Clínicas e da Faculdade de Medicina da Universidade de São Paulo, em sessão de 10.09.03. APROVOU o Protocolo de Pesquisa $n^{\circ} 324 / 03$. intitulado: "Estudo do efeito de três técnicas de yoga na musculatura respiratória em pacientes com distrofia muscular progressiva tipo Duchenne" apresentado pelo Departamento de NEUROLOGIA, inclusive - Termo de Consentimento Livre e Esclarecido.

Pesquisador(a) Responsável: PROFA. DRA. SUELY KAZUE NAGAHASHI MARIE

CAPPesq, 10 de Setembro de 2003.

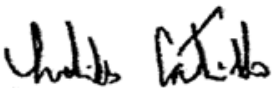

PROF. DR. EUCLIDES AYRES DE CASTILHO Presidente da Comissão de Ética para Análise de Projetos de Pesquisa

\footnotetext{
OBSERVAÇÃO: Cabe ao pesquisador elaborar e apresentar d CAPPesq, os relatórios parciais e final sobre a pesquisa (Resoluça do Conselho Nacional de Saúde $n^{\circ}$ 196, de 10.10.1996, inciso IX.2, letra "c")
} 


\title{
Anexo XI - Folha de Rosto do Ministério da Saúde para Pesquisa Envolvendo Seres Humanos
}

\author{
MINISTÉRIO DA SAƯDE \\ Conselho Nacional de Saúd \\ Comissäo Nacional de Étios em Pescuisa - CONEP
}

FOLHA DE ROSTO PARA PESOUISA ENVOLVENDO SERES HUMANOS (versão ontubro/99) 1. Projeto de Pesquisa: ESTUDO DO EFEITO DE TRES TÉCINICAS DE YOGA NA MUSCULATURA RESPIRATORIA EM PACIENTES COM DISTROFIA MUSCULAR PROGRESSIVA TIPO DUCHENNE

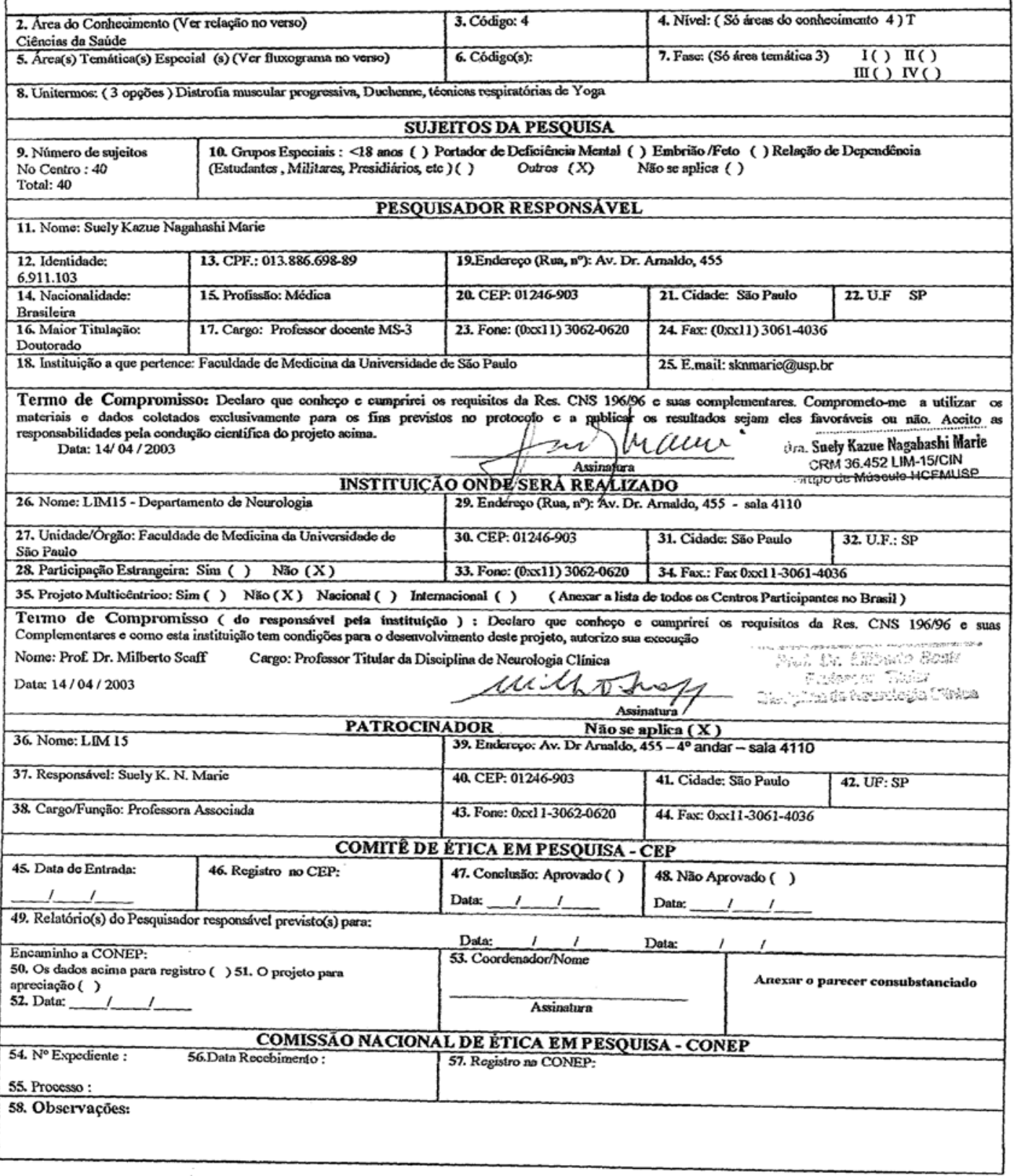




\title{
Anexo XII - Termo de Consentimento Livre Esclarecido
}

\author{
HOSPITAL DAS CLÍNICAS
}

$D A$

FACULDADE DE MEDICINA DA UNIVERSIDADE DE SÃO PAULO

TERMO DE CONSENTIMENTO LIVRE E ESCLARECIDO

\author{
(Instruçōes para preenchimento no verso)
}

1 - DADOS DE IDENTIFICAÇÃO DO SUJEITO DA PESQUISA OU RESPONSÁVEL LEGAL

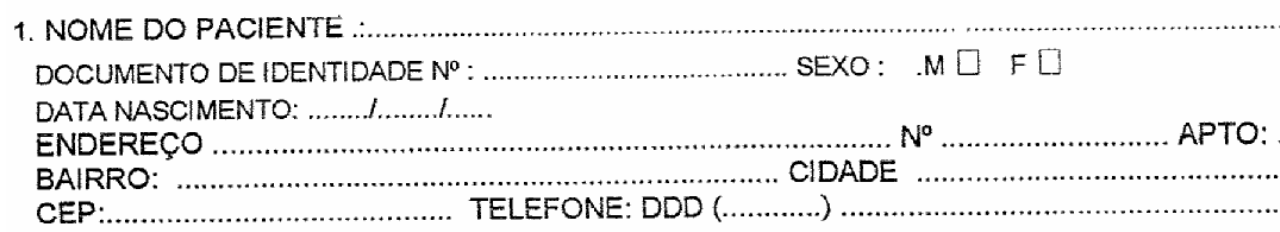

2.RESPONSÁVEL LEGAL

NATUREZA (grau de parentesco, tutor, curador etc.)

DOCUMENTO DE IDENTIDADE : SEXO: $M \square \quad F \square$

DATA NASCIMENTO : ....................

ENDEREÇO CIDADE:

$\mathrm{N}^{\circ}$

APTO:

BAIRRO TELEFONE: DDD ..).

\section{II - DADOS SOBRE A PESQUISA CIENTÍFICA}

1. TITULO DO PROTOCOLO DE PESQUISA Estudo do efeito de três técnicas de yoga na musculatura respiratoria em pacientes com distrofia muscular progressiva tipo Duchenne.

PESQUISADOR: Suely Kazue Nagahashi Marie

CARGO/FUNÇÃO: Professora Associada

INSCRIÇÃO CONSELHO REGIONAL N ${ }^{\circ} 36.452$ UNIDADE DO HCFMUSP: Divisão de Clinica Neurológica

3. AVALIAÇÄO DO RISCO DA PESQUISA:

$\begin{array}{llll}\text { SEM RISCO } & X & \text { RISCO MINIMO } & \text { RISCO MÉDIO } \\ \text { RISCO BAIXO } & \square & \text { RISCO MAIOR } \sqcup\end{array}$

(probabilidade de que o individuo sofra algum dano como consequência imediata ou tardia do estudo)

4. DURAÇĀO DA PESQUISA : 2 anos 


\section{III - REGISTRO DAS EXPLICAÇŐES DO PESQUISADOR AO PACIENTE OU SEU REPRESENTANTE LEGAL SOBRE A PESQUISA CONSIGNANDO:}

1. justificativa e os objetivos da pesquisa Os pacientes com distrofia Muscular tipo Duchenne apresentam fraqueza muscular, inclusive da musculatura intercostal e diafragmática, sendo a insuficiência respiratória a causa mais frequente de complicaçōes. Este projeto tem por objetivo avaliar três técnicas respiratórias de yoga na evolução destes pacientes.

2. procedimentos que seräo utilizados e propósitos, inciuindo a identificação dos procedimentos que săo experimentais. Serão empregadas três técnicas respiratórias de yoga (uddiyana, kapalabhati e agnisara).

3. desconfortos e riscos esperados. Não há riscos ou desconfortos na aplicaçăo destas técnicas.

4. benefícios que poderão ser obtidos. Fortalecimento da musculatura intercostal $\theta$ diafragmática, minimizando as pneumonias de repitição, retardando o estabelecimento da insuficiência respiratória e melhorando a qualidade de vida com o incremento do conforto respiratório.

5. procedimentos alternativos que possam ser vantajosos para o individuo

\section{IV - ESCLARECIMENTOS DADOS PELO PESQUISADOR SOBRE GARANTIAS DO SUJEITO DA PESQUISA CONSIGNANDO:}

1. acesso, a qualquer tempo, às informaçöes sobre procedimentos, riscos e benefícios relacionados à pesquisa, inclusive para dirimir eventuais dúvidas.

2. liberdade de retirar seu consentimento a qualquer momento e de deixar de participar do estudo, sem que isto traga prejuizo à continuidade da assistência.

3. salvaguarda da confidencialidade, sigilo e privacidade.

4. disponibilidade de assistência no HCFMUSP, por eventuais danos à saúde, decorrentes da pesquisa. 
V. INFORMACÕES DE NOMES, ENDERECOS E TELEFONES DOS RESPONSÁVEIS PELO ACOMPANHAMENTO DA PESQUISA, PARA CONTATO EM CASO DE INTERCORRÊNCIAS CLINICAS E REAÇÕES ADVERSAS.

Suely Kazue Nagahashi Marie

Marcos Rojo Rodrigues

Susan Krause Bierrenbach

Laboratório de Investigaçóes Neurológicas

Faculdade de Medicina da USP

Av. Dr. Arnaldo, $4554^{\circ}$ andar, sala 4110

Tel: $3062-0620$

V. OBSERVAÇÕES COMPLEMENTARES:

\section{VII - CONSENTIMENTO POS-ESCLARECIDO}

Declaro que, após convenientemente esclarecido pelo pesquisador e ter entendido o que me foi explicado, consinto em participar do presente Protocolo de Pesquisa

São Paulo,

de

de 19

assinatura do sujeito da pesquisa ou responsável legal

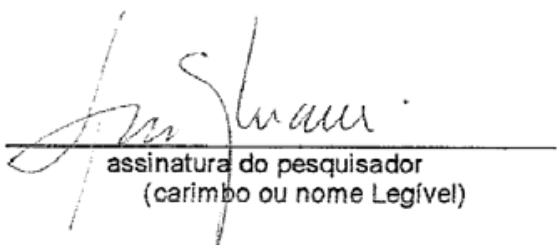


Abe K, Matsuo Y, Kadekawa J, Inow S, Yanagihara T. Respiratory training for patients with myotonic dystrophy. Neurology. 1998; 51: 641-2.

Anand BK, Chhina GS, Singh B. Studies on Shri Ramanand yogi during stay in an air tight box. The Indian $J$ of Med Res. 1961; 49: 82-89.

Bach JR, Rajaraman R, Ballanger F, Tzeng AC, Ishikawa Y, Kulessa R, Bansal T. Neuromuscular ventilator insufficiency: effect of home mechanical ventilation vs oxygen therapy on pneumonia and hospitalization rates. Am J Phys Med Rehabil. 1998; 77: 8-19.

Bach JR. Conventional approaches to managing neuromuscular ventilatory failure. In: Bach JR, ed. Pulmonary Rehabilitation: the obstructive and paralytic conditions. Philadelphia: Hanly \& Belfus, 1996; 285-301.

Baldwin KM, haddad F. Skeletal muscle plasticity, cellular and molecular resonses to altered physical activity paradigms. Am J Phys Med Rehabil 2002; 81:s40-51.

Baydur NMT. Respiratory muscle strength and control of ventilation in patients with neuromuscular disease. Chest. 1991; 99: 330-338.

Bernardi L, Passino C, Wilmerding V, Dallan GM, Parker DL, Robert AR, Appenzeller O. Breathing patterns and cardiovascular autonomic modulation during hypoxia induced by simulated altitude. J of Hypertension. 2001; 19: 947-58.

Black LF, Hyatt RE. Maximal respiratory pressures: normal values and relationship to age and sex. Am Rev Respir Dis. 1969; 99: 696-702.

Braun NMT, Arora NS, Rochester DF. Respiratory muscle and pulmonary function in polymyositis and other proximal myopathies. Thorax 1983; 38: 616-623.

Brooke MH, Fenichel GM, Griggs RC, Mendell JR, Moxley R, Florence J, King WM, Pandya S, Robison J, Schierbecker J. Duchenne muscular dystrophy: patterns of clinical progression and effects on supporting therapy. Neurology. 1989; 38: 475-81.

Carvalho, CRF. Caracterização da Evolução Respiratória em Distrofia Muscular de Duchenne: Implicações da Força Muscular Respiratória Máxima. Tese de LivreDocência. FM-USP. 2004; 78p. Submetido para publicação 2006. 
Cohn RD, Campbell KP. Molecular basis of muscular dystrophies. Muscle Nerve. 2000; 23: 1456-1471.

Coutler DH. Anatomy of hatha yoga: a manual for students, teachers, and practitioners. Honesdale, PA, USA. 1939.

De Troyer A, Borenstein S, Cordier R. Analysis of lung restriction in patients with respiratory muscle weakness. Thorax. 1980; 35: 603-610.

Di Marco AF, Kelling JS, Di Marco M, Jacobs I, Shields R, Altose MD. The effects of inspiratory resistive training on respiratory muscle function in patients with muscular dystrophy. Muscle Nerve. 1985; 8: 284-90.

Digambarji S, Gharote ML. Gheranda Samhita: Kaivalyadhama SMYM, 1978.

Digambarji S, Kokaje RG. Hathapradipika of Svatmarana: Kaivalyadhama SMYM, 1970 .

Dubowitz V. Special Centennial Workshop-101st ENMC Internacional Workshop: Therapeutic Possibilities in Duchenne Muscular Dystrophy, $30^{\text {th }}$ November- $2^{\text {nd }}$ December 2001, Naarden, The Netherlands. Neuromuscul Disord 12:421-31,2002.

Dolmage TE, Avendabi MA, Goldstein RS. Respiratory function during wakefulness and sleep among survivors of respiratory and nonrespiratory polyomyelitis. Eur Respir J. 1992; 5: 864-870.

Eliade M. Yoga inmortalidade e libertade. São Paulo: Editora Palas Athena: 1996.

Ervasti JM, Campbell KP. Membrane organization of the dystrophin-glycoprotein complex. Cell. 1991; 66: 1121-31.

Fallat RF, Jewitt B, Bass M, Kamm B, Norris FH Jr. Spirometry in amyotrophic lateral sclerosis. Arch Neurol. 1979; 36: 74-80.

Gayan-Ramires G. Decramer M. Effects of mechanical ventilation on diafhragm function and biology. Eur Respir J 2002,20;1579-86.

Gaulthier C, Zinman R. Maximal static pressures in healthy children. Respir Med. 1983; 51: 45-61.

Gharote ML. Técnicas de yoga. Phorte Editora. Tradução Forguieri DS. 2000

Goleman D. Emoções que curam. Tradução Duarte CG. Rocco. 1999.

Gomez-Merino E, Bach JR. Duchenne Muscular Dystrophy: Prolongation of life by nonivasive ventilation and mechanically assisted coughing. Am J Phys Med Rehabil. 2002; 81: 411-15. 
Inkley SR, Oldenburg PC, Vignos PJ. Pulmonary function in Duchenne muscular dystrophy. Am J Med. 1974; 56: 297-306.

Johnson BD, Bobcock MA, suman OE et al. Exercise induced diaphragmatic fatigue in healthy humans. $J$ Physical 1993;460:385-405.

Karambelkar PV. The significance of Swami Kuvalayanandaji's life-work. YogaMimansa. 1983; 24: 17-34.

Kawamura J, Ishihara D, Gomi S. Respiratory movement in patients with late-stage DMD. Clin Neurol. 1989; 29: 797-98.

Koessler W, Wanke T, Winkler G, Nader A, Toifl K, Kurtz H, Zwick H. 2 Years' Experience With Inspiratory Muscle Training in Patients With Neuromuscular Disorders. Chest. 2001;120:765-9.

Kuvalayananda S, Vinekar SL. Yogic therapy. Central Health Bureau/Gov of India. 1971.

Kuvalayananda S. Pranayama. Kaivalyadhama. 1983

Kuvalayananda, S. Asanas. Tradução Ignez NR. São Paulo: Cultrix, 1993.

Lanini B, Misuri G, Giglioti F, Jandelli I, Pizzi A, Romagnoli I, Scano G. Perception of dyspnea in patients with neuromuscular disease. Chest. 2001; 120: 402-408.

Lido HGW, Selig S, Kunkel LM. Dp1140: A novel 140Kd CNS transcript from the dystrophin locus. Hum Mol Genet. 1995; 4: 329-335.

Lippert L. Cinesiologia clínica para fisioterapeutas. Revinter. 1996

Love DR, Byth BC, Tinsley JM, Blake DJ, Davies KE. Dustrophin and dystrophinrelated proteins: A review of protein and RNS studies. Neuromuscul Disord.1993; 3: $5-21$

Martin AJ, Stern L, Yeates J, Lepp D, Little J. Respiratory muscle training in Duchenne muscular dystrophy. Dev Med Child Neurol. 1986; 28: 314-318. McDonald CM, Abresch RT, Carter GT, Fowler WM Jr, Jonhson ER. Kilmer DD, Sigford BJ. Profiles of neuromuscular disease: Duchenne muscular dystrophy. Am J Phys Med Rehabil. 1995; 74: S70-92.

Mier-Jedrzejowicz A, Brophy C, Green M. Respiratory muscle weakness during respiratory tract infections. Am Rev Respir Dis. 1988; 138: 5-7.

Mukoyama M, Kondo K, Hizawa K, Nishitani H. Life spans of Duchenne muscular dystrophy patients in the hospital care program in Japan. J Neurol Sci. 1987; 81: 155-58.

Narici MV, Kayser B, Barantini P, et al. Changes in electracaly evoked skeletal muscle contractions during 17-day spaceflight and bed rest. Int J Sports Med 1997;18(Suppl 4):S290-2. 
Patel C, North WRS. Randomised controlled trial of yoga and biofeedback in management of hypertension. The Lancet. 1975; 19: 93-5.

Patel C. Yoga and biofeedback in the manegement of hypertension. The Lancet. $1973 ; 10: 1053-55$.

Petrof BJ. The molecular basis of activity-induced muscle injuri in Duchenne muscular dystrophy. Mol Cell Biochem. 1998; 179: 111-123.

Philip JR. Cinesiologia e anatomia aplicada. Trad. Vasconcelos MM. Guanabara Koogan. 1989.

Rideau Y, Gatin G, Bach J, Gines G. Prolongation of life in Duchenne's muscular dystrophy. Acta Neurol. 1983; 5: 118-124.

Rimmer KP, Whitelaw WA. The respiratory muscles in multicore myopathy. Am Rev Respir Dis. 1993; 148: 227-231.

Rochester DF. Respiratory muscle weakness, pattern of breathing, and $\mathrm{CO} 2$ retention in chronic obstructive pulmonary disease. Am Rev Respir Dis. 1991; 143: 901-903.

Rodillo E, Noble-Jamieson CM, Aber V, Hckmatt J. Respiratory muscle training in duchenne muscular dystrophy. Arch Dis Childhood. 1989; 64: 736-737.

Simonds, AK. Respiratory Complications of the Muscular Dystrophy. Sem Resp Crit Care Med. 2002; 23: 231-8.

Smith PE, Calverley PM, Edwards RH, Evans GA, Campbell EJ. Practical problems in the respiratory care of patients with muscular dystrophy. $N$ Engl J Med. 1987; 316: 1197-1205.

Souto A. Una luz para el hatha yoga. Lonavla Yoga Institute. 2004.

Spicuzza L, Gabutti A, Porta C, Montano N, Bernardi L. Yoga and chemoreflex response to hypoxia and hypercapnia. The Lancet. 2000; 356: 28.

Stanescu DC, Nemery B, Veriter C, Marechal C. Patterno f breathing and ventilatory response to CO2 in subjects practicing hatha-yoga. J of Appl Phys.1981; 51:1625-29.

Taimni IK. A ciência do yoga. Tradução Lavrador M. Teosófica, 1996.

Topin N, Matecki S, Bris S, Rivier F, Echenne B, Prefaut C, Ramonatxo M. Dosedependente effect of individualized respiratory muscle training in children with Duchenne muscular dystrophy. Neuromuscular Disorders. 2002; 12: 576-83.

Victor M, Ropper AH. Muscular Dystrophy. In: Victor M and Ropper AH ed. Adams and Victor's Principles of Neurology. 7th ed. USA: McGraw Hill: 2001: 799-810. 
Vilovzni D, Bar-Yishay E, Gur I, Shapira Y. Computerized respiratory muscle training. Neuromuscul Disord. 1994; 4: 249-55.

Vincken W, Elleker MG, Cosio MG. Flow-volume loop changes reflecting respiratory muscle weakness in clinical neuromuscular disorders. Am J Med. 1987; 83: 673-680.

Wanke T, Toifl K, Merkle M, Formanek D, Lahrmann H, Zwick H. Inspiratory muscle training in patients with Duchenne muscular dystrophy. Chest. 1984; 105: 475-482.

Winkler G, Zifko U, Nader A, Frank W, Zwick H, Toifl K, Wanke T. Dosedependent effects of inspiratory muscle training in neuromuscular disorders. Muscle Nerve. 2000; 23: 1257-60.

Yasuma F, Takashi K, Matusoka Y, Konagaya M. Row-a-boat Phenomenon: Respiratory compensation in advanced Duchenne Muscular Dystrophy. Chest. 2001; 119: 1836-39. 